Portland State University

PDXScholar

$1-1-2012$

\title{
Involvement in the Online Autistic Community, Identity, Community, and Well-Being
}

Colleen Anne Kidney

Portland State University

Follow this and additional works at: https://pdxscholar.library.pdx.edu/open_access_etds Let us know how access to this document benefits you.

\section{Recommended Citation}

Kidney, Colleen Anne, "Involvement in the Online Autistic Community, Identity, Community, and Well-Being" (2012). Dissertations and Theses. Paper 627.

https://doi.org/10.15760/etd.627

This Thesis is brought to you for free and open access. It has been accepted for inclusion in Dissertations and Theses by an authorized administrator of PDXScholar. Please contact us if we can make this document more accessible: pdxscholar@pdx.edu. 
Involvement in the Online Autistic Community, Identity, Community, and Well-Being

by

Colleen Anne Kidney

A thesis submitted in partial fulfillment of the requirements for the degree of

Master of Science

in

Psychology

Thesis Committee:

Katherine McDonald, Chair

Eric Mankowski

Keith Kaufman

Christina Nicolaidis

Portland State University

C)2012 
Online Autistic Community i

\begin{abstract}
The values of the disability rights movement and community psychology promote research that focuses on improving the lives of individuals with disabilities (Dowrick \& Keys, 2001). Using the Internet for social interactions has been shown to contribute to an individual's identity development, sense of community, and well-being (Obst, Zinkiewicz, \& Smith, 2002a; Turkle, 1995). While challenges in typical social interactions have traditionally been considered a defining feature of autism spectrum disorder, autistic individuals have taken advantage of the Internet to develop social interactions (Blume, 1997a). The present study focused on the online Autistic community and how the importance and value of involvement in it is related to Autistic identity, sense of community, and psychological well-being.

The Academic Autistic Spectrum Partnership in Research and Education (AASPIRE) partnered with the Gernsbacher Lab to form the Gateway Project. Using the Gateway Project, AASPIRE conducted the Internet Use, Community, and Well-Being Study and collected data from 72 autistic adults online. It was hypothesized that the importance and value of involvement in the online Autistic community would be positively related to Autistic identity and sense of community, Autistic identity and sense of community would be positively related, and Autistic identity and sense of community would be positively related to psychological well-being. It was also hypothesized that the positive relationship between the importance and value of involvement in the online Autistic community and psychological well-being would be mediated by Autistic identity and sense of community.
\end{abstract}




\section{Online Autistic Community ii}

Correlations were examined among the hypothesized relationships, and a mediated regression model (Baron \& Kenny, 1986) was used to explore the relationship between the importance and value of involvement in the online Autistic community and psychological well-being with Autistic identity and sense of community as mediators. Significant relationships were found between the importance and value of involvement in the online Autistic community and Autistic identity, between the importance and value of involvement in the online Autistic community and sense of community, and between autistic identity and sense of community. As a first step to test the mediated regression models, psychological well-being was regressed on the importance and value of involvement in the online Autistic community. The regression was not significant; therefore the hypothesized model was not significant.

Despite non-significant mediated regression model results, significant relationships among the importance and value of involvement in the online Autistic community and Autistic identity and sense of community offer important results. These finding illuminate the potential positive impact of the importance and value of involvement in the online Autistic community, including evidence counter to the myth that autistic individuals lack skills necessary for social relationships. These findings support the positive utility of involvement in the online Autistic community for autistic adults. Further research with a larger sample size is recommended, due to low power coefficients in the analyses. Additional research may also further illuminate the findings of the current study. Possible topics may include sense of community and Autistic identity in individuals that do not use the Internet, differences in the way the Internet is 
Online Autistic Community iii

used in autistic individuals, and different measures of involvement in the online Autistic community and well-being. 


\section{Acknowledgements}

I would like to express my gratitude and thanks for all those who contributed to my thesis project. I want to thank the Academic Autistic Spectrum Partnership In Research and Education (AASPIRE) research team and our community partner, the Autistic Self-Advocacy Network. Specifically, I would like to thank the AASPIRE codirectors Dr. Christina Nicolaidis and Dora Raymaker, as well as the team members (former and current) Elesia Ashkenazy, Amanda Baggs, Cody Boisclair, Anne Corwin, Sebastian Dern, Paula Durbin-Westby, Andrea Gillespie, Dr. Katherine McDonald, Ari Ne'eman, Aubrey Perry, Scott Robertson, and Emily Williams. I would also like to thank members of the Gateway Project, Dr. Morton Gernsbacher and Jennifer Stevenson. Further, I would like to thank my advisor and thesis chair, Dr. Katherine McDonald, and my thesis committee members, Dr. Keith Kaufman, Dr. Eric Mankowski, and Dr. Christina Nicolaidis. 


\section{Table of Contents}

Acknowledgements .

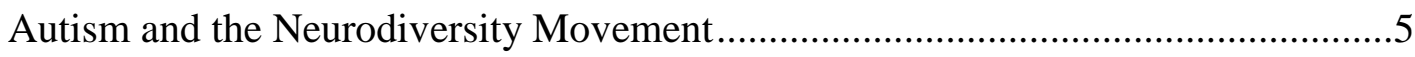

The Internet and the Online Autistic Community.....................................................13

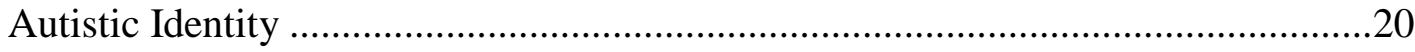

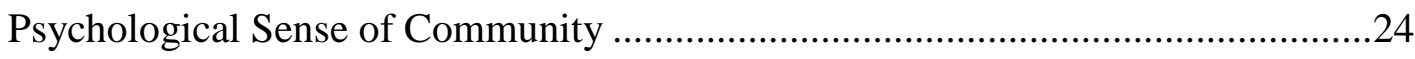

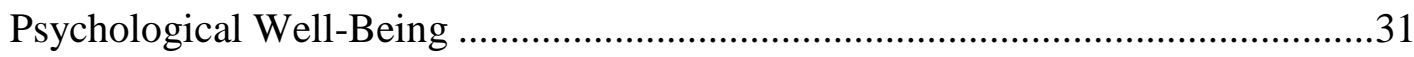

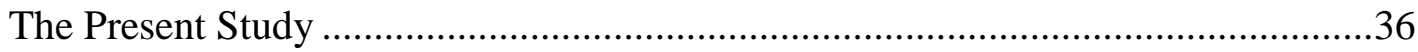

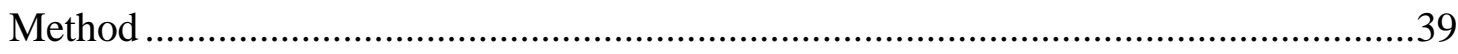

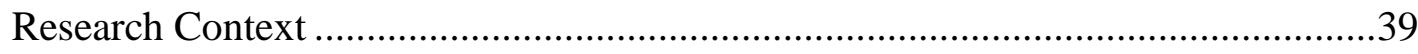

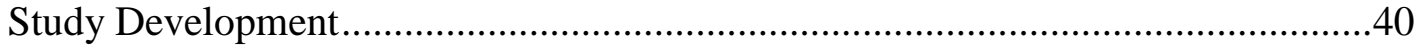

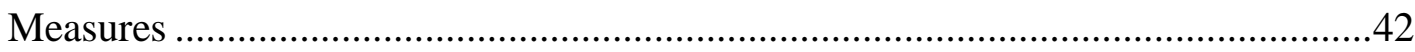

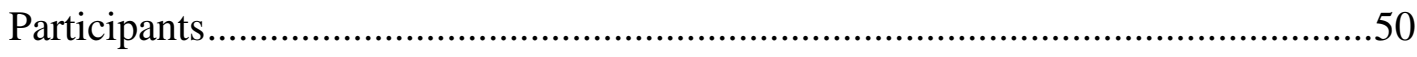

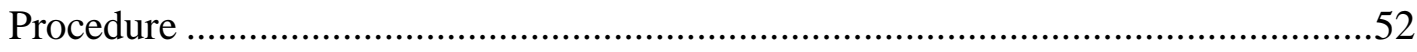

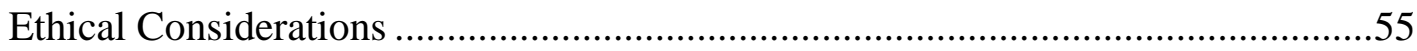

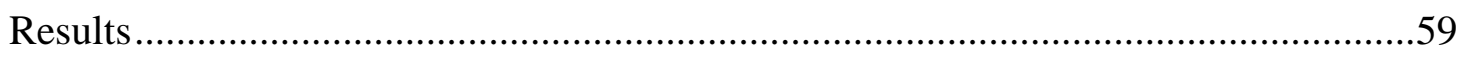

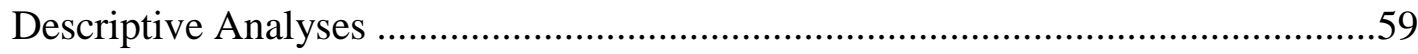

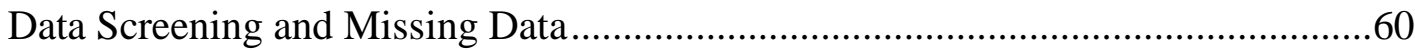

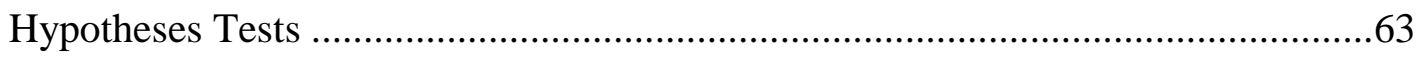

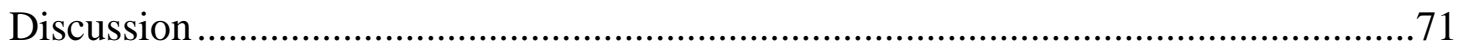

Involvement in the Online Autistic Community and Autistic Identity......................72

Involvement in the Online Autistic Community and Sense of Community ..............74

Autistic Identity and Sense of Community ..............................................................

Autistic Identity, Sense of Community, and Psychological Well-Being ....................80 
Autistic Identity and Sense of Community Mediating the Relationship Between the Importance and Value of Involvement in the Online Autistic Community and

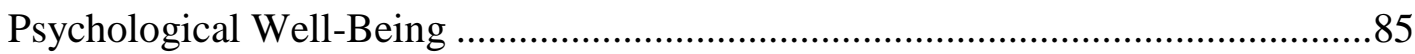

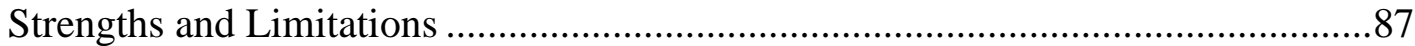

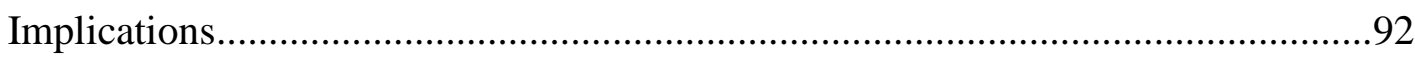

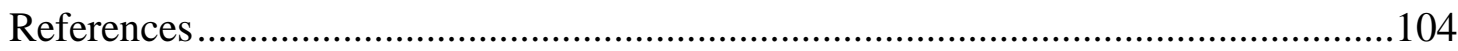

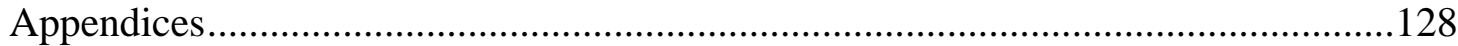

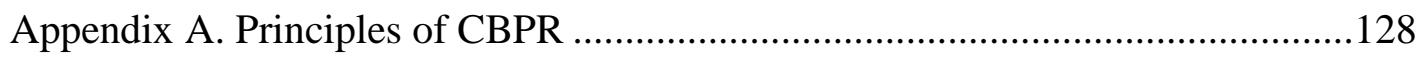

Appendix B. Gateway Project recruitment announcement..................................129

Appendix C. Gateway Project participant information sheet ..............................130

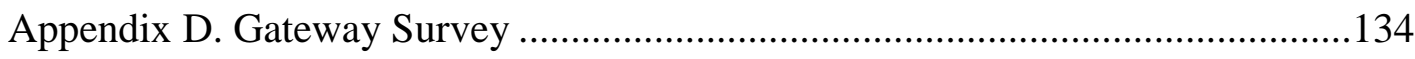

Appendix E. AASPIRE Internet Use, Community, and Well-Being Study general

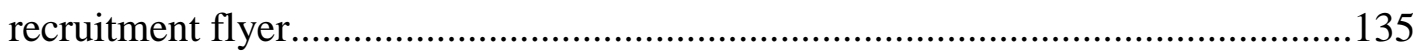
Appendix F. AASPIRE Internet Use, Community, and Well-Being Study participant

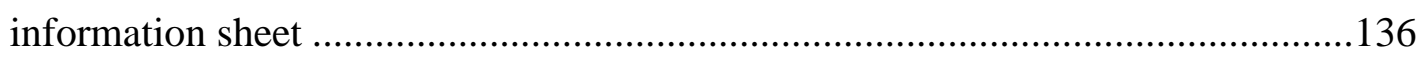
Appendix G. AASPIRE Internet Use, Community, and Well-Being Survey.........138 
Online Autistic Community vii

\section{List of Tables}

Table 1. Participant demographics ...........................................95

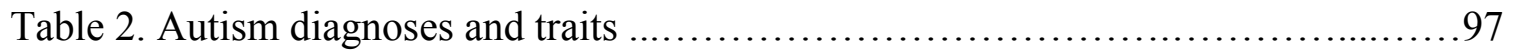

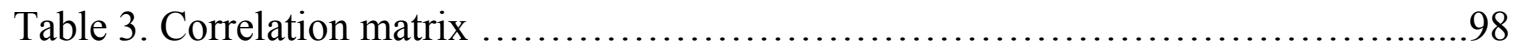

Table 4. Regression analysis of psychological well-being ...........................99 
Online Autistic Community viii

\section{List of Figures}

Figure 1. AASPIRE's academic and community partner contribution to CBPR

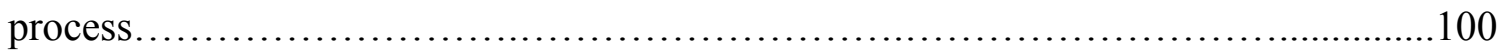
Figure 2. Relationships among involvement in online Autistic community, Autistic identity, sense of community, and psychological well-being (Hypotheses 1.1 to $1.6)$.

Figure 3. Mediation model of psychological well-being on involvement in the online Autistic community mediated by Autistic identity and sense of community

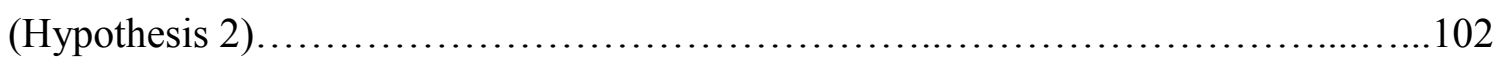

Figure 4. Participants and measures of the Gateway Project utilized in the AASPIRE Internet Use, Community, and Well-Being Study...........................103 
Online Autistic Community 1

\section{Involvement in the Online Autistic Community, Identity, Community, and Well- Being}

The Internet is a hub for creating personal relationships, giving and receiving social support, and organizing social action (Brownlow \& O’Dell, 2002; Wellman \& Gulia, 1999). The Internet creates the ability to communicate with others around the world and holds endless sources of information accessible to many people from their own homes. Relevant to the present study, the Internet has been shown to contribute to an individual's identity development, sense of community, and well-being (Obst, Zinkiewicz, \& Smith, 2002a; Turkle, 1995). As Internet usage across all people increases (Morales, 2009), it is not surprising that autistic individuals have taken advantage of this tool to connect with others, despite diagnostically defined atypicality in social interaction and communication skills (Szatmari, 2004).

Utilizing a community based participatory research approach (CBPR; Minkler \& Wallerstein, 2003), the present study investigates the benefits that autistic adults may derive from participating in the online Autistic community. Appendix A contains the principles of CBPR as derived from Isreal (2003; http://aaspire.org/about/cbpr.html). The long-term goals of this study are to understand how involvement in the online Autistic community may be related to the positive outcomes of autistic identity, sense of community, and well-being. Understanding these relationships is significant due to the lack of empirical research investigating how involvement in the online autistic community may result in such positive outcomes. That is, the results may be informative about autistic adults' social interaction and communication and identify mechanisms that 
Online Autistic Community 2

foster positive outcomes for this underresearched population. Further, in order to understand whether we can promote well-being through the online Autistic community, it is necessary to examine the effects of involvement on the online Autistic community on individuals. Lastly, empirical support for positive outcomes of involvement in the online Autistic community can be rationale for wider use and access to the Internet for autistic individuals.

The present study focuses on the online Autistic community and how the importance and value of involvement in it is related to Autistic identity, sense of community, and psychological well-being. Here, first I discuss the broader context in which the proposed study takes place and then the specific constructs examined in the present study including sense of community, Autistic identity, and psychological wellbeing.

\section{Study Context and Approach}

Autistic self-advocates have called for strengths-based research, conducted by or with autistic adults, that addresses ways to improve the quality of life for autistic adults (Ne'eman, 2010). As an effort to promote respect, accessibility, inclusion, and relevance to the autistic adult community, a community based participatory research approach lead to the formation, development, execution, and dissemination of the current study.

The Academic Autistic Spectrum Partnership in Research and Education

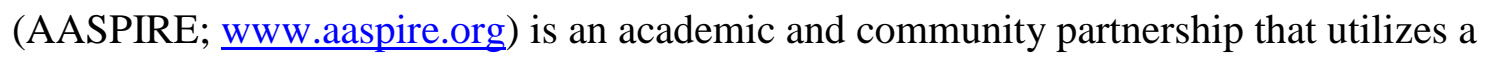
community based participatory research (CBPR) approach (Minkler \& Wallerstein, 2003) with projects that aim to improve the lives of autistic adults. This project differs from 
Online Autistic Community 3

traditional research in that the academic and community partners collaborate as equal partners to create a team of people with unique skills and knowledge to inform the entire process of research, facilitating co-learning and capacity building among partners as well as research focused on community relevance (Brydon-Miller, 1997; Isreal, 2000). See Figure 1 for a visual display of the academic and community partners contributing to the research process through the CBPR approach.

The AASPIRE partnership consists of disability and health service academics from two universities, autistic adults, disability service providers, and family members. In addition to collaboration among individuals from these stakeholder groups, we partner with the Autistic Self-Advocacy Network (ASAN; www.Autisticadvocacy.org), a community-based organization that seeks to advance the Autistic self-advocacy movement through organizing the community to have their voices heard in order to promote the same access, rights, and opportunities as other citizens. The AASPIRE team consists of Dr. Christina Nicolaidis from Oregon Health and Sciences University and Dora Raymaker from the Autistic Self Advocacy Network as the Academic and Community Co-Directors. The Community Council is chaired by Elesia Ashkenazy and consists of Ari Ne'eman, Cody Boisclair, Dora Raymaker, Jane Rake, Kim Goldman, and Sebastian Dern. The Academic Council is chaired by Dr. Katherine McDonald and contains Dr. Christina Nicolaidis and Dr. Melanie Fried-Oken. Dr. Katherine McDonald and Dora Raymaker serve as the academic and community principal investigators and Dr. Christina Nicolaidis, Colleen Kidney, and Aubrey Perry serve as co-investigators of the 
Online Autistic Community 4

study from which data for the present study is extracted, which is supported by a Portland State University Faculty Enhancement Grant to Dr. McDonald.

The AASPIRE partnership exists to bring together members from the academic community and the Autistic community to develop and perform research projects that focus on improving the lives of adults on the autistic spectrum (see www.aaspireproject.org). Its goals are to encourage community based participatory research and the inclusion of autistic people as equal partners, answer research questions relevant to autistic adults, and to effect positive change with research findings. The partnership agrees upon these goals, and respects the unique expertise every individual brings to the work. All members of the group are responsible for the formulation of questions, research design, recruitment, materials, analyses, conclusions, and dissemination.

AASPIRE collaborates with the Gernsbacher Lab at the University of WisconsinMadison to conduct the Gateway Project. The Gateway Project serves to enhance research conducted with autistic adults through four values. The four values of the Gateway Project are 1) inclusion: autistic individuals are involved in the development of all studies; 2) respect: all phases of research utilize strengths-based and respectful perspectives and languages; 3 ) accessibility: research participation is made as physically and culturally accessible as possible; 4) relevance: research questions are relevant to the Autistic community. The Gateway Project identifies eligible participants, recruits them for continuing studies, and collects data on variables that will inform subsequent studies. The Gateway Survey collected data on Internet and computer use, demographic 
Online Autistic Community 5

information, disability and Autistic identity and diagnoses, presence of autistic traits, and future research. After participating in the Gateway Survey, demographic data and data on diagnoses are used to identify eligible participants for AASPIRE's continuing projects, including the present study. Data from the Gateway Survey are also used in the present study as sample descriptors and as an analysis covariate.

CBPR provides greater insight into the population of interest and relevance of the work being conducted. Relevant to the present study, the three years I have worked in partnership with AASPIRE have provided me with a lens through which I have understood and defined the constructs of autism and the neurodiversity movement. Further, the partnership has allowed a deeper appreciation of the findings and implications of the current study. The constructs, findings, and implications under scrutiny in this study reflect my position of working with autistic self-advocates, the experts of their own experiences (Yergeau, 2010).

\section{Autism and the Neurodiversity Movement}

Autism has garnered much media attention in the past decade, due in part to false claims of an autism epidemic and autism being caused by environmental toxins or vaccines (Grinker, 2010). The politicized debates on defining autism, the causes of autism, and the goals of educators, researchers, and practitioners in the field of autism are highly polarized and publicized (Solomon, 2008). Different characterizations of autism come from various traditions of medicine, but also social sciences, the media, and autism organizations (Murray, 2010). In order to express definitions of autism and autism research beyond the "typical" autism conceptualization (Yergeau, 2010), or the 
Online Autistic Community 6

traditional medical conceptualization, I will first provide a definition and brief background about autism as a diagnosis. I will then discuss how being on the autism spectrum can be considered a difference in how persons live, think, and communicate, which is a characterization of autism by many neurodiversity advocates and within the AASPIRE team.

Autism is characterized by impairments or differences in communication and social interaction (National Institute of Neurological Disorders and Stroke, 2008). Eugen Bleuler first used the term 'autism' to describe a branch of schizophrenia in 1911 (Brownlow, 2007). Kanner (1943) then reintroduced the term into psychiatry as a unique syndrome. A year later, Hans Asperger (1944) independently presented clinical case studies detailing the deficits and special abilities of a small group of boys. Despite the decades that have passed since these initial studies of autism, a single definition and diagnosis of autism is still not universally accepted. The Diagnostic and Statistical Manual of Mental Disorders IV (American Psychiatric Association, 1994) included a category of pervasive developmental disorders with subtypes, including Autistic disorder, Asperger's Disorder, Rett's Disorder, Childhood Disintegrative Disorder, and Pervasive Developmental Disorder Not Otherwise Specified (PDD-NOS). These diagnoses are all broadly termed as autism spectrum disorders (ASD), considered to exist on a spectrum of disorders with the defining triad features of impairments in socialization, impairments in verbal and nonverbal communication, and restricted and repetitive behaviors (American Psychiatric Association, 1994). 
Online Autistic Community 7

In contemporary research and diagnosis, autism has been thought of as a 'triad of impairments' that interact with one another uniquely in every individual (Wing, 1997). The triad includes social development, language development, and rigid and repetitive behaviors. As the disorders are considered on a spectrum and therefore are manifested differently in every individual, other characteristics of the disorder are not universal to those on the spectrum. However, there are common characteristics that are associated with ASD (National Institute of Child Health and Human Development, NICHD, 2005). These characteristics include having a range in verbal communication abilities, with some individuals unable to use oral language at all. Other forms of communication or body language may be difficult, such as pointing, eye contact, or smiling. Expressing emotions or understanding others' expressions of emotions may be difficult, as well as the length or timing of any social interactions. Autistic individuals may exhibit repetitive behaviors or stringent routines and attachments. Physical movements such as rocking, hand or finger flapping or twisting, or whole body movements may occur, and autistic individuals often describe feelings of sensory overload, or sensitivity to multiple physical or mental stimuli, such as bright lights or large crowds (Filipek, Accardo, Baranek, Cook, Dawson, et al., 1999).

Autism is broadly considered a developmental disability, a life-long condition starting before the age of 22 characterized by mental and/or physical impairments that impact self-care, comprehension, language, skills, learning, mobility, capacity for independent living, economic self-sufficiency, and/or the ability to function without assistance (Center for Disease Control and Prevention, 2004; DHHS: US Department of 
Online Autistic Community 8

Health \& Human Services, 2009). While little research exists that examines disparities specifically in autistic adults, physical and psychological health disparities exist in persons with developmental disabilities (Havercamp, Scandlin, \& Roth, 2004;

Sutherland, Couch, Iacono, 2002) that may also be true in the autistic adult population (Nicolaidis et al., 2011b).

A longitudinal study of 120 diagnosed autistic individuals found that as adults, $90 \%$ of the participants had social deficits, only $35 \%$ achieved near-normal fluency of oral language and only $29 \%$ achieved near-normal comprehension of oral language (Ballaban-Gil, Rapin, Tuchman, \& Shinnar, 1996). Another study suggested that autistic adults faced many challenges in having close friends, living independently, or obtaining permanent employment (Hawlin, Good, Hutton, \& Rutter, 2004). However, there is little research on the impact of social skills in different contexts, with the majority of autism research focusing on the diagnosis and childhood of individuals (e.g., Bradley, Summers, Wood, \& Bryson, 2004; US Department of Health and Human Services Interagency Autism Coordinating Committee, 2010) or with outcomes of autistic adults as reported by parents and siblings (Farley, McMahon, Fombonne, Jenson, \& Miller, 2009). Bishop (1989) describes the importance of a lifespan approach for children with ASD. Bishop argues that focusing on childhood diagnoses and research may result in the misrepresentation of autism as a disability resulting in static, unchanging behaviors and abilities as well as the perception of autistic individuals as eternal children. Furthermore, the research and literature in the field of autism is often influenced by the perspectives of researchers, parents, teachers, and professionals — rather than autistics— and tend to 
Online Autistic Community 9

define autism and research within a deficit-oriented model (Biklen, 2005; Singh, Illes, Lazzeroni, \& Hallmayer, 2009). Through this framework, research that informs opinions, therapies, and treatments focuses on something being intrinsically wrong with being autistic or wrong with how autistic individuals experience the world (Boundy, 2008). This deficits-oriented paradigm can further contribute to marginalization and physical and psychological disparities among autistic adults.

The disability rights movement has yielded notable progress in the past decades to address marginalization, yet persons with disabilities continue to experience unique obstacles in achieving inclusion in society. Before the 1970's, a medical model of disability was applied, claiming such communicatory, social, and behavioral impairments were considered medical in nature, with a focus on the individual and attempts to rehabilitate or normalize the person according to mainstream standards (Brisenden, 1986). Because of historical oppression and modern challenges faced by people with disabilities, their status as a minority group became likened to other societal minorities such as racial minorities or struggles faced by women (Gordon \& Rosenblum, 2001). Problems of employment, healthcare, discrimination, abuse, and fair housing that are often discussed regarding minority groups overlap the issues faced by people with disabilities. By shifting the lens through which society views people, empowering the disability community and individuals with disabilities has begun to bridge the disparities of this social minority group and create equality (Pledger, 2003). There is a differentiation between the terms impairment and disability, with impairment referring to the condition of losing or having a difference in physiological or psychological function 
Online Autistic Community 10

(Oliver, 1996). Disability refers to the resulting loss or limitations of opportunities due to the interaction of impairment and the environment. As the environment becomes more supportive and inclusive, individuals and the disability community gain more control and influence over the environment (Fawcett, White, Balcazar, Suarez-Balacazar, Mathews et al., 1994). This new paradigm, referred to as the socioecological model of disability, rejects the medical model and views disability as a function of society's shortcomings and systemic barriers (Tate \& Pledger, 2003). The new paradigm is reflected in policies such as the Americans with Disabilities Act (ADA: Public Law 101-336 U.S.C. § 12101, 1990), which utilizes Nagi’s (1969) framework of disability to recognize that improvements in the environment reduce disability and promote inclusion (Stern \& Brault, 2005).

The self-advocacy movement of the Autistic community, considered within the broad context of the socioecological model of disability and the disability movement, is known as the neurodiversity movement (Chamak, 2008). Like activists in the disability rights movement, neurodiversity movement activists work toward changing the structural inequalities that prevent individuals from meaningfully participating in society and reaching personal goals (Boundy, 2008; Broderick \& Ne’eman, 2008; Hurlbutt \& Chalmers, 2002). Organizations such as the Autistic Self Advocacy Network (ASAN; see www.Autisticadvocacy.org) were created to raise consciousness about these inequalities and advocate efforts toward changes in policy, practice, and research.

While the conceptualization of autism within the neurodiversity movement is not completely separate from the traditional medical conceptualization, there are unique 
emphases that are common within the diverse perspectives of the neurodiversity movement. Autistic advocates in the neurodiversity movement tend to be critical of definitions of autism by non-autistic professionals in the field of autism research, rejecting the pervasive influence of these definitions on the media, in power over resources, and public mindshare (Clarke \& Amarom, 2008; Yergeau, 2010). Instead such individuals identify multiple subjective understandings of autism through the perspective of each autistic individual (Biklen, 2005). Most autobiographical accounts by autistic individuals are focused on the unique strengths and challenges, perspectives, and knowledge that come with autism rather than considering autism a deficit (Davidson, 2008; Happé \& Ronald, 2008; Wing, Gould, \& Gillberg, 2011).

Autistic individuals who identify with the neurodiversity movement often reject notions of a cure for ASD because the disorder is a pervasive aspect of every autistic person's life (Sinclair, 1993). Unlike many people with disabilities, many autistic people reject "person first" language (i.e., person with autism) and prefer identity first language (i.e., autistic person) when referring to being on the spectrum, presenting autism as an integral aspect of their being, not simply an add-on (Bagatell, 2010; O’Neil, 2008; Orsini \& Smith, 2010; Ortega, 2009; Silverman, 2008). While autistic individuals recognize the challenges of being on the spectrum, including unique support needs, these individuals also feel that the majority of the difficulties experienced by autistic individuals are rooted in the pressures of society to conform to typical social norms (Boundy, 2008). Supporters of the neurodiversity movement are also in favor of the individuals having the knowledge 
Online Autistic Community 12

and choice of the use of therapies, treatments, and medications in their lives (Boundy, 2008).

Additionally, neurodiversity advocates emphasize that autism spectrum disorders are not considered on a continuum of mild to severe forms of autism; because disabilities are a function of the context, individuals deemed "severely autistic" are in a severely unaccommodating environment (Biklen, 2005). The binary or spectrum of functionality is often considered within the neurodiversity movement as a medical construct that uses neurotypicality as a standard, although the concept of neurotypicality is undefined, unstable, and contextually dependent (Yergeau, 2010). Furthermore, as each autistic individual embodies unique characteristics related to and not related to autism, a continuum does not account for the unevenness of functioning within an environment or across various environments. Educators, practitioners, and researchers who adopt this perspective of autism tend to emphasize the strengths of autistic individuals and recalibrate the focus of their work to see the autistic person as an individual with gifts and talents as well as potential challenges (Robertson, 2010). This perspective is in contrast to much traditional research that relies on proxy report to represent the voices of autistic individuals (Shipman, Sheldrick, \& Perrin, 2011).

Community psychology, with its focus on minority populations and participatory methods, has clear ties to research within the socioecological model of disability (Dowrick \& Keys, 2001; Goodley \& Lawthom, 2005; McDonald, Keys, \& Balcazar, 2007). Researchers are called to use cultural sensitivity within the paradigm of disability, and seek and spread knowledge for the benefit of the community (Pledger, 2003). To be 
culturally relevant and for the purpose of empowering marginalized populations, community psychology calls on research to be informed by and performed with the population of interest. There is also a strong call for cultural relevance and emphasis on improving quality of life for autistic adults by Autistic self-advocates (Ne'eman, 2010; Robertson, 2010). Furthermore, research should reflect the desired shift in policy and thinking towards cooperation and empowerment among all people and an interdependence of all people and resources rather than "fixing" the marginalized community itself (Lord \& Hutchison, 1993, Sprague \& Hayes, 2000). By conducting research with the values of cultural sensitivity, community relevance, and empowerment, AASPIRE aims to focus on topics deemed important by autistic adults and give the underresearched population a voice.

\section{The Internet and the Online Autistic Community}

With the emergence of the neurodiversity movement within a social model of disability, autism is now being viewed as a culture of its own, containing identifiable values, beliefs, and unique knowledge (Silverman, 2008). Along with autism culture emerging, the last decade has seen an increase in Internet use among all age and socioeconomic groups (Morales, 2009). During this time, an online community of autistic individuals has developed. Reaching wide audiences on the Internet, people like Amanda Baggs (creator of the eight and a half minute video In My Language, posted on YouTube in January 2007) and the Autistic Self-Advocacy Network (see No Myths, public service announcement posted on YouTube in April 2009) have become symbolic of the neurodiversity movement and autistic people asserting their voices online. In a 
Online Autistic Community 14

recent New York Times article, Harvey Blume (1997a) said, "the impact of the Internet on autistic individuals may one day be compared in magnitude to the spread of sign language among the deaf. By filtering out the sensory overload that impedes communication among autistic individuals, the Internet opens vast new opportunities for exchange." Not only can others online be sources of information and resources, but also intimate, quality relationships can be developed over the Internet (Wellman \& Gulia, 1999). Blume (1997b) describes the Internet as an important tool in addressing what Wing (1997) would consider one of the 'triads of impairment'- social development. Considering the wide range of oral language abilities in autistic individuals, the Internet allows individuals to communicate and foster such relationships with greater ease than in face-to-face interactions (Benford \& Standen, 2009), potentially leading to supportive networks and access to friendships and resources. As is true for all Internet users, autistic adults also benefit from the ability to have relationships with individuals across geographic distance, increasing the likelihood of finding individuals with similar interests (Bagatell, 2007; Jones \& Meldal, 2001; Jordan, 2010). Additionally, many listserves (e.g., Autism-AAD), chat groups (e.g., Autistichat), and other interactive websites (e.g., AS-and-Proud-of-It) exist to provide such support for autistic adults and their families, friends, and caregivers.

To understand how people with autism can maximize their social abilities online, it is necessary to understand Internet communication. Suler (1997) describes the common language and interactions that take place in synchronous (real-time) online communication. Where humor or sarcasm may be confusing in face-to-face interaction 
for some individuals, use of common emoticons (e.g., $:$, : :), ;), :o, : ; :(, :D, :?, <3) explicitly convey the intentions of the writer. A common language of acronyms has also developed to supplement emoticons and typical written language in exhibiting emotion and informality, such as LOL (laugh out loud). Additionally, use of different fonts and font styles non-verbally add emphasis or tone to conversation, such as capitalizing whole words or sentences. Because a delayed response is still considered appropriate for any individual, a member of an online exchange is free to take time to read, understand, and formulate a response (Benford \& Standen, 2009; Burke, Kraut, \& Williams, 2010; Suler, 1997). Even with the non-verbal cues available through online interactions, misinterpretations can often occur (Seymour \& Lupton, 2004). Therefore, there is an attempt at writing with literal meanings and minimal non-verbal cues (Suler, 1997), which parallels the typical communication style of many autistic individuals. Further, patterns in socializing over the Internet create schemas that individuals may use as a guide to their own social behaviors (Shirky, 2003).

Researchers have explored the use of the Internet by persons with disabilities, which serves as a tool for empowerment and social interaction (Brownlow \& O’Dell, 2002; Seymour \& Lupton, 2004; Siddiquee \& Kagan, 2006). Many people with disabilities use the Internet in the same way as people without disabilities, such as for information finding, personal communications, and shopping (Burks, Pardos, Waddell, \& Nakane, 2000). A study comparing deaf adolescents to hearing adolescents found that the deaf group used the Internet more than the hearing participants (Barak \& Sadovsky, 2008). However, it is important to recognize the possible difficulties faced by people with 
Online Autistic Community 16

disabilities in using the Internet, including visual difficulties and confusing site layout (Burks et al., 2000). Cognitive or neurological differences may create sensitivity to flickering or strobing websites or find navigation through websites more challenging (Brownlow, 2007). Beyond issues faced when using the Internet, access remains a broader problem, as disability and poverty are often closely associated, limiting opportunities to own or use computers with Internet capability (Cromby \& Standen, 1999). Additionally, individuals with differences in motor skills, inability to physically access computer space without assistance, or other physical difficulties may limit the ability of a person to use the computer or keyboard.

Many of the people with disabilities interviewed for a study by Seymour and Lupton (2004) used the Internet for social interaction and making friends. People with disabilities are sometimes identified as having a disability by others because of physical characteristics, such as using a wheelchair or displaying behaviors associated with having a disability (Seymour \& Lupton, 2004). This results in many people being forced to be "out" about their disability. However, such face-to-face interactions do not always occur on the Internet. This creates the ability to disclose as little or as much information on one's disability as desired. The researchers found that participants emphasized the ability to find and relate to others like themselves, while retaining anonymity and not using physical appearance and presentation as part of identity. Bowker and Tuffin (2002) consider this ability to be an advantage for individuals who may wish to express different parts of their identity in different contexts. Another advantage may be decreased discrimination towards people with disabilities. Guo, Bricout, and Huang (2005) found 
Online Autistic Community 17

that $54 \%$ of their respondents with disabilities said there is less discrimination toward people with disabilities online than in face-to-face interactions, suggesting that the option of disclosing disability may decrease discrimination. When specifically considering the Autistic community, using the Internet for communicating with others may serve to lessen differences in social interactions, making language use similar to neurotypical Internet users (Benford \& Standen, 2009; Burke, Kraut, \& Williams, 2010; Newton, Kramer, \& McIntosh, 2009).

In addition to creating a venue for social connections, the Internet can be a source of information for and about autistic individuals. Autism-focused websites and listserves provide the opportunity for sharing first-hand accounts and perspectives and providing more complex and accurate portrayals of the emotional and social lives of people with autism (Jones, Zahl, \& Huws, 2001; Jordan, 2010). Having the voices of these individuals heard among the disability community and beyond may create a powerful movement that will be reflected in all aspects of autistic individuals' lives (Blume, 1997b) and well as how autism is perceived by mainstream society (Davidson, 2008).

The Internet has value to the Autistic community beyond social interaction. Folstein (1999) argues that differences in social abilities in autistic adolescents and adults can account for under-employment and difficulty in relationships. Autistic adults are not often given the tools or opportunities to access to information, people, or services that can assist them in making critical life decisions (Barnard, Harvey, Potter, \& Prior, 2001). The Internet allows individuals to learn from one another as well as work together for advocacy purposes. Additionally, as many of these websites are free and have open 
Online Autistic Community 18

access, they create an opportunity for others not on the spectrum to learn and understand more about the nature of autism.

The online Autistic community may be a unique population of individuals; however, this community has not been thoroughly studied enough to draw conclusions about demographics or diagnoses. Because of the lack of research on this population, many have called for a greater understanding of the personal experiences of autism (Barrett, 2006) and the way autistic people are part of communities (Silverman, 2008). Because of the lack of information on exactly who participates in the online Autistic community, we must be cautious about generalizing findings from the online Autistic community to all individuals (Jones, Zahl, \& Huws, 2001).

However, among the general population, individuals under the age of 30 are the most frequent users of the Internet (Morales, 2009). Therefore, the online Autistic community may be mostly populated with people within a certain age range (Cromby \& Standen, 1999). Also, older adults may not have a diagnosis or identify as ASD, or may not have developed technical skills to use a computer or browse the Internet or been exposed to the ideas of the autistic self-advocacy movement (Schur, Shields, \& Schriner, 2005), thus limiting involvement in the online Autistic community. Age was examined in the current study and used as a control variable to compensate for the impact age may have on Internet use and Autistic identity.

In addition to age, income has been studied in relation to Internet use, with individuals making more than $\$ 75,000$ per year are the most frequent users of the Internet (Morales, 2009). Therefore, the online Autistic community may be mostly populated with 
people above a certain income (Cromby \& Standen, 1999). Contrary to Internet use in the general population, disability and poverty are closely associated (Erickson \& Lee, 2008). Therefore, income was examined in the current study as well.

Autistic culture has been studied both online (Davidson, 2008) and more generally (Silverman, 2008). Additionally, personal accounts of how the Internet has impacted the lives of autistic individuals are readily available on many blogs, videos, chat rooms, and listserves (e.g., www.wrongplanet.net). Research has also investigated how identity plays a major role in this community, finding that Autistic identity and identification with the Autistic community is a complex, dynamic construction for every individual involved in the online Autistic community (Brownlow, 2007). There exists a need to further understand how involvement in this community affects Autistic identity, specifically through the framework of disability identity.

Additionally, while sense of community has been explored in other online communities (Forster, 2004), there is no empirical work on how involvement in the online Autistic community is related to a sense of community. Research has shown strong links between identity and sense of community (Obst \& White, 2004), suggesting a need to examine this relationship in the online Autistic community. Research has also shown links between sense of community and social action (Chuiper and Pretty, 1999). Autistic self-advocates use the Internet to disseminate information and advocate for social action (Blume, 1997a), which may contribute to sense of community. Understanding the relationship between the importance and value of involvement in the online autistic community and sense of community may increase understanding of the utility and 
Online Autistic Community 20

effectiveness of Internet use as a tool for social action and the positive outcome of sense of community.

The values derived from the disability rights movement and community psychology support the promotion of research that focuses on improving the lives of individuals with disabilities (Dowrick \& Keys, 2001). As research links involvement in online communities (Valkenburg \& Peter, 2007), identity development (Berkman, Glass, Seeman, \& Brisette, 2000), and sense of community (Albanesi, Cicognani, \& Zani, 2007) to well-being, there is a need to further understand the relationships among these variables. By addressing this gap in the literature, we can inform how participation in the online Autistic community may promote well-being in this population. The current study addresses the relationships among the importance and value of involvement in the online Autistic community, Autistic identity, sense of community, and psychological well-being (see Figure 2).

\section{Autistic Identity}

Involvement in the online Autistic community may potentially create an opportunity for autistic individuals to develop Autistic identity. Research has shown that participation in social movements, such as the neurodiversity movement, involves the development of a personal identity around the community and a sense of self-realization (Gamson, 1992; Teske, 1997). Further, involvement in any social context is related to the development of identity and increased well-being (Berkman, Glass, Seeman, \& Brisette, 2000; Hendry, 1983; Wandersman \& Florin, 2000).

Identity has been studied in the past as the individual's perception of self and as a 
Online Autistic Community 21

dynamic, lifespan process of differentiating oneself from the environment and context (Erikson, 1956; Marcia, 1966). This definition was later expanded on with the inclusion of the social element of identity, suggesting that people use social categories to identify themselves and others within the same and different categories (Tajfel \& Turner, 1979). Many theories of identity now propose that context must be considered in the development of identity (Adams \& Marshall, 1996). When considering the identity of an individual within a context, it is necessary to also acknowledge the dynamic systems of power and oppression that influence and are influenced by developing individuals (Abberley, 1987; Friere, 1972). Barriers exist in society that block out people perceived to be different, such as autistic individuals (Fine \& Asch, 1988). However, with the label of disability or autism, this group may find commonality with one another apart from those without such labels (Fine \& Asch, 1988). As all these layers impact the development of identity, it is necessary to consider identity as an individual, social, and ecological construct within a transactional model. Thus, disability identity is an interactional, dynamic concept that integrates the biological, cognitive, social, and historical contexts of self (Gill, 1997a).

Disability identity has been defined as the development of a positive self-concept, understanding and acceptance of the perceptions others have about one's disability or oneself, and understanding of how disability impacts one's life (Olney \& Kim, 2001). Gill's construct of disability identity uniquely uses a social constructionist and transactional model of identity development, which can be applied to many marginalized identities in society, such as gay and lesbian identity (Cramer and Gilson, 1999). This 
Online Autistic Community 22

model of disability identity can also be specifically applied to Autistic identity. Disability identity, therefore, is a developmental, integrative process that occurs on the individual and group level. Boykin's (1986) Triple Quandary Theory posits that Black identity is formed through socialization into three groups with often competing agendas: mainstream society, Black culture, and minority identity. Similarly, Gill's theory of disability identity involves individuals forming identity through integration into different social categories. Gill describes the four types of integration which underlie the process as integration into society ('coming to feel we belong'), integration into the disability community ('coming home'), internal integration of sameness and differentness with society and disability community ('coming together'), and integration of feelings about self and presentation of self ('coming out').

Integrating into society occurs on an individual level as a person asserts his or her right to belong in society (Gill, 1997a). On a group or community level, this dimension is reflected in the disability rights movement, Americans with Disabilities Act, and the demand for equal rights and accommodations. This process includes the shift from blaming one's disability as creating a separation from "normal" life to redirecting the blame on the makers of uninclusive and unaccommodating environmental conditions. In the online Autistic community, this dimension is reflected in sharing of information on rights and advocacy that can be brought to mainstream society.

The dimension of integrating into the disability community involves overcoming any fears of past memories of disability segregation or stigma associated with mainstream ideas of relationships among people with disabilities (Gill, 1997a). Once attitudes about 
Online Autistic Community 23

integration with the disability community are overcome, a person may find such integration and relationships rewarding and uniquely strong due to an acceptance and understanding that surpasses many people without the experiences of disabilities. In the online Autistic community, this is expressed in solidarity and meaningful relationships members form with one another within communities designed and run by autistic adults. Internal integration of sameness and differentness with society and disability community involves resolving the conflict of self as broken or not whole with a sense of pride and belonging (Gill, 1997a). This also relates to supporting self-esteem and the ability to perceive the self as a part of both the disability community and mainstream society. Since a true sense of belonging to these communities relies on the resolution of the fractured parts of the self, the stability and progress of integrating into society and integrating into the disability community may be dependent on this dimension.

Lastly, integration of feelings about self and presentation of self involves resolving the private perception of self with the ideal image presented to others (Gill, 1997a). The integration is the final stage of identity that results in stability in how comfortable an individual is with herself. This dimension is reflected in a lack of internal conflict or discomfort with how the individual perceives herself as well as within social environments.

Qualitative support has been shown for Gill's theory of disability identity among individuals with spinal cord injuries (Hernandez, 2005) and among queer women with disabilities (Whitney, 2006). However, this theory has not been applied quantitatively or with the specific population of autistic adults. Research has shown that identity 
Online Autistic Community 24

development is related to Internet use (Turkle, 1995) and sense of community (Obst \& White, 2005). Further, while Autistic identity has been studied qualitatively (Brownlow, 2007), no quantitative study has explored Autistic identity or its relation to sense of community. The next section will describe the relationship of sense of community and identity in the current study.

\section{Psychological Sense of Community}

Sarason (1974) defines community as "a readily available, mutually supportive network of relationships on which one could depend" (p.1). Communities can be dichotomized into two types of communities. Communities of locality or geographic communities include blocks, neighborhoods and cities. Relational communities or communities of interest are support groups, church congregations, or Internet groups. Many report an alarming decrease in community involvement and sense of community (Putnam, 2000; Dalton, Elias, \& Wandersman, 2001). However, these reports do not consider the impact of technology and our shifting, global world, where others have cited the Internet as a new, exciting tool to promote sense of community (Obst, Zinkiewicz, \& Smith, 2002a).

Psychological sense of community (PSOC) is defined by Sarason (1974) as "the perception of similarity to others, an acknowledged interdependence with others, a willingness to maintain this interdependence by giving to or doing for others what one expects from them, the feeling that one is part of a larger dependable and stable structure" (p. 157). PSOC has been shown to be a catalyst for community involvement, cooperative action, community justice and social change (Bachrach \& Zautra, 1985; Allen \& Allen, 
Online Autistic Community 25

1987; Chuiper and Pretty, 1999). Additionally, PSOC is related to the perception of the quality of available healthcare (Ahern, Hendryx, \& Siddharthan, 1996), health-promoting activities (Allen \& Allen), and subjective well-being (Davidson \& Cotter, 1991; Ferrell, Aubry, \& Coulombe, 2004). Considering the physical and psychological disparities faced by autistic adults (Ballaban-Gil, Rapin, Tuchman, \& Shinnar, 1996; Hawlin, Good, Hutton, \& Rutter, 2004), the outcomes such as those of sense of community may be invaluable. Additionally, a sense of community in this population may contribute to and strengthen the neurodiversity movement, which broadly aims to improve the quality of life for all autistic individuals.

McMillan and Chavis (1986) developed a theoretical model of the dimensions of PSOC (membership, influence, integration and fulfillment of needs, and shared emotional connection). Much of the research investigating PSOC uses and supports the model, both in communities of locality (Davidson \& Cotter, 1986) and in relational communities (Obst, Zinkiewicz, \& Smith, 2002a). Additionally, qualitative research has supported the dimensions of the model (Brodsky, 1996).

Membership is defined as a sense of belonging or feeling a part of the community. Membership provides emotional safety and includes having a personal investment in the community, which lead to stronger bonds (McMillan, 1996). Having boundaries defining the community and feeling as though one is within them is also important in this concept. In the case of Internet communities, boundaries can be defined as loosely as subscribing to a listserve or as strict as requiring an invitation to join a messageboard (Forster, 2004). 
Online Autistic Community 26

These boundaries may play a part in the strength of feeling of membership a person has with her community (McMillan \& Chavis, 1986).

The dimension of influence is defined by having a sense of control over the community. It is a bidirectional concept with the community having control over the individual as well (McMillan \& Chavis, 1986). The idea of influence is related to group processes such as conformity and the tensions of leader and follower dynamics (McMillan, 1996). This dimension also captures the cohesiveness and development of community norms. In Internet communities, this may involve respect and trust in message board moderators and the feelings that accompany heavy moderation, such as approval for messages sent out to the community. Additionally, influence can be observed in more homogeneous and conforming messages and emails over the community, indicating the influence of the community on the individuals participating, pressures of conformity, and community norms leading to order.

The concept of integration and fulfillment of needs involves an individual's perception of the rewards of being a member of a community (McMillan \& Chavis, 1986). Because of similarities among members and the support provided to one another, there is a perception of fulfillment from being a part of a community. If a member sees the community as successful with competent members cooperating and helping one another out, she is likely to feel as though her needs are being fulfilled as expected from the community. This dimension of integration and fulfillment of needs encompasses the emotional rewards from a sense of togetherness. In Internet communities, this may 
involve helpful and engaging discussion and a positive sense of accomplishing goals as a community.

The fourth dimension, shared emotional connection, is the sense of shared history and understanding among members (McMillan \& Chavis, 1986). McMillan and Chavis described this connection as requiring close relationships and identification with members to feel a connection. The more people interact in a community, the closer the relationships may be. Additionally, the more positive these interactions are, the stronger the bonds between members will be. If members have strong, positive bonds, they will give more and care more about the community. For autistic individuals on the Internet, this shared emotional connection may stem from shared experiences and lifestyles of having autism and seeking community and information via Internet communities, as well as the amount of time spent with the community and the quality of the interactions. It will also be reflected in the emotional investment in the success of the community.

The theoretical model has been accepted and broadly used in sense of community research (Brodsky, 1996; Chipuer \& Pretty, 1999). However, the measurement of sense of community has been scrutinized and modified since its original form. Chavis, Hogge, McMillan, and Wandersman (1986) developed the Sense of Community Index (SCI), a 46-item scale to measure psychological sense of community according to the four theoretical dimensions. As the theoretical model can be applied to any locality or relational community, the SCI can be used to measure PSOC in any community (Chavis et al., 1986). A 12-item index was created using a Brunswik's lens methodology, a process of developing items through consensus of the experience of sense of community 
Online Autistic Community 28

and prediction of sense of community by the items and language agreed upon (Chavis, Hogge, McMillan, \& Wandersman, 1986). This index became the most widely used measurement of PSOC in community psychology, adapted for a wide variety of communities such as the workplace (Brodsky \& Marx, 2001), neighborhoods (Brodsky, O’Campo, \& Aronson, 1999; Kingston, Mitchell, Florin, \& Stevenson, 1999), immigrant groups (Sonn, 2002), and the Internet (Forster, 2004; Obst, Zinkiewicz, \& Smith, 2002b). The index is also the only measurement developed from the sound McMillan and Chavis model (Obst \& White, 2004).

However, many critiques of the scale exist. Chipuer and Pretty (1999) used principal components analysis and found subscale internal consistency reliabilities ranging from .16 to .72 with the majority below acceptable levels. Other researchers have used exploratory factor analysis techniques to extract items from various PSOC scales and related scales to create an ideal scale measuring PSOC (Proescholdbell, Roosa, \& Nemeroff, 2006; Obst, Zinkiewicz, \& Smith, 2002a). These measurement development studies have yielded conflicting results about the dimensionality of the scale, including finding unidimensionality of the construct (Buckner, 1988) and a fifth dimension (Obst, Zinkiewicz, \& Smith, 2002a). A confirmatory factor analysis was performed on 11 of the 12 items of the scale with more positive results indicating support for the four dimensions proposed by McMillan and Chavis’s theoretical framework (Obst \& White, 2004). However, individual items loaded onto dimensions other than predicted, so a revised scale moved items to factors they loaded on best and a confirmatory factor analysis was performed again and showed acceptable internal consistency reliability (alphas between 
Online Autistic Community 29

.70 and .84 on subscales). The same data set was used for the second confirmatory factor analysis, increasing the possibility that results were due to sampling error variance, and two of the dimensions were supported by only two items each, which is not sufficient to be a stable measure of a dimension (Obst \& White, 2004).

Because of the lack of success with the SCI or its development, researchers began questioning its validity (Peterson, Speer, \& Hughey, 2006). Scales specific to virtual communities began to emerge, claiming theoretical differences from McMillan and Chavis's model, such as an absence of the dimension of influence (Blanchard \& Markus, 2002; Blanchard, 2007). A virtual community is defined as a community that interacts through electronic communication, including via IM, email, and cell phones (Blanchard $\&$ Markus, 2002). These communities are similar to the online Autistic community in that they incorporate a variety of communication methods including the Internet, but are not the same as the online Autistic community in that they generally have connections to certain businesses or products, such as correspondence in an organization or reviewers on Amazon.com. Because of the similarities and shared emotional connection among the online Autistic group (Silverman, 2008), McMillan and Chavis's theory is more applicable to the online Autistic community. Furthermore, this theory has been shown to apply to relational communities online in past research (Forster, 2004).

Recent work has been done to improve the measurement of sense of community. The latest measurement development on the SCI involved creating a 24 item scale based on the original 12 item scale, but utilizing a Likert scale rather than the original true-false format (Chavis, Lee, \& Acosta, 2008). This scale, the SCI-2 was piloted, revised, and 
Online Autistic Community 30

tested with a large population. Analyses show the SCI-2 has high internal consistency, with an overall coefficient alpha of .94 and subscales with coefficient alpha scores of .79 to .86 .

There is a need to study the relationship between involvement in the online Autistic community and sense of community. Although the Internet is used to gather information and advocate for the neurodiversity movement, there has not yet been any research on whether involvement in the community is related to experiencing a sense of community. Our understanding of positive outcomes of involvement in the online Autistic community can be linked to the development of sense of community.

Psychological sense of community has shown to be related to social identity in different communities (Davidson \& Cotter, 1986; Obst, Zinkiewicz, \& Smith, 2002b). This is particularly salient in communities of interest, where the idea of choice in belonging to a community is stronger than within geographic locations (Obst, Zinkiewicz, \& Smith, 2002b). Because autistic adults are motivated by choice rather than locality in the decision to participate in the online community, one might expect a strong relationship with this population between Autistic identity and psychological sense of community. That is, a person who identifies as being autistic is more likely to frequent a community and have a sense of community with others in it than a person who does not identify as autistic or has a low level of identification with autistic individuals. The dimensions of membership and shared emotional connection are particularly highly correlated with identity, due to the nature of these dimensions including different types of identity (Obst, Smith, Zinkiewicz, 2002). Identity with the community itself would 
Online Autistic Community 31

create a higher membership while identifying with autistic adults will create a higher shared emotional connection.

Previous research has shown that sense of community is related to positive outcomes such as well-being (Pretty, Andrewes, \& Collett, 1994). Because community psychology and the Autistic community call for research exploring strengths-based research with autistic adults, the next section will describe the current study's focus on the relationships of the importance and value of involvement in the online Autistic community, Autistic identity, and sense of community to psychological well-being.

\section{Psychological Well-Being}

It is important to study positive outcomes for autistic adults in order to identify factors that contribute to the understanding of how to improve the quality of life for these individuals. There is research on the well-being of mothers of autistic individuals (Abbeduto, Seltzer, Krauss, Orsmond, \& Murphy, 2004) and even the well-being of siblings of autistic children (Bauminger \& Yirmiya, 2001; Orsmond \& Seltzer, 2007). While quality of life for autistic adults has been assessed (Burgess \& Gutstein, 2007; Gerber, Baud, Giroud, \& Carminati, 2008; Renty \& Roeyers, 2006), there has been no study addressing well-being in autistic adults themselves, which is an important determinant of quality of life (Cohen, Mount, Tomas, \& Mount, 1996). Among other groups, well-being has been linked to technology use (Cotton, 2008) and identity (Berkman, Glass, Seeman, \& Brisette, 2000). Sense of community is also a strong predictor of well-being (Albanesi, Cicognani, \& Zani, 2007), even beyond social support, which is considered the individual-level construct related to the extra-individual construct 
Online Autistic Community 32

of sense of community (Pretty, Andrewes, \& Collett, 1994; Pretty, Conroy, Dugay, Fowler, \& Williams, 1996). Moreover, in a study evaluating social support, loneliness, sense of community, and subjective well-being in neighborhoods and schools, social support was not a significant predictor of well-being (Pretty, Conroy, Dugay, Fowler, \& Williams, 1996). Because of the strong relationships among variables presented in this study, as well as the interest in studying positive outcomes for autistic adults, the present study explores psychological well-being in the online Autistic community.

Well-being is generally described as being in an optimal psychological condition. Keyes, Shmotkin, and Ryff (2002) define psychological well-being as the "perception of engagement with existential challenges of life" (p. 1). Therefore, a person with high psychological well-being is satisfied with her relationships with others, has meaning in life, and feels positively about herself. This is related to, but distinct from the construct of subjective well-being, defined as satisfaction with life and a balance between positive and negative affect (Keyes, Shmotkin, \& Ryff, 2002). Ryan and Deci (2001) describe two traditions of well-being: hedonic and eudaimonic. The first tradition involves studying hedonic well-being, or pleasure and happiness, as the most accurate framework for discussing well-being. Theories of subjective well-being are based on hedonic wellbeing. Eudaimonic well-being refers to the idea that well-being lies in fulfilling one's own human potential (Ryan \& Deci, 2001). The eudaimonic tradition is the basis of psychological well-being. It suggests that well-being goes beyond happiness and satisfaction with life, but encompasses an actualization of one's potential and to live according to one's true self (Waterman, 1993). Ryff (1989) argues that subjective well- 
Online Autistic Community 33

being encompasses only a narrow conception of well-being and that psychological wellbeing should go beyond short-term happiness to emphasize sense of purpose and achievement in life. The present study utilizes the theory of psychological well-being to account for the broader definition of well-being.

Ryff (1989) developed a theory of psychological well-being that takes into consideration previously identified constructs and consolidates the eudaimonic aspects of well-being into six dimensions: self-acceptance, autonomy, environmental mastery, purpose in life, positive relations with others, and personal growth. These dimensions are interactional, spanning developmental and contextual perspectives. The three dimensions of interest in the proposed study are self-acceptance, autonomy, and environmental mastery. The dimensions of purpose in life, positive relations with others, and personal growth have relevance to many individuals' psychological well-being. However, due to language barriers and different style of interpersonal relationships, these abstract, normative dimensions of well-being are not easily applicable to the Autistic community (Gillberg, 2001; Orsmond, Krauss, \& Seltzer, 2004). As a result of discussions and decisions made by the CBPR team, these dimensions are not explored in the current study.

An individual who has high self-acceptance has a positive attitude towards oneself presently and about one's past and accepts the positive and negative aspects of the self (Ryff, 1989). Self-esteem, a closely related construct, has been found to have a positive relationship with time spent on the Internet for communicative purposes (Rohall, Cotton, \& Morgan, 2002). This dimension is also likely closely related to the dimensions 
Online Autistic Community 34

of disability identity involving internal integration of differentness and sameness and integration of feelings about self and presentation of self, and therefore is salient to the online Autistic community. It is possible that those who have strong Autistic identity will have the coping skills and sense of community to have higher self-acceptance.

Autonomy refers to the characteristics of self-determination and ability to evaluate the self by standards within the individual rather than looking for outside social pressures to conform to. While self-determination and choice have been discussed with people with intellectual disabilities (Brown \& Brown, 2005) as well as autistic adults (Burgess \& Gutstein, 2007), no empirical work has been done addressing autonomy in autistic adults. This dimension is also likely determined by strength of disability identity and will be positively related to sense of community.

Environmental mastery involves knowing how to choose, create, or control one's activities and contexts in order to utilize one's own strengths and competencies. This dimension captures the idea of an individual's awareness of a person- environment fit most appropriate to the self. It allows the individual to have greater comfort in social situations, better management of everyday activities, and the ability to take advantage of opportunities in certain contexts. The online Autistic community uses environmental mastery in locating a venue that allows for ease of communication and flow of information that caters to individual needs.

Psychological well-being has been explored in relation to Internet use in a variety of ways (Shklovski, Kiesler, \& Kraut, 2006). First, the Internet increases social networks and social capital, a person's resources within social networks (Boase, Horrigan, 
Online Autistic Community 35

Wellman, \& Rainie, 2006). Much research has also been conducted on how the Internet effects social interactions (see meta-analysis: Shklovski, Kiesler, \& Kraut, 2006), with results indicating an increase in social interactions over time with Internet users. Third, despite some studies showing that Internet has a negative impact on well-being (Kraut, Patterson, Lundmark, Kiesler, Mukhopadhyay, \& Scherlis, 1998), Valkenburg and Peter (2007) found the negative relationship disappears when controlling for closeness to friends and online interactions with strangers. These findings suggest that when the Internet is used for social purposes, such as connecting autistic adults with one another, the Internet can contribute to a person's well-being. It is important to consider how the Internet may impact well-being with the unique population of autistic adults. In prior research, while well-being was generally lower for the Deaf group compared to the hearing group of Barak and Sadovsky's (2008) study (as measured by loneliness and selfesteem), those who used the Internet more intensively had higher well-being than those who used the Internet less. Because of the communicatory challenges faced by the Deaf participants may compare to some of the challenges faced by autistic individuals, these results may also be true in the online Autistic community.

As noted, psychological sense of community has also been shown to be a predictor of well-being (Davidson \& Cotter, 1991; Ferrell, Aubry, \& Coulombe, 2004). Feeling of membership, having needs fulfilled, feeling influential and part of a group, and having shared emotional connection with a community have been found to contribute to personal coping and overall health (including well-being) when the community is stable and contains positive relationships within it (Farrell, Aubry, \& Coulombe, 2004). 
Online Autistic Community 36

Additionally, minority identity is positively related to well-being (Gray-Little \& Hafdahl, 2000; Kiang et al., 2006; Ryff, Keyes, \& Hughes, 2003; Umaña-Taylor, Diversi, \& Fine, 2002). Research has supported a moderating effect of identity on coping strategies and resilience, which results in well-being and other positive mental health outcomes of individuals (Kiang, Yip, Gonzales-Backen, \& Witkow, 2006; Shelton, Yip, Eccles, Chatman, Fuligni, \& Wong, 2005; Yoo \& Lee, 2005).

\section{The Present Study}

The present study has one overarching aim and one specific research question. The present study examines the relationships among the importance and value of involvement in the online Autistic community, sense of community, Autistic identity, and psychological well-being in the data available to date. Here, I describe the research question and hypotheses of the study.

My research question addresses the relationships among the importance and value of involvement in the online Autistic community, Autistic identity, sense of community, and psychological well-being. Importance and value of involvement in the online Autistic community is operationalized in the present study as an individual's evaluation of importance and value of involvement in the online Autistic community. Specifically, how are the importance and value of involvement in the online Autistic community, Autistic identity, sense of community, and psychological well-being related to one another in the online Autistic community? As depicted in the conceptual model for the study (Figure 2), I predicted that the importance and value of involvement in the online Autistic community will be positively related to psychological well-being $(\mathrm{H} 1.1)$, the importance 
and value of involvement in the online Autistic community will be positively related to Autistic identity (H 1.2), Autistic identity will be positively related to sense of community (H 1.3), the importance and value of involvement in the online Autistic community will be positively related to sense of community (H 1.4), Autistic identity will be positively related to psychological well-being ( $\mathrm{H}$ 1.5), and sense of community will be positively related to psychological well-being (H 1.6). Further, I predicted that Autistic identity and sense of community will mediate the relationship between the importance and value of involvement in the online Autistic community and psychological well-being when controlling for age (H 2). Hypothesis 2 is depicted in Figure 3.

Hypothesis 1.1. The importance and value of involvement in the online Autistic community will be positively related to well-being.

Hypothesis 1.2. The importance and value of involvement in the online Autistic community will be positively related to Autistic identity.

Hypothesis 1.3. Autistic identity will be positively related to sense of community.

Hypothesis 1.4. The importance and value of involvement in the online Autistic community will be positively related to sense of community.

Hypothesis 1.5. Autistic identity will be positively related to psychological wellbeing.

Hypothesis 1.6. Sense of community will be positively related to psychological well-being.

Hypothesis 2 . Autistic identity and sense of community will partially mediate the relationship between the importance and value of involvement in the 
Online Autistic Community 38

online Autistic community and psychological well-being when controlling for age. 
Online Autistic Community 39

\begin{abstract}
Method
The present study examines the relationships among the importance and value of involvement in the online Autistic community, sense of community, Autistic identity, and psychological well-being. It utilized a cross-sectional online survey design. As indicated, a community based participatory research approach was used for the current study. Figure 1 shows how academic and community partners contribute to the research process through the CBPR approach within the AASPIRE team (Nicolaidis, Raymaker, McDonald, Dern, Boisclair, Robertson, \& Baggs, 2011). Members collaborate using their strengths to develop and implements the projects, then disseminate project results and use findings to inform future studies.
\end{abstract}

\title{
Research Context
}

The Gateway Project, the collaboration between AASPIRE and Dr. Morton Gernsbacher's Lab at University of Wisconsin-Madison, serves as a gateway to research that is committed to values pertaining to community based participatory research, including respect, accessibility, inclusion, and relevance to the autistic adult community. The purpose of the Gateway Project is to identify eligible participants, recruit them for continuing online studies, and collect data on variables that will inform subsequent studies. The Gateway Survey collected data on variables used in the current study, including Internet and computer use, demographic information, disability and Autistic identity and diagnoses, hand preferences, interests, habits, and social interactions, and future research. After participating in the Gateway Survey, the demographic data and the 
Online Autistic Community 40

data on diagnoses are used to identify eligible participants for AASPIRE's continuing projects, including the Internet Use, Community, and Well-Being Study. Data from the Gateway Survey and the Internet Use, Community, and Well-Being Study are used in the present study.

\section{Study Development}

The AASPIRE team first identified the importance of examining involvement in the online Autistic community. The AASPIRE team nominated the constructs of involvement in the online Autistic community, Autistic identity, sense of community, and psychological well-being to be included in the study. We then developed all procedures and materials for the study as a team consisting of the academic principal investigator, Dr. Katherine McDonald, the community principal investigator, Dora Raymaker, and the academic co-investigator Dr. Christina Nicolaidis. The principal investigators and the AASPIRE team reviewed the procedures and materials. Online meetings are conducted via Skype instant messaging, email, or in person to discuss any concerns or ideas team members wish to share. Revisions are made in accordance to the group's discussions, and a next draft is reviewed once again by the whole AASPIRE team.

This system of constant communication and checking in with all research partners results in much revision of procedures and materials to create understanding and relevance among the whole team. The researchers provide support by ensuring the quality of the design and measures, while the autistic partners ensure respectfulness, relevance, and clarity of procedures and measures. The principal investigators and co-investigators made minor or time sensitive decisions. 
Online Autistic Community 41

We made decisions around choice of instruments and items by presenting options to the team and educating community partners on the reliability and validity of existing options. The team chose the Sense of Community Index 2, Autistic Identity Scale, and three of the more relevant Psychological Well-Being Scales based on theoretical appropriateness, accessibility, and face validity. The community partners approved usage of the scales overall, but required definitions or word changes within some of the items.

In order to retain the scientific validity of the psychometrically sound instruments while allowing for optimal comprehension, the AASPIRE research team utilized hotlinks for clarifying words or phrases within items. The AASPIRE research team worked extensively to create the most comprehendible hotlinks to supplement the original items if the participant requires clarification. The process of modifying survey items and hotlinks was utilized when community partners indicated that some of the items contained vague or confusing words or phrases. During team meetings, we identified vague or confusing aspects of individual items. We then discussed what words, phrases, or definitions would make the item comprehendible to our study population. We reached consensus on every item during team meetings. After team meetings, the investigators created hotlinks with the decided upon language. The team was asked to review the survey again with the hotlink changes and provide feedback in the next team meeting. This process was repeated until consensus was reached on the comprehension of all survey items. Hotlinks for the survey versions can be found in Appendix G. 
Online Autistic Community 42

\section{Measures}

The current study utilizes five measures that are described below and can be found in Appendices 3-6. These include the Gateway Survey, and the four measures from the AASPIRE Internet Use, Community, and Well-Being Study, including Internet Usage, Sense of Community Index 2, Autistic Identity Scale, and Psychological WellBeing.

Gateway Survey. The Gateway Survey asked about Internet and computer use, demographic information, disability and Autistic identity/ diagnoses, hand preference, interests, habits, social interactions, and future research. This survey contains five items that were used in the current study that asked about demographics, including age, country, gender, and race/ ethnicity.

The current study used the 18 items about disability status and diagnoses. The questions asked the participant if she identifies with being a person with a disability. The questions that specifically ask about autism spectrum diagnoses were used in the current study. These five autism-specific questions include one item that was used as an inclusion criterion for the proposed study. This item is: "I identify as a person on the autistic spectrum (including Autistic disorder, Asperger's, and PDDNOS), either because I have been formally diagnosed or because I have recognized that the criteria fit me: a. Yes, and I have been formally diagnosed, b. Yes, but I have not been formally diagnosed, c. No, d. Do not wish to say." A participant must have indicated that she identifies as a person on the autistic spectrum by responding to this item with "a" or " $b$ " to be included in the present study. 
Online Autistic Community 43

The Autism-Spectrum Quotient (Baron-Cohen et al., 2001) is a 50-item

instrument measuring the degree to which an adult has traits associated with the autistic spectrum. The AQ assesses five different areas that represent autistic traits. These areas are social skill (e.g., "I prefer to do things with others rather than on my own"), attention switching (e.g., "I prefer to do things the same way over and over again"), attention to detail (e.g., "I often notice small sounds with others do not"), communication (e.g., “Other people frequently tell me that what I've said is impolite, even though I think it is polite"), and imagination (e.g., "If I try to imagine something, I find it very easy to create a picture in my mind"). Ten items ask about each of these areas. The items are completed on a scale response of "definitely agree", "slightly agree", "slightly disagree", and “definitely disagree". Positively scored items indicate that a response of "definitely agree" or "slightly agree" score one point on the AQ rating. Negatively scored items indicate that a response of "definitely disagree" or "slightly disagree" score one point on the AQ rating. A total AQ score is derived from the sum of all items.

The cut-off score of 32 indicates that a person scoring 32 or higher has indicators consistent with clinically diagnosed ASD. The AQ has been shown to be a reliable measure (overall alpha .71 and .81 in two samples) as well as good screening properties when compared to clinical diagnostic criteria (Hoekstra, Bartels, Cath, \& Boomsma, 2008). Studies have shown good discriminative validity and screening properties for the AQ using a cut-off of 26 or higher (Woodbury-Smith, Robinson, Wheelwright, \& BaronCohen, 2005). The AQ also shows good reliability in the current study with an overall alpha of .84 . While the inclusion criteria for the current study is self-identifying as on the 
Online Autistic Community 44

autistic spectrum, AQ cutoff scores were included for descriptive purposes and to compare differences between participants who have autistic traits and do not have autistic traits. In the current sample, no significant differences were shown between the group using a cut-off of 26 or higher and the group using a cut-off of 32 or higher in demographics or constructs. Therefore, the more conservative cut-off of 32 or higher was used for descriptive purposes and to compare differences. The items of the AQ are in Appendix C, under the section entitled "Interests, Habits, and Social Interactions".

Finally, three questions with multiple choice responses ask about education and seven questions ask about employment and income. Two questions on education ("The highest level of education that I have obtained is:" and "The highest level of education either of my parents obtained is:”) and four items on employment (“My employment status is:”) and income ("During the past 12 months, my main sources of income were:") was used in the current study. This survey can be found in Appendix D.

AASPIRE Internet Use, Community, and Well-Being Study. Four sections of the AASPIRE Internet Use, Community, and Well-Being Study were used in the current study.

Internet Usage. The Internet Usage survey asked about participants' computer use, Internet access, involvement in any online communities, and involvement specifically in the online Autistic community. The item that was used in the current study asked about the importance and value of involvement in the online Autistic community ("I consider my involvement with online Autistic communities to be an important and valuable part of my life"). Previous research has extensively investigated the relationship among received social support, such as number of people in a person's 
Online Autistic Community 45

community or time spent with the community, and perceived social support, which is the subjective value of the support a person receives (Sarason, Sarason, \& Pierce, 1995). Perceived social support, however, has been shown to be necessary for social support to be linked to positive health outcomes, accounting for more of the variance of the effect of overall social support than received social support. (Haber, Cohen, Lucas, \& Baltes, 2007). Since social support is considered the individual-level construct related to the extra-individual construct of sense of community (Pretty, Andrewes, \& Collet, 1994; Pretty, Conroy, Dugay, Fowler, \& Williams, 1996), it is likely that the strong findings related to social support can also apply to sense of community. The item used in the current study was developed by the AASPIRE team to tap into the subjective, perceived value of the community in order to mirror findings from previous research.

The Internet Usage measure was developed for the current study. Items for this section were modeled from similar items in the Gateway Survey and Gallup Poll (Gallup, Inc., 2009), and then modified by the AASPIRE research team with input from the community partners on comprehension of the language.

Sense of Community Index 2 (SCI-2). The Sense of Community Index version 2 (SCI-2) is the second version of the original SCI that contains 25 items that measure a person's sense of community (Chavis, Lee, \& Acosta, 2008). The first item ("How important is it to you to feel a sense of community with other community members?") is a validating question that has a strong positive correlation with the total sense of community score (Chavis, Lee, \& Acosta). The remaining 24 items contain statements that represent how the participant feels about the community. For example, "I can trust 
Online Autistic Community 46

people in this community". The items of the Sense of Community Index version 2 are in Appendix G.

The scale is based on the theory of sense of community developed by McMillan and Chavis (1986). The SCI-2 contains four subscales corresponding to the four dimensions of the theory. The subscale of membership contains six items including: "Being a part of this community is part of my identity." The subscale of influence contains six items including: "Fitting into this community is important to me." The subscale of integration and fulfillment of needs contains six items including: "Being a part of this community makes me feel good." Lastly, the subscale of shared emotional connection contains six items including: "Members of this community care about each other." All items were completed on a Likert scale response ranging from 0 (Not at All) to 3 (Completely). Subscale scores were the means of the respective items within each subscale. A total sense of community mean was derived from the mean of items 1 through 24, which was used for analyses in the current study. Responses to negatively scored items were reversed in the final scoring procedures so that high scores indicate high ratings on each dimension of sense of community. The SCI-2 has been shown to be a very reliable measure (overall alpha $=.94$ ) with reliable subscales with coefficient alpha scores ranging from .79 to .86 (Chavis, Lee, \& Acosta, 2008). The coefficient alpha of the current study sample shows excellent overall reliability (Cronbach, 1951) with an alpha of .94 . The subscales of the current study indicate the reliability of the membership subscale as acceptable $(\alpha=.78)$, the influence subscale is acceptable $(\alpha=.72)$, integration 
Online Autistic Community 47

and fulfillment of needs is excellent $(\alpha=.90)$, and shared emotional connection is excellent $(\alpha=.90)$.

Autistic Identity Scale. The Autistic Identity Scale is adapted from Gill's Disability Identity Scale (1997b). The scale includes 17 items containing statements about how the participant feels about being autistic. The scale is based on the theoretical work of Gill on disability identity (Gill, 1997), but language was adapted to be autism specific (e.g., "I believe that because I am a person with a disability, I have many strengths" was modified to "I believe that because I am autistic, I have many strengths"). In addition to adapting the scale to be autism specific, the AASPIRE research team worked to adapt some of the scale language for clarity and appropriateness for the participants. This included changing the original phrase "my destiny" to "my future".

Despite its theoretical grounding, no study has explored the psychometric properties of this scale. However, the items of the survey address each of the four dimensions of Gill's theory. These dimensions are integration into society (“Overall, people on the autistic spectrum are considered valuable by others"), integration with the Autistic community ("I have a strong sense of belonging to the Autistic community"), internally integrating one's similarities and differences with others ("In general, others respect people on the autistic spectrum"), and integrating how one feels with how one presents oneself ("Being autistic is an important reflection of who I am"). Each item was completed on a Likert scale response ranging from 1 (Strongly Disagree) to 5 (Strongly Agree). The mean of all Likert scale responses results in a composite score that was used in analyses. Responses to negatively scored items were reversed in the final scoring 
Online Autistic Community 48

procedures so that high scores indicate high ratings on the dimension. The current study sample indicated acceptable reliability (Cronbach, 1951) with an alpha of .73. It is possible that this alpha may increase by understanding the dimensionality of the scale or by removing certain items. However, the current sample size restricts the psychometric tests that may be applied to understand the scale. The Autistic Identity Scale is in Appendix G.

Psychological Well-Being. The Ryff Scales of Psychological Well-Being (PWBS; Ryff, 1989) measures six domains of psychological well-being: autonomy, environmental mastery, personal growth, positive relations with others, purpose in life, and self-acceptance. Three forms of each psychological well-being scale exist. These are the long form (14 items), medium form (9 items), and short form (3 items). The scales in short form have shown low internal consistency and were not used for the present study. No psychometric properties are available from previous studies utilizing the 9-item survey version (medium form), which was used for the present study because of considerations for respondent burden. In the current study, the overall scale indicated excellent reliability (Cronbach, 1951) with an overall alpha of .91. The alpha coefficients of the subscales indicated good reliability for autonomy $(\alpha=.84)$, good reliability for environmental mastery ( $\alpha=.84)$, and good reliability for self-acceptance $(\alpha=.89)$.

The dimensions of purpose in life, positive relations with others, and personal growth have relevance to many individuals' psychological well-being. However, due to language barriers and different style of interpersonal relationships, these abstract, normative dimensions of well-being are not easily applicable to the Autistic community 
Online Autistic Community 49

(Gillberg, 2001; Orsmond, 2004). Therefore, based on a team decision, these dimensions were not explored in the current study. Three domains were studied: autonomy, environmental mastery, and self-acceptance. Autonomy involves evaluating oneself by personal standards and showing resistance to conformity. Environmental mastery is the ability to choose and participate in one's environment. Self-acceptance is considered having positive attitude about oneself. Each of these aspects of psychological well-being is an indicator of well-being in the general population as well as indicators in the Autistic community.

The Psychological Well-Being Scales used for the current study can be found in Appendix G under the title "Attitudes and Perceptions". Each subscale of the medium form Psychological Well-Being Scales contains nine items. The scale of autonomy contains statements about how the participant feels about her own autonomy (e.g., "I have confidence in my opinions, even if they are contrary to the general consensus"). The environmental mastery scale contains statements about how the participant feels about the mastery of her environment ("In general, I feel I am in charge of the situation in which I live"). The self-acceptance scale contains statements about how the participant feels about herself ("I like most aspects of my personality"). All scales items were completed on a Likert scale response ranging from 1 (Strongly Disagree) to 6 (Strongly Agree). Responses to negatively scored items were reversed in the final scoring procedures so that high scores indicate high ratings on the dimension. A mean was calculated of the 27 items contained in all three scales to create a composite score of psychological well-being that was be used for analyses. 
Online Autistic Community 50

\section{Participants}

The present study utilized data from the autistic participants of the Gateway Project and the AASPIRE Internet Use, Community, and Well-Being Study. To be eligible for participation in the Gateway Project, participants must be online and able to read in English. However, participants completed the survey from anywhere in the world. To be eligible for participation in the AASPIRE Internet Use, Community, and Well-Being Study, participants must have completed the Gateway Survey. To be eligible for participation in the present study, participants must identify as an autistic person. This included any participant who has not been professionally diagnosed with ASD but who indicated on the item in the Gateway Survey that she identified as a person on the autistic spectrum. Gateway Survey participants who indicated they would like to receive extra credit in a course at the University of Wisconsin-Madison were ineligible for participation in order to ensure a more diverse sample compromised of individuals from a variety of ages, socioeconomic backgrounds, and geographic locations.

Participants range in age from 18 to $70(\mathrm{M}=36.46, \mathrm{SD}=12.23)$. The majority of participants identified as White (90.3\%). Participants who identify as Latino or Hispanic make up $4.2 \%$ of the participants. Of the 72 participants, $45.8 \%$ were male, $45.8 \%$ were female, $1.4 \%$ was transgender, and $6.9 \%$ were androgynous or gender neutral. Almost $90 \%$ of the sample has obtained education past a high school diploma or GED. Participants were also asked about the highest level of education one or both of their parents achieved, indicating that almost $75 \%$ of at least one parent obtained education past a high school diploma or GED. See Table 1 for detailed information on age, 
Online Autistic Community 51

ethnicity, gender, education level, and parent education level. Demographic variables related to the presence of autistic traits and autism spectrum disorder diagnoses are presented as frequencies and percentages of the sample in Table 2.

Of the 72 participants who identified as autistic, $73.6 \%$ indicated the diagnosis that fits them best is Asperger's disorder, 15.3\% indicated autistic disorder, $1.4 \%$ indicated Rett's disorder, $2.8 \%$ identified as pervasive developmental disorder- not otherwise specified, $1.4 \%$ wrote in "on the autism spectrum," and 5.6\% did not know or wish to say. When asked about formal diagnoses, $65.3 \%$ of participants indicated they have a formal diagnosis with an autism spectrum disorder and $34.7 \%$ indicated they do not have a formal diagnosis with an autism spectrum disorder.

Also, $81.9 \%$ of participants scored a 32 or higher in the Autism-Spectrum Quotient, indicating characteristics consistent with clinically diagnosed ASD (BaronCohen et al., 2001). Using the less conservative AQ cut-off score of 26 that is recommended in current clinical screening measurements (Woodbury-Smith, Wheelwright, \& Baron-Cohen, 2005), the sample consists of $88.9 \%$ participants with characteristics consistent with clinically diagnosed ASD. The sample contains $11.1 \%$ (26 AQ cut-off) to $18.1 \%$ (32 AQ cut-off) individuals who do not meet the AQ cut-off scores but identify as autistic.

The AASPIRE team decided on the inclusion criteria (identifying as autistic) for a number of reasons. Some individuals identify as autistic without a professional diagnosis (Jordan, 2010). The AQ and other screening and diagnostic tools have been shown to have a gender bias, leading to females being under-diagnosed and improperly screened 
Online Autistic Community 52

out of autism research (Kim et al., 2011; Lord \& Schopler, 1985), as well a theory of autism being an "extreme male brain" (Baron-Cohen, 1999). In addition to problems of screening and diagnostic tools, many other factors contribute to individuals not receiving a professional diagnosis, including the DSM-IV changes to pervasive developmental disorder diagnoses creating a disparity in diagnoses among older adults who received a diagnosis inconsistent with current PDD or no diagnosis at all (Wing \& Potter, 2002), as well as sociocultural factors (e.g., poverty, stigma, lack of education). Population-based studies indicate that autism spectrum disorders may be underdiagnosed (Brugha et al., 2011; Kim et al., 2011). Therefore, the inclusion criteria for the sample allows for a broader sample that may be more representative of autistic adults than excluding based on diagnosis or AQ score.

\section{Procedure}

Eligible participants were recruited for the Gateway Project via autism-related and disability-related organizations, websites, listserves, and blogs as well as through postings on campus at the three participating universities and word of mouth. To register for the Gateway Project and complete the Gateway Survey, an email address is entered and the respondent creates a password so that the survey can be started and returned to later if incomplete (and so that data from different studies can be linked together). After the username and password were entered, the participant was directed to a page containing a description of the Gateway Project. This description includes the purpose of the study, details about the types of questions asked in the survey, and provides the benefits and minimal risks of participating. Consent from the participant was indicated 
Online Autistic Community 53

after the participant read this information and continued to the next page. The following pages contained measures of computer and Internet use, demographic information, disability and Autistic identity and diagnoses, hand preferences, presence of autistic traits, and future research. The survey took approximately 20-40 minutes to complete. Participants were not compensated for participating in the study, although students at the University of Wisconsin-Madison were compensated with an extra credit point for participating in the Gateway Survey. However, if the participant completed the study, she chose to be entered into a drawing for a $\$ 25$ gift certificate to Amazon.com. A winner was chosen randomly after each group of 25 participants completed the survey, so 1 in 25 participants received the gift card.

AASPIRE also disseminated recruitment messages about the Gateway Project and the new study (i.e., the AASPIRE Internet Use, Community, and Well-Being Study) over listserves and posted in diverse communities with permission from moderators, directing those who were not yet registered with the Gateway Project to register and complete the Gateway Survey. Initiations to participate in the AASPIRE Internet Use, Community, and Well-Being Study occurred with those who participated in the Gateway Project, completed the Gateway Survey and met eligibility criteria (i.e., completed the Gateway Survey and did not indicate they would like to receive extra credit in a course at the University of Wisconsin-Madison). Eligible individuals received up to three notifications of the AASPIRE Internet Use, Community, and Well-Being Study lead by Dr. Katherine McDonald and Dora Raymaker. Information on individuals' decision to actively or passively decline participation was not stored; therefore no information on 
Online Autistic Community 54

response rate is available. The message linked participants to a personal study webpage (which required participants to login with their Gateway Project login and password) with information on the AASPIRE Internet Use, Community, and Well-Being Study.

After the username and password were entered, the participant was directed to a page containing a description of the study. This description includes the purpose of the study, details about the types of questions asked in the survey, and provides the benefits and minimal risks of participating. Consent from the participant was indicated after the participant read this information and continued to the next page. The following pages contained measures of Internet use, psychological well-being, Autistic identity, sense of community, online social support, face-to-face social support, and demographic information. The survey took approximately 30-45 minutes to complete.

Participants were not compensated for participating in the AASPIRE Internet Use, Community, and Well-Being Study. However, if the participant completed the study, she chose to be entered into a drawing for a $\$ 25$ gift certificate to Amazon.com. A winner was chosen randomly after each group of 15 participants completed the survey, so 1 in 15 participants receive a gift card. The survey was open for participation and data was collected for the present study for five weeks.

For the current study, we collected data from 76 eligible cases as of May 22, 2011. The confidentiality of data collection, including not collecting IP addresses, led the AASPIRE team to further scrutinize the validity of the data prior to including all eligible cases in the current study. In order for a case to be included in the current study, we examined whether the value for date of birth in the Gateway Survey matched the value 
Online Autistic Community 55

for date of birth in the AASPIRE Internet Use, Community, and Well-Being Study. Four of the 76 cases were excluded from the current study, because the date of birth of each of the cases was mismatched by more than two months and more than two years between the Gateway Survey date of birth and AASPIRE Internet Use, Community, and WellBeing Study date of birth. For the present study, the overall sample size was 72.

\section{Ethical Considerations}

Unique ethical considerations must be made for research involving online communities (Brownlow \& O’Dell, 2002). The present study also concerns research with a potentially vulnerable population of autistic adults. Here I address the risks and the associated safeguards of the present study.

There was a small risk in loss of confidentiality by sharing personal information. However, we protected participants' information by not recording any Internet Protocol (IP) addresses and using Secure Sockets Layer (SSL) encryption to make sure no one can see the information sent through the Internet. All information is stored on a passwordprotected computer to which only AASPIRE research team members and Gateway Project researchers have access. Participants were informed that they can ask the investigators to delete their information from the data file at any time by contacting them. Also, a code number was used to link the information provided to identifying information. Only the investigators are able to link the code numbers to identifying information. Finally, no identifying information is used in any publications, presentations, or reports. 
Online Autistic Community 56

In addition to confidentiality risks, participants may have become frustrated completing the survey if the computer or Internet is having problems. Also, there is a small risk that the participants might have become tired or found questions difficult or frustrating to answer. Participants were informed that they may exit the survey at anytime, with the ability to start where they left off if they wish to later.

Ethical considerations were also made in accordance with the Portland State University Human Subjects Research Review Committee as well as the Oregon Health and Science University (OHSU) and University of Wisconsin-Madison Institutional Review Boards. In an effort to not duplicate IRB review, PSU has entered into an IRB authorization agreement with OHSU for the AASPIRE Internet Use, Community, and Well-Being Study. The IRB at University of Wisconsin-Madison and the IRB at OHSU provided approval for the Gateway Project. In accordance with the Office of Graduate Studies at Portland State University, the Human Subjects Research Review Committee reviewed the proposed study. Furthermore, by our close collaboration and use of community based participatory research methods, we were able to bolster the ethical issues related to the process of the project by ongoing conversations and actions around promoting the ethical issues relevant to respect, accessibility, inclusion, and relevance of the current study (Snow, Grady, \& Goyette-Ewing, 2000).

Due to the low risk nature of the study, the consent process was modified to fit the constraints of online data collection. Participants were recruited through the Gateway Project and directed to the Gateway Survey before having access to the present study. Eligible participants were invited to participate in the AASPIRE Internet Use, 
Online Autistic Community 57

Community, and Well-Being Study via email, and directed to the AASPIRE website and the AASPIRE project descriptions, which both described in detail the mission and purposes of the studies in a broader sense. This created a necessary level of transparency to the research process (Brownlow \& O’Dell, 2002). An online Information Sheet provided all the necessary information regarding purpose and procedures of the study, which the participants could have printed off if desired. After reading the Information Sheet, participants were asked to check a box if they agree to proceed, after which the participant was granted access to the survey with consent assumed. This modified consent procedure was appropriate due to the minimal risk of the study. The AASPIRE team also concluded that the assessment of decisional capacity would be offensive to participants and not a necessary safeguard given our population of interest and the low risk nature of the research (Dye, Hendry, \& Hare, 2004). The team has worked diligently to create materials that are clear and comprehendible to all participants able to understand the communication occurring in the websites, blogs, and listserves from which they were recruited from. The present study utilized the same method of informed consent procedures as the Gateway Project. The participants were directed to the project's description, which described the mission and purpose of AASPIRE and the current study. The online Information Sheet provided the necessary information regarding purpose and procedures, and finally, the participants were asked to check a box if they wish to proceed, indicating consent.

There were no direct benefits from participating in the study. However, participants may have felt satisfied by possibly benefiting persons with disabilities or 
Online Autistic Community 58

persons on the autistic spectrum in the future. Also, participants may have felt satisfied from contributing to research and having their voice and perspective represented in science. 
Online Autistic Community 59

\section{Results}

\section{Descriptive Analyses}

In order to describe the sample of participants, I first conducted descriptive analyses using IBM SPSS 19. I calculated the mean and standard deviation of the demographic variable of age. Frequencies were calculated for the categorical demographic variables gender, income, language, race/ ethnicity, employment, disability status, and diagnoses. Results of the descriptive analyses are in Table 1. Means were then calculated for the constructs of Autistic identity $(M=4.07, S D=.61)$, sense of community $(\mathrm{M}=2.38, \mathrm{SD}=.58)$, and psychological well-being $(\mathrm{M}=3.78, \mathrm{SD}=.69)$. Subscale means were also calculated for the sense of community subscales of membership $(M=2.12$, $\mathrm{SD}=.69)$, integration and fulfillment of needs $(\mathrm{M}=2.44, \mathrm{SD}=.67)$, influence $(\mathrm{M}=2.25$, $\mathrm{SD}=.57)$, and shared emotional connection $(\mathrm{M}=2.46, \mathrm{SD}=.75)$. Subscale means were then calculated for the psychological well-being subscales of environmental mastery $(\mathrm{M}=3.26$, $\mathrm{SD}=.95)$, autonomy $(\mathrm{M}=4.38, \mathrm{SD}=.83)$, and self-acceptance $(\mathrm{M}=3.69, \mathrm{SD}=1.01)$.

Correlations were examined among the variables age, gender, income, education, parent education, involvement in the online Autistic community, Autistic identity, sense of community, and well-being in order to detect relationships among variables that should be included in analyses. Age was predetermined to be included as a control variable, due to previous research indicating the most frequent users of the Internet as under the age of 30 (Morales, 2009). Because no demographic variables were correlated with the constructs of interest including involvement in the online Autistic community, Autistic identity, sense of community, and psychological well-being, no other control 
variables were used in the mediated regression of hypothesis 2 . The correlation matrix displaying the relationships among variables is in Table 3.

\section{Data Screening and Missing Data}

Before analyses were conducted, exclusion criteria were applied to the sample. We did not collect IP address or have access to email address to protect participant confidentiality, so we reasked items from the Gateway Survey that should typically remain consistent over time in order to check for invalid data. The repeated questions included date of birth, gender, and ethnicity. Of the 76 eligible cases, four were excluded for the participant's date of birth in the Gateway Survey being two or more months off and two or more year off the participant's date of birth in the AASPIRE Internet Use, Community, and Well-Being Study.

In order to dissipate the problem of missing data, participants were notified that a response is needed for each item before continuing to the next page of the survey. However, participants were given the option of choosing "Do not know or do not wish to say" for every item, creating missing data values. To deal with the problem of missing data with the measurements utilized for the current study, I first tested for significant differences between cases with missing data and cases without missing data with the Autism-Spectrum Quotient (Baron-Cohen et al., 2001), psychological well-being, Autistic identity, and sense of community. Significant differences did not exist among the variables or among demographic variables reported in the current study.

Once it was determined that data were missing at random, the Autism-Spectrum Quotient (Baron-Cohen et al., 2001) score was calculated as a percentage of nonmissing 
Online Autistic Community 61

data rather than sum of data to compensate for missing data. This percentage allowed for a cutoff rate of 32 and higher (64\% or higher) to indicate the presence of autistic traits in the participant for all participants regardless of missing data.

Next, composite variables were calculated for the variables psychological wellbeing, Autistic identity, and sense of community. Because of the small sample size and randomness of missing data, inclusion in analyses was considered for each variable rather than listwise deletion of cases. The mean of the overall Psychological Well-Being Scale (Ryff, 1989) was calculated for participants with at least $74 \%$ of items with responses (20 of 27 items), which included $100 \%$ of participants in analyses containing psychological well-being ( $n=72)$. The mean of the overall Autistic Identity Scale (Gill, 1997) was calculated for participants with at least $72 \%$ of items with responses ( 13 out of the 18 items responded to), which included $94 \%$ of the participants $(n=68)$. The mean of the overall Sense of Community Index-2 (Chavis, Lee, \& Acosta, 2008) was calculated for participants with at least $75 \%$ of the items with responses (18 out of 24 items), which included $71 \%$ of the entire sample $(n=51)$.

The lower proportion of the sample that completed $75 \%$ or more of the SCI- 2 is also attributable to a skip pattern in the survey design in addition to missing data. Participants were asked frequency of involvement in the online Autistic community ("In the past six months, I have used the Internet to socialize, interact, exchange information, coordinate events, or participate in any activity that involved interacting with other autistic people over the Internet:"). If the participant responded with the option "Never," she was not asked any of the Sense of Community Index-2 (Chavis, Lee, \& Acosta) 
Online Autistic Community 62

items. There were eight participants $(11 \%)$ who were not asked the SCI-2. Therefore, $84 \%$ of participants who were asked items from the SCI- 2 were included in the analyses involving sense of community $(n=51)$. The same skip pattern was applied to the question on the importance and value of involvement in the online Autistic community ("I consider my involvement with online Autistic communities to be an important and valuable part of my life"), so that the same eight participants who were not asked the SCI-2 were not asked the importance and value of involvement in the online Autistic community item. In addition to those eight participants who were not asked the importance and value of involvement in the online Autistic community item, eight additional participants responded to the item with "Do not know or do not wish to say," resulting in missing data from 16 participants $(22 \%)$. Therefore, $77 \%$ of all participants were included in analyses considering the importance and value of involvement in the online Autistic community $(\mathrm{n}=56)$.

These remaining data were screening for normality and outliers. The Autistic Identity Scale, Sense of Community Index 2, and Psychological Well-Being Scales were all normal. The importance and value of involvement in the online Autistic community had a slight positive skew, which is likely due to selection bias in sampling. A logarithmic transformation was applied to the importance and value of involvement in the online Autistic community item. However, the transformation did not significantly impact the significance of the correlations or mediated regression. Therefore, the original data without transformation were used for analyses. Few outliers existed in the data (one in the importance and value of involvement in the online Autistic community, one in 
Online Autistic Community 63

Autistic identity, and one in psychological well-being). Analyses were run with and without outliers in order to determine whether outliers had significant impact on results. Analyses indicated the same pattern of results when run with and without outliers. Since the presence of outliers did not have a significant impact on results, outliers were included for analyses. Multivariate normality was determined by a low kurtosis coefficient and a high tolerance coefficient in the first step of the hypothesized mediation regression. Mahalanobis distances were examined, and no multivariate outliers were found.

\section{Hypotheses Tests}

The hypotheses examined the relationships among the importance and value of involvement in the online Autistic community and psychological well-being ( $\mathrm{H} \mathrm{1.1)}$; the importance and value of involvement in the online Autistic community and Autistic identity (H 1.2); Autistic identity and sense of community (H 1.3); the importance and value of involvement in the online Autistic community and sense of community (H 1.4); Autistic identity and psychological well-being (H 1.5); and sense of community and psychological well-being ( $\mathrm{H}$ 1.5). Hypothesis 2 examined the relationship between the importance and value of involvement in the online Autistic community and psychological well-being when mediated by Autistic identity and sense of community. The results of the correlational analyses are presented in Table 3. Significance level for the correlations and regression model was set at $p<.05$.

Hypothesis 1.1. The importance and value of involvement in the online Autistic community is positively related to psychological well-being. The correlation 
Online Autistic Community 64

coefficient was computed between the importance and value of involvement in the online Autistic community and psychological well-being in participants who responded to the item on importance and value of involvement in the online Autistic community and 74\% of the items in the psychological well-being measure $(n=56)$. The result of the correlation analysis did not support the hypothesis that the importance and value of involvement in the online Autistic community is positively related to psychological well-being ( $r=-.03$, $p=.808)$. A post-hoc power analysis was performed, and the power was determined to be .06. The correlation between importance and value of involvement in the online Autistic community was very weak, and the power indicated a very low probability of determining a significant effect if one is present.

Post-hoc analyses were conducted to further explore the relationships among the importance and value of involvement in the online Autistic community and well-being by examining correlations between the importance and value of involvement and the three well-being subscales of environmental mastery, autonomy, and self-acceptance. The data showed no significant relationships between the importance and value of involvement in the online Autistic community and environmental mastery $(\mathrm{n}=57, r=-.16, p=.241)$, autonomy $(\mathrm{n}=57, r=.16, p=.242)$, or self-acceptance $(\mathrm{n}=57, r=.02, p=.891)$.

\section{Hypothesis 1.2. The importance and value of involvement in the online}

\section{Autistic community is positively related to Autistic identity. The correlation}

coefficient was computed between the importance and value of involvement in the online Autistic community and Autistic identity in participants who responded to $72 \%$ or more of the items in the Autistic identity measure $(n=54)$. The result of the correlation analysis 
Online Autistic Community 65

supported the hypothesis that the importance and value of involvement in the online Autistic community is positively related to Autistic identity $(r=.37, p<.01)$. A post-hoc power analysis was performed, and the power was determined to be .80 . The significant and positive correlation of .37 has medium strength (Cohen, 1988), and the power coefficient was medium, indicating a moderate probability of determining a significant effect.

\section{Hypothesis 1.3. Autistic identity is positively related to sense of community.}

The correlation coefficient was computed between Autistic identity and sense of community in participants who responded to $72 \%$ or more of the items in the Autistic identity measure and $75 \%$ or more of the items in the sense of community measure $(\mathrm{n}=51)$. The result of the correlation analysis was a significant medium correlation that support the hypothesis that Autistic identity is positively related to sense of community $(r=.42, p<.01)$. A post-hoc power analysis was performed, and the power was determined to be .88 . The positive correlation of .42 is medium strength (Cohen, 1988), and the power coefficient indicates a moderate probability of determining a significant effect.

Post-hoc correlation analyses were also conducted to further explore the relationships between Autistic identity and the subscales of the SCI-2. Significant relationships were found between Autistic identity and the integration and fulfillment of needs subscale $(\mathrm{n}=56, r=.38, p<.01)$ and Autistic identity and the shared emotional connection subscale $(\mathrm{n}=53, r=.37, p<.01)$. There was no significant relationship between Autistic identity and influence $(\mathrm{n}=57, r=.17, p=.20)$, and the relationship between Autistic identity and membership was approaching significance $(\mathrm{n}=55, r=.26, p=.052)$. 
Online Autistic Community 66

The significant post-hoc findings indicate the data show a moderately strong positive relationship between Autistic identity and the integration and fulfillment needs subscale, as well as a moderately strong positive relationship between Autistic identity and the shared emotional connection subscale. The data also trend towards a positive relationship between Autistic identity and membership.

\section{Hypothesis 1.4. The importance and value of involvement in the online}

Autistic community is positively related to sense of community. The correlation coefficient was computed between the importance and value of involvement in the online Autistic community and sense of community in participants who responded to $75 \%$ or more of the items in the sense of community measure and the item measuring importance and value of involvement in the online Autistic community $(n=50)$. The result of the correlation analysis supported the hypothesis that the importance and value of involvement in the online Autistic community is positively related to sense of community $(r=.45, p<.01)$. A post-hoc power analysis was performed, and the power was determined to be .92 . The correlation coefficient indicates a moderately positive relationship (Cohen, 1988) between the importance and value of involvement in the online Autistic

community and sense of community. The high power coefficient indicates a high amount of power for rejecting the null hypothesis.

Post-hoc analyses were conducted to further inform the relationship between the importance and value of involvement in the online Autistic community and sense of community by examining correlations between the importance and value of involvement and the subscales of the SCI-2. All of the four subscales of the SCI-2 were significantly 
related to the importance and value of the online Autistic community, including membership $(\mathrm{n}=56, r=.35, p<.01)$ influence and fulfillment of needs $(\mathrm{n}=57, r=.52, p<.01)$, influence $(\mathrm{n}=57, r=.32, p<.05)$, and shared emotional connection $(\mathrm{n}=54, r=.31, p<.05)$. There is a moderately strong positive relationship between the importance and value of involvement and membership; a strong positive relationship between the importance and value of involvement and integration and fulfillment of needs; a moderately strong relationship between importance and value of involvement and influence; and a moderately strong relationship between the importance and value of involvement and shared emotional connection.

\section{Hypothesis 1.5. Autistic identity is positively related to psychological well-}

being. The correlation coefficient was computed between Autistic identity and psychological well-being in participants who responded to $72 \%$ or more of the items in the Autistic identity measure and $74 \%$ or more of the items in the psychological wellbeing measure $(n=68)$. The result of the correlation analysis did not support the hypothesis that Autistic identity is positively related to psychological well-being $(r=.16$, $p=.194)$. A post-hoc power analysis was performed, and the power was determined to be .26. The nonsignificant correlation coefficient is weak, indicating no relationship between Autistic identity and psychological well-being. The low power coefficient indicates a lower probability of determining a significant effect.

Post hoc correlations were also conducted in order to more meaningfully interpret the relationships between Autistic identity and the three scales utilized from the Psychological Well-Being Scales. Autistic identity was not significantly related to the 
Online Autistic Community 68

Well-Being subscales of environmental mastery $(\mathrm{n}=69, r=.05, p=.658)$, autonomy $(\mathrm{n}=69$, $r=.14, p=.256)$, or self-acceptance $(\mathrm{n}=69, r=.18, p=.143)$.

\section{Hypothesis 1.6. Sense of community is positively related to psychological}

well-being. The correlation coefficient was computed between sense of community and psychological well-being in participants who responded to $75 \%$ or more of the items in the sense of community measure and $74 \%$ or more of the items in the psychological wellbeing measure $(n=51)$. The result of the correlation analysis did not support the hypothesis that sense of community is positively related to psychological well-being ( $r=-$ $.01, p=.940)$. A post-hoc power analysis was also performed, and the power was determined to be .05 . The nonsignificant correlation coefficient is very weak indicating no relationship between sense of community and psychological well-being. The extremely low power coefficient indicates a lower probability of determining a significant effect.

Post hoc correlations were also conducted in order to more meaningfully interpret the relationships between the four subscales of the SCI-2 and the three scales utilized from the Psychological Well-Being Scales. The SCI-2 subscale of membership was not significantly related to the Well-Being scales of environmental mastery $(\mathrm{n}=57, r=-.002$, $p=.990)$, autonomy $(\mathrm{n}=57, r=-.17, p=.210)$, or self-acceptance $(\mathrm{n}=57, r=.14, p=.291)$. The SCI-2 subscale of integration and fulfillment of needs was not significantly related to any of the Well-Being Scales subscales (environmental mastery $\mathrm{n}=58, r=-.03, p=.832$; autonomy $\mathrm{n}=58, r=-.10, p=.462$; or self-acceptance $\mathrm{n}=58, r=.04, p=.761$ ); nor were there significant relationships between the SCI-2 subscale of shared emotional connection 
Online Autistic Community 69

with the Well-Being Scales (environmental mastery $\mathrm{n}=55, r=-.04, p=.787$; autonomy $\mathrm{n}=55, r=-.16, p=.254$; self-acceptance $\mathrm{n}=55, r=.16, p=.25)$. While there was not significant relationship between the SCI-2 subscale of influence and the Well-Being scales of environmental mastery $(\mathrm{n}=59, r=.01, p=.941)$ and self-acceptance $(\mathrm{n}=59, r=.08$, $p=.527)$, the data supported a significant and negative relationship between the influence subscale and the autonomy subscale $(\mathrm{n}=59, r=-.32, p=.014)$. This finding indicates a moderately strong negative relationship (Cohen, 1988) between the SCI-2 influence subscale and the Well-Being autonomy subscale.

\section{Hypothesis 2. Autistic identity and sense of community will partially mediate}

\section{the relationship between the importance and value of involvement in the online}

Autistic community and psychological well-being. To evaluate hypothesis 2, a series of regression analyses (Baron \& Kenny, 1986) were proposed to determine whether Autistic identity and sense of community mediate the relationship between the importance and value of involvement in the online Autistic community and psychological well-being. To satisfy the first step of the mediation analysis, psychological well-being was regressed on the importance and value of involvement in the online Autistic community. The confidence intervals for the regression slope contained the value zero, indicated that psychological well-being is not related to the importance and value of involvement in the online Autistic community. Importance and value of involvement in the online Autistic community did not significantly predict psychological well-being, $\beta=-0.03, t(55)=-0.16$, $p=.872,95 \% \mathrm{CI}=-0.182,0.142$. The regression had an effect size $\mathrm{f}^{2}$ of .07 and power of .40. In order to find mediation in the mediated regression analysis, importance and value 
Online Autistic Community 70

of involvement in the online Autistic community would have to significantly predict the outcome of psychological well-being as the first step. Since this prediction was not significant, Autistic identity cannot mediate the relationship and sense of community cannot mediate the relationship, and no other steps in the analysis were conducted. 
Online Autistic Community 71

\section{Discussion}

This study examined the relationships among the importance and value of involvement in the online Autistic community, Autistic identity, sense of community, and psychological well-being. Correlations were conducted to examine the relationships between (1) the importance and value of involvement in the online Autistic community and well-being; (2) the importance and value of involvement in the online Autistic community and Autistic identity; (3) Autistic identity and sense of community; (4) the importance and value of involvement in the online Autistic community and sense of community; (5) Autistic identity and well-being; and (6) sense of community and wellbeing.

The data supported the relationship between the importance and value of involvement in the online Autistic community and Autistic identity, the relationship between the importance and value of involvement in the online Autistic community and sense of community, and the relationship between Autistic identity and sense of community. Specifically, autistic adults that have higher levels of importance and value of involvement in the online Autistic community have a higher Autistic identity and a greater sense of community. Autistic adults who have a higher autistic identity have a higher sense of community in the online autistic community. However, the data did not support the relationship between the importance and value of involvement in the online Autistic community and psychological well-being, the relationship between Autistic identity and psychological well-being, and the relationship between sense of community and psychological well-being. Finally, I explored the relationship between the importance 
Online Autistic Community 72

and value of involvement in the online Autistic community and psychological well-being with Autistic identity and sense of community as mediators while controlling for age. The data did not support the hypothesized relationship between the importance and value of involvement in the online Autistic community and psychological well-being, so the possibility that sense of community could mediate this relationship was eliminated.

\section{Involvement in the Online Autistic Community and Autistic Identity}

One of the correlational relationships in my model that was supported by the data was that autistic adults who are more involved in the online Autistic community also have a higher Autistic identity. This supports previous research that indicates that use of the Internet contributes to an individual's identity development (Turkle, 1995), and that involvement in a social context is related to identity development (Hendry, 1983).

Further, research has shown that participation in social movements involves the development of a personal identity around the community and a sense of self-realization (Gamson, 1992; Teske, 1997). This result specifically contributes that the importance and value of involvement in the online Autistic community, and potentially the neurodiversity movement, leads to a stronger sense of Autistic identity. Since positive outcomes such as well-being have resulted from identity development (Berkman, Glass, Seeman, \& Brisette, 2000; Hendry, 1983; Wandersman \& Florin, 2000), the positive development of Autistic identity in individuals involved in the online Autistic community may lead similarly to similar positive outcomes.

This result may be due to what previous research points out about marginalized persons' identity development. Specifically, a marginalized community may find 
Online Autistic Community 73

commonality with one another apart from those not experiencing marginalization (Fine \& Asch, 1988). In adapting Gill's (1997) theory of disability identity development to Autistic identity, Autistic identity is strengthened by integration into society at large ('coming to feel we belong'), integration into the Autistic community ('coming home'), internal integration of sameness and differentness with society and Autistic community ('coming together'), and integration of feelings about self and presentation of self ('coming out'). The online Autistic community can serve to promote positive identity by supplying resources and confidence to integrate into society, create social relationships and support to feel integrated in the Autistic community, educate and work together for social action to internally integrate feelings of sameness and differentness of society and Autistic community, and provide self-realization and a depth of understanding of oneself to integrate feelings about self and presentation of self.

Additionally, the relationship between importance and value of the online Autistic community and Autistic identity may also be attributed to the context of the Internet allowing individuals to strengthen aspects of the self-concept through becoming aware of a new identity outside that of the offline world (Amichai-Hamburger, 2005; Suler, 2004). Self-expression, self-reflection, and dialogue may allow individuals to explore dimensions of themselves uniquely visible in the online Autistic community.

In the current study, autistic individuals may find commonality and identity around being an autistic person through contact with others experiencing the same societal barriers. Rejection of person first language (person with autism) by advocates of the neurodiversity movement is an example of asserting and shaping identity as an 
Online Autistic Community 74

autistic person as central to a person's being (Silverman, 2008), and likely reflective of a strong sense of Autistic identity. Brownlow (2007) points out that identifying with the Autistic community is central to involvement with the community, and that identity is a complex dynamic construction for every individual involved. The complexity of identity may be attributed to the online documentation of autobiographical accounts of the unique strengths and challenges, perspectives, and knowledge that come with autism (Davidson, 2008), creating multiple subjective understandings of autism and the autistic self. Perhaps participation in the online Autistic community increases autistic identity through selfreflection and reading and sharing experiences around being an autistic adult. Evidence of the correlational relationship between the importance and value of involvement in the online Autistic community and Autistic identity provides information that can promote positive outcomes for autistic adults.

\section{Involvement in the Online Autistic Community and Sense of Community}

The second correlational relationship in my model that was supported by the data was that autistic adults who value their involvement in the online Autistic community more also feel a greater sense of community. These results are consistent with previous findings that the Internet is a hub for creating personal relationships, giving and receiving social support, and developing sense of community (Brownlow \& O’Dell, 2002; Obst, Zinkiewicz, \& Smith, 2002a; Turkle, 1995; Wellman \& Gulia, 1999). This result is further consistent with the previously empirically confirmed relationship between community involvement and psychological sense of community (Bachrach \& Zautra, 1985). The Internet has become an important tool in promoting sense of community in 
Online Autistic Community 75

geographically dispersed communities (Obst, Zinkiewicz, \& Smith, 2002a). Because autistic adults are motivated by choice rather than locality in the decision to participate in the online Autistic community, this finding of a strong positive relationship between the importance and value of involvement in the online Autistic community and sense of community is intuitive.

Further, McMillan and Chavis's (1986) theoretical model of psychological sense of community posits that membership is an important aspect of feeling a sense of community. By spending time and feeling involved with the online Autistic community, a feeling of membership in the community likely increases. The concept of integration and fulfillment of needs also seems closely tied to the importance and value of involvement in the online Autistic community. Judging involvement as important and valuable likely relates to feelings of reward and fulfillment through involvement. Relatedly, the dimension of a shared emotional connection in the community would come from involvement in the community and be related to the importance and value of involvement.

The Autistic community, both online and offline, has been studied and observed as its own culture, containing identifiable values, beliefs, and unique knowledge (Davidson, 2008; Silverman, 2008), which is in line with aspects of sense of community (McMillan \& Chavis, 1986). However, the result of the present study that importance and value of involvement in the online Autistic community is positively related to sense of community provides unique empirical evidence of this positive outcome. Positive 
Online Autistic Community 76

outcomes of sense of community may therefore exist within the population of autistic adults who seek community online.

\section{Autistic Identity and Sense of Community}

The relationship between Autistic identity and sense of community was also supported by the data. Previous research has shown strong links between identity and sense of community (Obst \& White, 2004). Sense of community has shown to be related to social identity in different communities (Davidson \& Cotter, 1986), including geographically dispersed communities (Obst, Zinkiewicz, \& Smith, 2002b). While a person does not choose to be autistic, an autistic person does make the decision to identify as autistic. Without the presence of group identity or community around being autistic, achieving an Autistic identity would be impossible. Awareness of the Autistic community is necessary for an individual to identify with the community.

Further, a person chooses whether to seek out a community based upon their identity as an autistic person, and then whether or not to seek out an Autistic community online if they have the means and skills to do so. By choosing to belong to a community formed around sharing the strengths, challenges, and personal experiences of being an autistic individual, a transactional relationship between Autistic identity and sense of community is likely, with the individual's Autistic identity developing with her increased sense of community in the online Autistic community and vice versa. Just as an individual initially chooses to belong to the online Autistic community, being a member over time is likely related to increased Autistic identity, or an increase in identifying with the community as a sense of community strengthens. A supportive community of like- 
minded autistic people in a context that uniquely promotes socialization and communication increases pride and support in individuals who readily and strongly identify as autistic (Davidson, 2007; Jorndan, 2010). This perspective of pride and ownership of an Autistic identity is important to autistic individuals in self-advocacy (Ashby \& Causton-Theoharis, 2009; Chamak, Bonniau, Jaunny, \& Cohen, 2008; Davidson \& Henderson, 2010; Müller, Schuler, \& Yates, 2008; Sperry \& Mesibov, 2005), perhaps making a strong Autistic identity necessary for membership in the online Autistic community.

In McMillan and Chavis's (1986) theory, sense of community necessitates the presence of four dimensions: membership, influence, integration and fulfillment of needs. In minority populations united in shared experiences and interests in attaining rights and a higher quality of life, this sense of community is more obvious and necessary than in many communities of interest or geographic communities. This is evident in the sense of community observed in groups formed around social movements (Gamson, 1992; Teske, 1997). Past research has also shown evidence of a community formed by autistic individuals online that grew into a self-advocacy movement (Brownlow, 2010; Brownlow \& O’Dell, 2006; Davidson, 2008; Jones \& Meldal, 2001; Jordan, 2010). Identity development around one's self may be a necessary precursor to becoming a selfadvocate; therefore sense of community within a self-advocacy movement is not surprisingly closely related to identity around the community. The strength of such a community may directly impact individuals' lives; therefore a sense of community is vital. This may be the case in the online Autistic community, where autistic self- 
advocates participate in co-learning and actions geared towards eliminating societal barriers that impact the lives of autistic individuals (Bagatell, 2007; Charmak, 2008; Clarke \& van Amarom, 2007; Ward \& Meyer, 1999). This community exists outside neurotypical face-to-face boundaries, in a context in which individuals can meaningfully participate and become empowered. Therefore, an individual may feel a sense of community when formally or informally joining the online Autistic community while simultaneously strengthen her Autistic identity through integration into the community. The process of identity development and feeling a sense of community is likely dynamic, strengthening over time and subject to fluctuations based on changing multiple identities and differing social dynamics in the community.

In previous research, the dimensions of sense of community of membership and shared emotional connection are highly correlated with identity, due to the nature of these dimensions including different types of identity (Obst, Smith, Zinkiewicz, 2002). In fact, a study on the dimensionality of the SCI indicated that identity should be included as a fifth dimension of sense of community (Obst, Zinkiewicz, \& Smith, 2002a). The current study lends further evidence to the body of literature that shows a relationship between identity and sense of community.

Also, the importance and value of involvement in the online Autistic community is related to Autistic identity in the current study as well as sense of community. These relationships can both be attributed to involvement being a choice a person makes. A person who identifies as being autistic is more likely to frequent a community and have a sense of community with others in it than a person who does not identify as autistic nor 
Online Autistic Community 79

has a low level of identification with the Autistic community. These relationships may also exist due to the nature of the Internet allowing an individual to hold individual multiple identities while simultaneously belonging to a community (Amichai-Hamburger \& Furnham, 2007). Even outside the online community, involvement in the autistic selfadvocacy movement is associated with developing self-awareness around being an autistic individual and increasing social interaction (Muller, 2008).

Interestingly, the influence subscale of sense of community was not significantly related to Autistic identity, perhaps due to the dimension's emphasis on conformity and adapting to community norms rather than individuality. This emphasis may be in contrast to an individual's sense of Autistic identity. Further exploration into the dimensionality of identity may reveal a subscale matching Gill's (1997a) disability identity dimension around integration into the disability community that would be positively related to the influence subscale. Integration into the disability community concerns the aspects of one's identity on becoming part of the disability community. This dimension relates less to one's self and more with conforming to the community. The similarity with the influence subscale of the sense of community scale may be evident with further exploration of the Autistic identity subscales.

Another potential explanation for the lack of a significant relationship between Autistic identity and the influence subscale is missingness of data. Two of the items in the influence subscale contained more missing data than all other items in the Sense of Community Index. The mean number of missing values within each item in the Sense of Community index was $6.04(\mathrm{SD}=2.65)$. However, the items "this community has symbols 
Online Autistic Community 80

and expressions of membership such as clothes, signs, art, architecture, logos, landmarks, and flags that people can recognize" and "this community has good leaders" were missing values for 13 and 12 participants, respectively. Perhaps the abstract context of the Internet made concepts of symbols, expressions, and leadership less applicable or not easily understood for the participants.

\section{Autistic Identity, Sense of Community, and Psychological Well-Being}

The next relationships hypothesized in the study were a positive relationship between Autistic identity and psychological well-being and a positive relationship between sense of community and psychological well-being. Both of these relationships were statistically nonsignificant. This is contrary to previous research that shows a positive relationship between identity, specifically minority identity and well-being (Berkman, Glass, Seeman, \& Brisette, 2000; Gray-Little \& Hafdahl, 2000; Kiang et al., 2006; Ryff, Keyes, \& Hughes, 2003; Umaña-Taylor, Diversi, \& Fine, 2002). This is also contrary to previous research that shows a relationship between sense of community and well-being (Albanesi, Cicognani, \& Zani, 2007; Davidson \& Cotter, 1991; Ferrell, Aubry, \& Coulombe, 2004). Psychological well-being is satisfaction with relationships with others, meaning in life, and positive feelings about oneself (Keyes, Shmotkin, and Ryff, 2002). Theoretically, Autistic identity and sense of community are highly related to the concept of psychological well-being.

One study specified that sense of community contributes to well-being when the community is stable and contains positive relationships within it (Farrell, Aubry, \& Coulombe, 2004). AASPIRE community partners have indicated that within the past few 
Online Autistic Community 81

years, the online Autistic community has experienced disagreements and divisions that have impacted people's comfort and safety within the community. Not being willing to openly share or feel a part of the community has likely had notable implications for the sense of community within the online Autistic community. Perhaps these feelings of discontent have led to instability and negative relationships, which would in turn not contribute to well-being. The disagreements and divisions may also be a contributing factor to missingness of values in the influence subscale of the Sense of Community Index. Feelings regarding community leaders and symbols of a unified community may not be readily expressed in a Likert-scale response when the complexity of negative group dynamics may be at the forefront of a participant's thoughts. Skipping the items could have been a way for such participants to avoid negative feelings, discomfort, or confusion.

The lack of findings around correlations with psychological well-being may also be beyond the scope of the current study. As compared to non-autistic individuals with developmental disabilities, autistic adults are less likely to live independently, less likely to have a mental illness diagnosis yet more likely to be taking psychotropic medications, less likely to exercise choice in major life decision areas, and less likely to report having their rights respected (National Core Indicators Consumer Survey, 2011). In the current sample, over half of participants earn an annual income of less than $\$ 25,000$. Although Autistic identity and sense of community in the online Autistic community may have a positive impact on the lives of autistic adults, correlations among these variables did not adjust for other potentially confounding variables. Perhaps the impact of Autistic identity 
Online Autistic Community 82

and sense of community is not relevant in the current population when more pressing and urgent needs must be fulfilled for an individual to feel well-being.

Three of the six Psychological Well-Being Scales (Ryff, 1989) were utilized in their 9-item medium-form for the current study. Calculated means of the subscales were not readily comparable to other studies that only reported overall mean of all six subscales (Hart, Fonareva, Merluzzi, \& Mohr, 2005) or used the large-form or short-form of the scales (e.g., Clarke, Marshall, Ryff, \& Wheaton, 2001; Hemenover, 2003; Kaplan, Shema, \& Leite, 1994; Kirby, Coleman, \& Daley, 2004; Ryff, 1995). Future work should investigate whether the current sample of autistic adults has comparatively lower, higher, or equivalent scores on the psychological well-being scales when compared to populations in previous research. Perhaps this comparison may further illuminate the nonsignificant findings of the current study. Understanding whether psychological wellbeing is lower among autistic individuals than in other populations would begin to explain how positive outcomes such as sense of community and Autistic identity are not sufficient for well-being.

One significant post-hoc finding among the sense of community subscales and well-being subscales was the negative correlation between influence (in sense of community) and autonomy (in well-being). Similarly to the nonsignificant relationship between influence and Autistic identity, perhaps this negative relationship is due to the aspects of the influence subscale on conformity and abiding by group norms. Also, items within the influence subscale ask specifically about community leadership, such as "this community has good leaders." The negative relationship between influence and Autistic 
Online Autistic Community 83

identity may be attributable to a lack of trust and respect in group leaders following the disagreements among specific Autistic sites and implosion of two major communities. AASPIRE community partners anecdotally attributed negative feelings from the disagreements to community leaders, which likely reflected the perspective of a portion of the community members.

A power coefficient was calculated for each correlation, and indicated very low power for both correlations. This is attributable to a small sample size. Perhaps a larger sample size will result in statistically significant correlations between Autistic identity and well-being and between sense of community and well-being. Alternatively, the relationships may remain nonsignificant, indicating these relationships do not exist, despite the contradictory literature. A nonsignificant relationship might be due to the unique sample of autistic adults seeking community online or due to measurement issues. Autistic identity has never been studied quantitatively, and the measurement adapted from Gill's disability identity scale (1997a) may not be a valid measure of the concept. Autistic identity is seen as separate and different from disability identity due to a different historical evolution of neurodiversity than the larger disability rights movement, as well as because of the unique strengths and challenges of autism separate from other disabilities (Davidson, 2008). Perhaps the adapted scale should be revisited and revised to compensate for aspects of identity that are unique to autistic adults.

Similarly, the Sense of Community Index 2 (Chavis, Lee, \& Acosta, 2008) has never been tested in this unique population. While the SCI has been successfully used in multiple contexts with different populations (e.g., Brodsky \& Marx, 2001; Forster, 2004; 
Online Autistic Community 84

Kingston, Mitchell; Sonn, 2002), perhaps the unique attributes of the online Autistic community make the measurement inaccurate. The environment of the online Autistic community is not static; the online Autistic community goes through periods of discontent and disagreement as well as celebration and togetherness. Further, the online Autistic community is composed of vastly different perspectives on autism and neurodiversity. Lastly, different sites have different formats that may create an inconsistency in how people relate to others in them, or feel a sense of community in them. The SCI-2 was not developed to consider these issues. However, due to the robustness of the measure in other populations and contexts, unique community attributes should not impact the findings. Further investigation on the validity of the scale should be performed with a larger sample to determine the extent of these issues.

Alternatively, the measurement issue may be in the measurement of well-being with Ryff’s (1987) Psychological Well-Being Scales. The AASPIRE team decided to only include three of the subscales of the measure, due to language barriers and different styles of interpersonal relationships that make some of the concepts in the measure too abstract to apply to the Autistic community (Gillberg, 2001; Orsmond, Krauss, \& Seltzer, 2004). The included dimensions of psychological well-being were self-acceptance, autonomy, and environmental mastery. Perhaps the excluded dimensions- purpose in life, positive relations with others, and personal growth- are necessary for relationships found in previous literature with identity and sense of community. 
Online Autistic Community 85

\section{Autistic Identity and Sense of Community Mediating the Relationship between the}

\section{Importance and Value of Involvement in the Online Autistic Community and}

\section{Psychological Well-Being}

The mediation model proposed as hypothesis 2 was not supported by the data. Autistic identity and sense of community did not mediate the relationship between importance and value of involvement in the online Autistic community and psychological well-being. The correlation between the importance and value of involvement in the online Autistic community and psychological well-being was nonsignificant, and the first step of the mediation model, the regression of well-being on the importance and value of involvement in the online Autistic community was also nonsignificant. These insignificant results are contrary to previous research showing a relationship between involvement in online communities and well-being (Barak \& Sadovsky, 2008; Boase, Horrigan, Wellman, \& Rainie, 2006; Rohall, Cotton, \& Morgan, 2002).

Research that has shown relationships between involvement in online communities and well-being has generally statistically modeled the relationship to compensate for the positive aspects of involvement in online communities, such as increased social capital, sense of community, identity, or closeness of relationships (Shklovski, Kiesler, \& Kraut, 2006). Due to a limited sample size, structural equation modeling was not conducted, which may illuminate the complexity of these relationships. Perhaps the importance and value of involvement in the online Autistic community is only positively related to psychological well-being when Autistic identity and sense of community are high. There is also research that indicates Internet use as having a 
Online Autistic Community 86

negative impact on well-being (Kraut, Patterson, Lundmark, Kiesler, Mukhopadhyay, \& Sherlis, 1998). Without a larger sample to boost power and further testing of the model that will compensate for the Autistic identity and sense of community, these results bear no conclusions for the relationships described in the study. As mentioned previously, perhaps statistical nonsignificance among the included variables can be attributed to the absence of impactful confounding variables. Well-being may be unobtainable or not related to the variables included in this study because of the existence of social and health disparities in this population that are not considered in the current analysis.

A power coefficient was calculated for the correlation between importance and value of involvement in the online Autistic community and psychological well-being as well as for the regression in first step of the mediation model, the regression of wellbeing on the importance and value of involvement in the online Autistic community. Both power coefficients indicated extremely low power in the analyses, indicating a very low probability of finding statistical significance of a possible true association. As previously discussed, the nonsignificant results may also be attributed to measurement issues with psychological well-being.

Additionally, the measurement of importance and value of involvement in the online Autistic community may be imperfect. The measurement of involvement was selected to tap into the subjective importance and value of involvement in the community, as recommended by the literature (Haber, Cohen, Lucas, \& Baltes, 2007). While the measure is correlated with Autistic identity and sense of community, perhaps it is not a valid measure for involvement in relation to well-being. Other data on 
Online Autistic Community 87

involvement in the online Autistic community collected in the study included years of involvement and frequency of involvement. While the AASPIRE team decided that importance and value of involvement in the online Autistic community was the most relevant and appropriate measure of involvement for the current study, the regression analysis was also conducted with years of involvement and frequency of involvement, yielding similar nonsignificant results.

\section{Strengths and Limitations}

The current study has many strengths, including that it concerns the psychological and social wellness of the under-researched population of autistic adults. Further, it involves a sample of a unique and unresearched segment of autistic adults, those seeking community online, using efficient methods to gather data in the easiest possible manner for the participant. The community based participatory research design implemented in the current study creates strengths as well. Because the entire research process is driven by the ideas and questions of the population of interest, the study has particular relevance and merit for autistic adults. As the protocol, materials, and measures are all created through the AASPIRE team, unique perspectives from researchers, practitioners, family members, service care providers, and autistic adults were all taken into account to improve them.

Further, the CBPR process required frequent communication about the present study and dialogue involving the implications and possible conclusions drawn from the study. From this process, I have a depth of understanding about the online Autistic community and the experiences within it, assisting in my understanding of the concepts 
and conclusions within the study. The results of the analyses were presented during AASPIRE team meetings in which members discussed potential explanations and conclusions from the results. The community perspective on the results reflected previous research and further clarified how the theoretical concepts of Autistic identity, sense of community, and psychological well-being play out in the online Autistic community, particularly with respect to community dynamics at the time of data collection.

However, several limitations to the study exist. First, limitations to internal validity include that the study does not utilize an experimental or longitudinal design, resulting in an inability to make causal inferences about the tested relationships in the data. Also, related constructs that may impact the variables such as coping and social support were excluded from the proposed study. Measuring such variables could shed light on the complicated relationships among the constructs of this study. Perhaps the addition of related variables into the model of the current study would explain more of the variance related to psychological well-being and more conclusions could be drawn from the data.

Limitations to the external validity exist in the generalizability of results of the study. The sample was a convenience sample of interested autistic adults who learned about the study online. Since the study recruited participants primarily through the community it is investigating, the sample may be limited by selection bias. Further, not all autistic websites were targeted for recruitment. Therefore, the sample may not encompass the breadth of differences in population demographics or reflect the full range of differences in customs, purpose, and environment. This may have an impact on the 
Online Autistic Community 89

variables of interest in the current study, including Autistic identity and sense of community.

Additionally, while Autistic identity is specific to the population of interest, research has shown a similar identity development in other marginalized communities, such as the gay and lesbian community (Cramer \& Gilson, 1999). Therefore, the model may apply to similar communities, particularly the disability community. Similarly, sense of community has not been quantitatively examined in the online Autistic community, but the theoretical models of sense of community apply across all types of communities. Therefore, a measurement should easily adapt for use in different communities. The small sample size further leads to questioning the generalizability of the results. It is unknown whether the sample encompasses the experience of all autistic adults in the online Autistic community.

Threats to construct validity also exist. Ryff's Psychological Well-Being Scale (1987) has not been tested without all six dimensions, so it is unknown whether the three dimensions measured in the current study adequately measure the entirety of psychological well-being. Gill's Disability Identity Scale (1997a) was adapted for the current study for the population of autistic adults. It is unknown whether the scale encompasses the necessary dimensions of Autistic identity, particularly the differences in identity an autistic person may have from a person with a disability. The internal consistency alpha of the identity score of .74 was acceptable, but could perhaps be higher with the removal of poor performing items. The lower alpha may also be due to multidimensionality that should be explored with further psychometric analyses. 
Online Autistic Community 90

Further, due to the small sample size, I was not able to further investigate the psychometric properties of the Autistic Identity Scale (Gill, 1997a), Sense of Community Index 2 (Chavis, Lee \& Acosta, 2008), or the Psychological Well-Being Scale (Ryff, 1987) with factor analyses. Because of this limitation, it is unknown how the measures performed in the population of autistic adults in the online Autistic community. Statistical tests may be impacted by poorly performing measures.

Also, the measure for involvement in the online Autistic community was developed to assess the importance and value of involvement in the online Autistic community, but has no known psychometric properties. Further, a single item was used to assess the importance and value of involvement in the online autistic community, which creates issues of measurement validity. However, the item was created and approved by the AASPIRE research team, who agreed that the item has face validity and contextual validity. Other options for operationalizing the variable of involvement in the online Autistic community included investigating the time since joining the community or frequency of involvement in the online community in the last six months. It was decided that the subjective judgment of importance of involvement may best illuminate the aspect of involvement in the online community that is most relevant to the study, which is the perception of the importance and value of involvement rather than specific hours or years. Nonetheless, these other ways of measuring involvement in the online Autistic community were tested in the model to confirm AASPIRE's decision to exclude them, and the pattern of results was similar, though the relationship between the importance and value of involvement in the online Autistic community and Autistic identity was not 
Online Autistic Community 91

significant. This insignificant result may indicate how perception of involvement is more closely tied to identity than superficially counting years or hours with the community. This reflects the literature on social support that indicates perceived social support accounts for more variance of overall social support than received social support (Haber, Cohen, Lucas, \& Baltes, 2007).

This measurement of involvement in the online Autistic community as important and valuable may also be simply conveying the participant's comfort or preference for socializing rather than use of the community as an important aspect of one's life. Of the participants who use the Internet for socializing with others, $45 \%$ of participants preferred online socializing over offline socializing with other autistic individuals, and $50 \%$ of participants preferred online socializing with other non-autistic individuals. Perhaps this preference for communicating online is why the participant deems the community important and valuable, not that the community itself is important or value to the individual. Further research should examine how these variables are related to the constructs of interest and how they may differentially impact identity, sense of community, and well-being.

There is also limited variance in the demographics of the participants. The sample is mostly white, highly educated, and identifies with Asperger's Syndrome. Since there is little research on the online Autistic community, it is unknown whether this study accurately represents the online population. Further research that recruits from different sources online may shed light on different perspectives of the community. Also, sampling autistic adults who do not seek community online may further illuminate how the online 
Online Autistic Community 92

Autistic community impacts the lives of autistic adults. Additionally, sampling from a wider population of people on the autism spectrum who do and do not seek community online will increase the generalizability of the current findings. Since it is unknown how involvement in the broader Autistic community is related to the current study focus on the online Autistic community, future research should investigate how these contexts are related.

Finally, the small sample size limited the statistical analyses able to be performed. Because of the complex relationships among the variables, structural equation modeling would be a more appropriate analysis to investigate the relationships among the importance and value of involvement in the online Autistic community, Autistic identity, sense of community, and psychological well-being. However, the sample size did not allow for such an analysis.

\section{Implications}

Though many of the hypotheses were not supported by the data, there are implications of the current study. The study sheds light on the relationships among the importance and value of involvement in the online Autistic community, Autistic identity, sense of community, and psychological well-being. Because of the limited research on autistic adults, the study is necessary in producing greater understanding of this population. The findings are an important first step to further research on the topic of involvement in the online Autistic community.

This study has shown that the importance and value of involvement in the online Autistic community has the positive outcomes of Autistic identity and sense of 
Online Autistic Community 93

community in online autistic adults. Because previous research shows a relationship between psychological sense of community and cooperative action, community justice, social change, health-promoting activities, and subjective well-being (Allen \& Allen, 1987; Chuiper \& Pretty, 1999; Davidson \& Cotter, 1991), sense of community may be invaluable to the Autistic community. Further, a sense of community and Autistic identity in this population may be contributing and strengthening the neurodiversity movement and thus contributing to improvements in quality of life for autistic persons. Research has shown that participation in social movements such as the neurodiversity movement is related to identity, as well as self-realization (Gamson, 1992; Teske, 1997).

By providing evidence of a relationship between the importance and value of involvement in the online Autistic community and sense of community, this study empirically negates inaccurate stereotypes that people on the autism spectrum are unable to have social relationships, understand or express emotion, or communicate (Szatmari, 2004). This evidence also informs mechanisms that foster such positive outcomes for this underresearched population. As Internet use continues to increase over time, this research provides some understanding of the positive utility of such a powerful global tool in gaining outcomes such as sense of community and Autistic identity.

Despite statistically nonsignificant results, power analyses with many of the hypothesized analyses indicate insufficient power for determining statistical significance. As the AASPIRE Internet Use, Community, and Well-Being Study is currently collecting more data, I recommend that analyses be performed on a larger sample. Many of the nonsignificant relationships among variables indicated positive nonsignificant 
correlations. Perhaps a larger sample size will provide sufficient power to indicate significance in the hypotheses that were not confirmed in this study.

This study has practical implications as well. Previous research has shown that knowledge and access to the Internet has the potential to be empowering for marginalized individuals (Siddequee \& Kagan, 2006). The study supports the understanding of positive outcomes of online communities for this population, and can potentially have implications for policy and programs for autistic adults, including advocating for access to Internet services. As communication and socialization interventions for autistic individuals increasingly utilize computers and the Internet (Sansosti and Powell-Smith, 2008; Silver and Oakes, 2001; Whalen et al., 2010), the current study supports positive outcomes that may be derived from gaining such skills and becoming involved in the online Autistic community. 
Table 1. Participant Demographics

\begin{tabular}{|c|c|}
\hline Participant Demographics & $n=72$ \\
\hline & $M(S D)$ \\
\hline Age & $\begin{array}{c}36.46 \\
(12.23) \\
\end{array}$ \\
\hline Race/ ethnicity & $n(\%)$ \\
\hline White & $65(90.3 \%)$ \\
\hline Multi-racial $^{1}$ & $6(8.4 \%)$ \\
\hline Do not wish to say & $1(1.4 \%)$ \\
\hline Latino/ Hispanic & $3(4.2 \%)$ \\
\hline \multicolumn{2}{|l|}{ Gender } \\
\hline Male & $33(45.8 \%)$ \\
\hline Female & $33(45.8 \%)$ \\
\hline Transgender & $1(1.4 \%)$ \\
\hline Androgynous/ neutral & $5(6.9 \%)$ \\
\hline \multicolumn{2}{|l|}{ Personal annual gross income } \\
\hline$\$ 24,999$ or less & $37(51.4 \%)$ \\
\hline$\$ 25,000-\$ 49,999$ & $15(20.8 \%)$ \\
\hline$\$ 50,000-\$ 74,999$ & $5(6.9 \%)$ \\
\hline$\$ 75,000-\$ 99,999$ & $4(5.6 \%)$ \\
\hline$\$ 100,000$ or more & $5(6.9 \%)$ \\
\hline Do not know/ wish to say & $6(8.4 \%)$ \\
\hline \multicolumn{2}{|l|}{ Education level } \\
\hline Less than high school or equivalent & $3(4.2 \%)$ \\
\hline GED (general equivalency diploma) & $1(1.4 \%)$ \\
\hline High school diploma or equivalent & $5(6.9 \%)$ \\
\hline Post-secondary certificate/ technical degree & $1(1.4 \%)$ \\
\hline Some college or university courses & $19(26.4 \%)$ \\
\hline 2 year or Associate's degree or equivalent & $4(5.6 \%)$ \\
\hline Bachelor's degree or equivalent & $19(26.4 \%)$ \\
\hline Some graduate school & $6(8.3 \%)$ \\
\hline Master's degree or equivalent & $10(13.9 \%)$ \\
\hline Doctoral or professional doctorate & $3(4.2 \%)$ \\
\hline Other & $1(1.4 \%)$ \\
\hline \multicolumn{2}{|l|}{ Parent education level $^{2}$} \\
\hline Less than high school or equivalent & $6(8.3 \%)$ \\
\hline GED (general equivalency diploma) & $1(1.4 \%)$ \\
\hline High school diploma or equivalent & $12(16.7 \%)$ \\
\hline
\end{tabular}


Online Autistic Community 96

\begin{tabular}{|c|c|}
\hline Post-secondary certificate/ technical degree & $4(5.6 \%)$ \\
\hline Some college or university courses & $6(8.3 \%)$ \\
\hline 2 year or Associate's degree or equivalent & $3(4.2 \%)$ \\
\hline Bachelor's degree or equivalent & $13(18.1 \%)$ \\
\hline Some graduate school & $2(2.8 \%)$ \\
\hline Master's degree or equivalent & $16(22.2 \%)$ \\
\hline Doctoral or professional doctorate & $5(6.9 \%)$ \\
\hline Do not know or do not wish to say & $4(8.3 \%)$ \\
\hline \multicolumn{2}{|l|}{ Employment status } \\
\hline Employed full-time at a regular job & $14(19.4 \%)$ \\
\hline Employed part-time at a regular job & $5(6.9 \%)$ \\
\hline Employed full-time via supported program & $1(1.4 \%)$ \\
\hline Employed part-time via supported program & $1(1.4 \%)$ \\
\hline Volunteering & $6(8.3 \%)$ \\
\hline In school & $9(12.5 \%)$ \\
\hline In school and employed or volunteering & $6(8.3 \%)$ \\
\hline In a transition program & $1(2.1 \%)$ \\
\hline Self-employed & $4(5.6 \%)$ \\
\hline Seeking employment & $2(4.2 \%)$ \\
\hline Seeking employment and volunteering & $2(2.8 \%)$ \\
\hline Not seeking employment & $1(1.4 \%)$ \\
\hline Retired & $2(2.8 \%)$ \\
\hline Other & $3(4.2 \%)$ \\
\hline Do not know or wish to say & $15(20.8 \%)$ \\
\hline \multicolumn{2}{|c|}{$\begin{array}{l}\text { Notes. 'One participant further specified Native American/ } \\
\text { American Indian and White and another participant specified } \\
\text { Native Hawaiian/ Pacific Islander and White; }{ }^{2} \text { Highest level of } \\
\text { education that either parent or current legal guardian obtained. }\end{array}$} \\
\hline
\end{tabular}


Table 2. Autism Diagnoses and Traits

\begin{tabular}{|l|c|}
\hline Autism Diagnoses and Traits $^{1}$ & $n=72$ \\
\hline Autism status & $n(\%)$ \\
\hline Formally diagnosed & $47(65.3 \%)$ \\
\hline Not formally diagnosed & $25(34.7 \%)$ \\
\hline & \\
\hline Presence of Autistic traits ${ }^{2}$ & \\
\hline Yes & $59(81.9 \%)$ \\
\hline No & $13(18.1 \%)$ \\
\hline & \\
\hline Autism diagnosis identified with & 3 \\
\hline Asperger's disorder & $53(73.6 \%)$ \\
\hline Autistic disorder & $11(15.3 \%)$ \\
\hline Rett's disorder & $1(1.4 \%)$ \\
\hline PDD-NOS & $2(2.8 \%)$ \\
\hline "On the autism spectrum" & $1(1.4 \%)$ \\
\hline Do not know/ wish to say & $4(5.6 \%)$ \\
\hline
\end{tabular}

Notes. 'All participants included in current sample identified as Autistic; "Yes" indicates a score of 32 or higher on the Autism Quotient (Baron-Cohen et al., 2001); " Response to the item: "Currently, I think that the autism spectrum diagnosis that fits me best is:"; ${ }^{4}$ Pervasive developmental disordernot otherwise specified. 
Table 3. Correlation Matrix

\begin{tabular}{|c|c|c|c|c|c|c|c|c|c|}
\hline \multicolumn{4}{|l|}{ Correlation matrix } & \multirow[b]{2}{*}{ Education } & \multirow[b]{2}{*}{$\begin{array}{c}\text { Parent } \\
\text { education }\end{array}$} & \multirow[b]{2}{*}{$\begin{array}{l}\text { Involvement } \\
\text { in } \mathrm{OAC}^{1}\end{array}$} & \multirow[b]{2}{*}{$\begin{array}{l}\text { Autistic } \\
\text { identity }\end{array}$} & \multirow[b]{2}{*}{$\begin{array}{c}\text { Sense of } \\
\text { community }\end{array}$} & \multirow[b]{2}{*}{$\begin{array}{l}\text { Well } \\
\text { being }\end{array}$} \\
\hline & Age & Gender & Income & & & & & & \\
\hline Age & 1 & & & & & & & & \\
\hline Gender & .33 & 1 & & & & & & & \\
\hline Income & $.27 *$ & .23 & 1 & & & & & & \\
\hline Education & .14 & .12 & .17 & 1 & & & & & \\
\hline Parent education & -.01 & -.03 & $.25 *$ & .14 & 1 & & & & \\
\hline $\begin{array}{l}\text { Involvement in } \\
\text { OAC }^{1}\end{array}$ & -.15 & .47 & .31 & .38 & .36 & 1 & & & \\
\hline Autistic identity & -.001 & .21 & $-.29 *$ & .03 & .13 & $.37 * *$ & 1 & & \\
\hline Sense of community & -.13 & -.13 & .05 & -.10 & -.06 & $.45 * *$ & $.42 * *$ & 1 & \\
\hline Well-being & -.02 & -.07 & .19 & .18 & .06 & -.03 & .16 & -.01 & 1 \\
\hline
\end{tabular}

Notes. 'Importance and value of involvement in the online Autistic community; *p<.05; **p<.01 
Table 4. Regression Analysis of Psychological Well-Being

\begin{tabular}{|l|c|c|c|c|c|c|c|c|}
\hline \multicolumn{2}{|l|}{ Regression Analysis of Psychological Well-Being } & & & & & \\
\cline { 1 - 7 } & $\begin{array}{c}\text { Adjusted } \\
\mathrm{R}^{2}\end{array}$ & $\mathrm{~B}$ & $\mathrm{SE} \mathrm{B}$ & $\beta$ & $\begin{array}{c}95 \% \mathrm{CI} \\
\text { Lower Bound }\end{array}$ & $\begin{array}{c}\text { 95\% CI } \\
\text { Upper } \\
\text { Bound }\end{array}$ & $\begin{array}{c}\text { Effect } \\
\text { size } \mathrm{f}^{2}\end{array}$ & Power \\
\hline Step 1: Age & -.02 & .003 & .01 & .05 & -0.014 & 0.019 & \multirow{2}{*}{.02} & .19 \\
\hline Step 2: Involvement in OAC & -.04 & -.01 & .07 & -.02 & -0.154 & 0.131 & & .19 \\
\hline
\end{tabular}

Note. ${ }^{~}$ Involvement in the Online Autistic Community 
Figure 1. AASPIRE's academic and community partner contribution to the CBPR process

\section{Community}

KEEPS RESEARCH RESPECTFUL, ACCESSIBLE, AND SOCIALLY RELEVANT

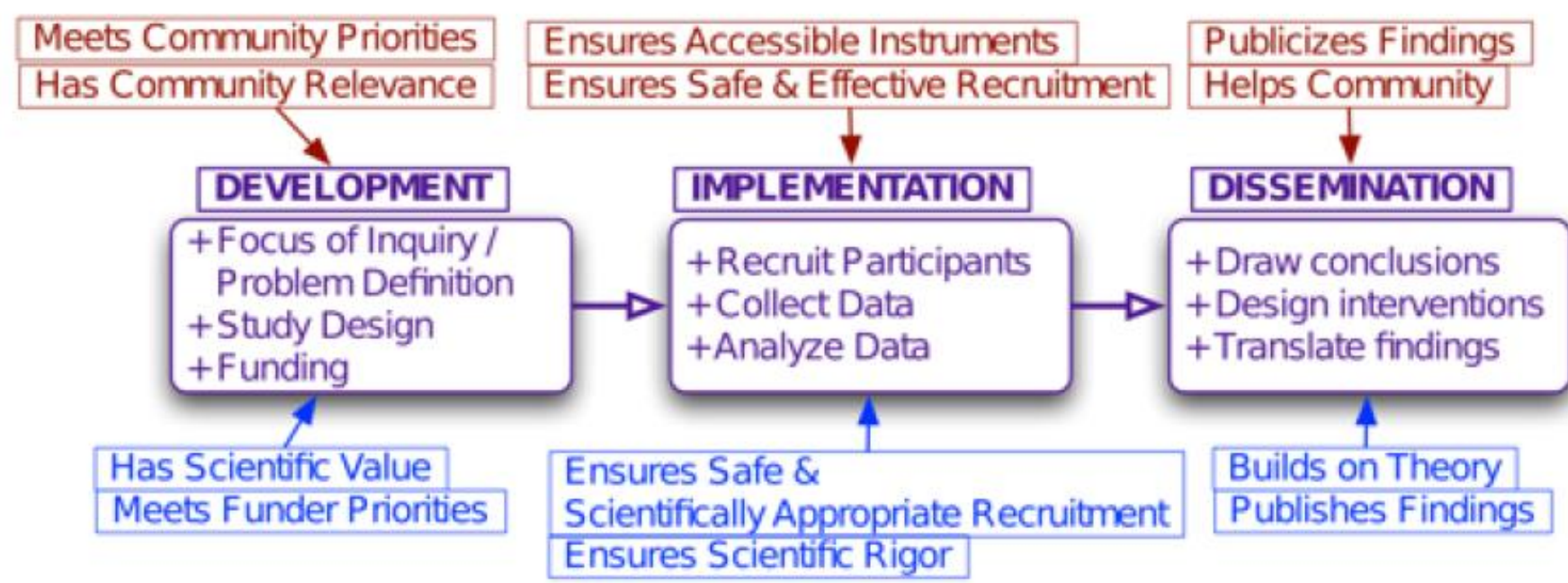

CBPR

Process

KEEPS RESEARCH SCIENTIFICALLY SOUND AND ACADEMICALLY RELEVANT

Researchers

(Nicolaidis, Raymaker, McDonald, Dern, Ashkenazy, Boisclair, Robertson, \& Baggs, 2011) 
Online Autistic Community 101

Figure 2. Relationships among importance and value of involvement in online Autistic community, Autistic identity, sense of community, and psychological well-being (Hypotheses 1.1 to 1.6)

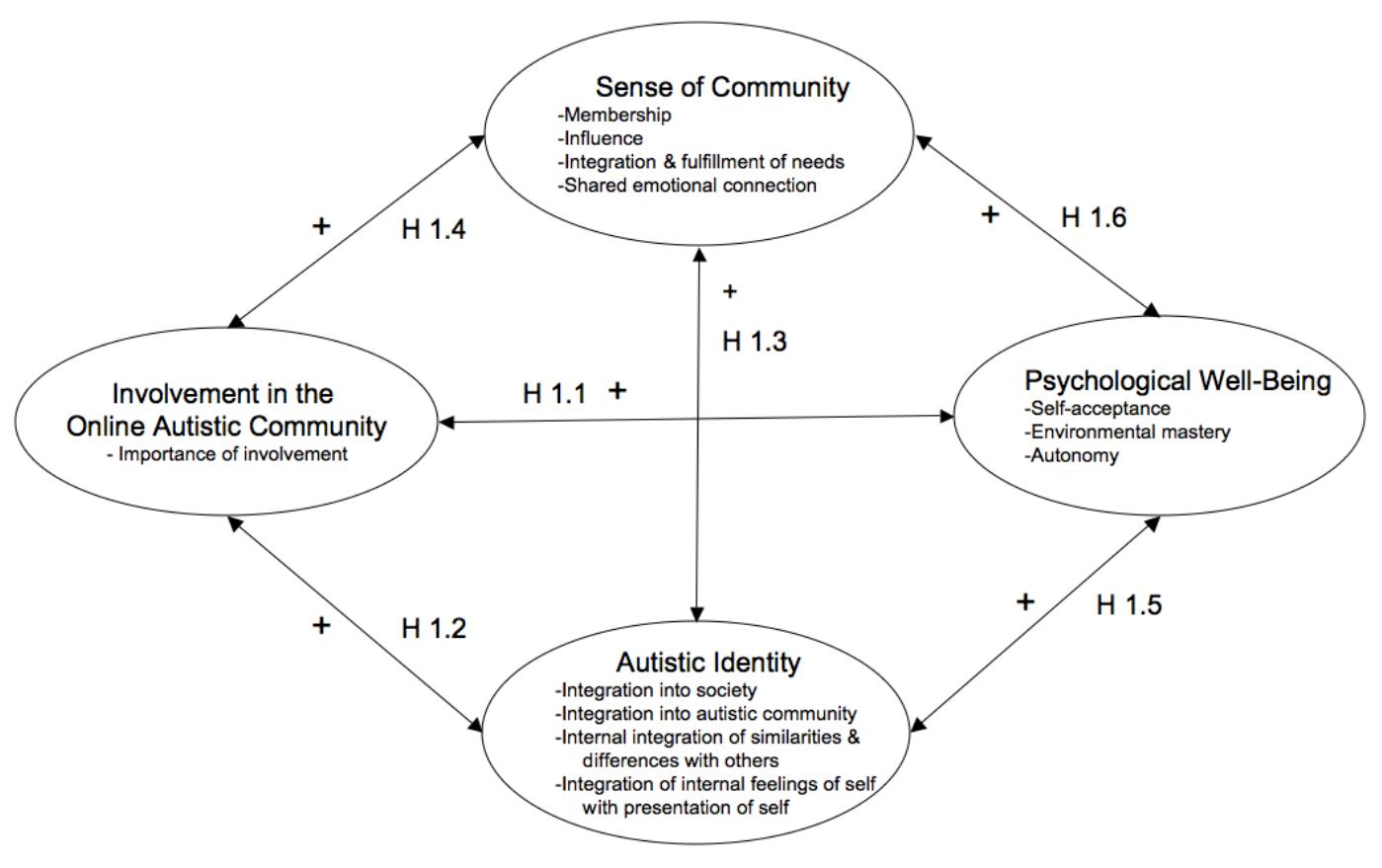


Online Autistic Community 102

Figure 3. Mediation model of psychological well-being on importance and value of involvement in the online Autistic community mediated by Autistic identity and sense of community (Hypothesis 2)

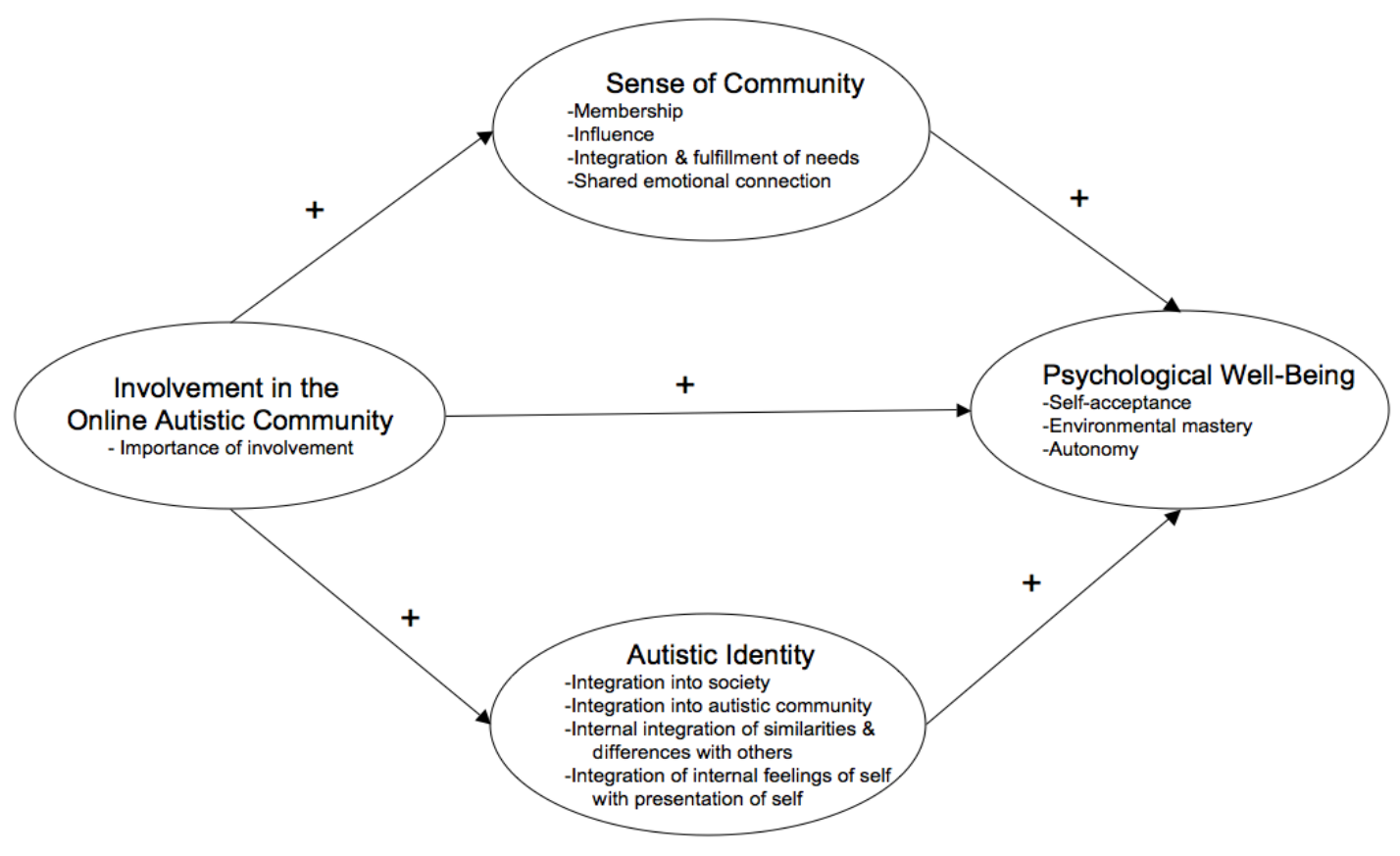


Figure 4. Participants and measures of the Gateway Survey utilized in the AASPIRE Internet Use, Community, and WellBeing Study

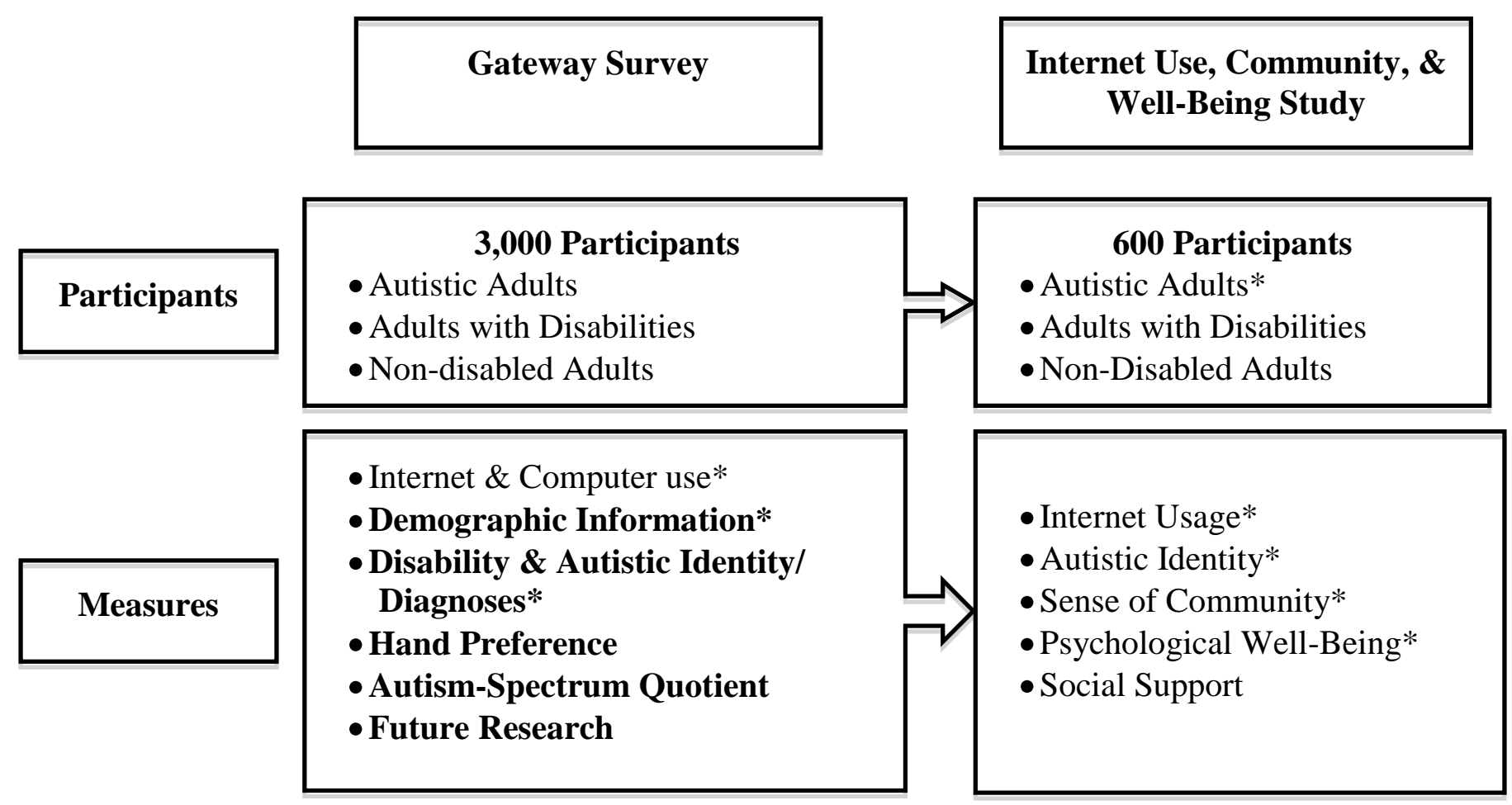

Note: Asterisked $(*)$ items indicate use in the proposed study 


\section{References}

Abbeduto, L., Seltzer, M.M. Shattuck, P., Krauss, M.W., Orsmond, G., \& Murphy, M.M. (2004). Psychological well-being and coping in mothers of youths with autism, down syndrome, or fragile X syndrome. American Journal on Mental Retardation, 109(3), 237-254.

Abberley, P. (1987). The concept of oppression and the development of a social theory of disability. Disability, Handicap, \& Society, 2, 5-19.

Adams, G.R. \& Marshall, S.K. (1996). A developmental social psychology of identity: Understanding the person-in-context. Journal of Adolescence, 19, 429-442.

Ahern, M., Hendryx, M., \& Siddharthan, K. (1996). The importance of a sense of community on people's perceptions of their health care experience. Medical Care, 34(9), 911-923.

Albanesi, C., Cicognani, E., \& Zani, B. (2007). Sense of community, civic engagement, and social well-being in Italian adolescents. Journal of Community and Applied Social Psychology, 17, 387-406.

Allen, R. \& Allen, J. (1987). A sense of community, a shared vision and a positive culture: core enabling factors in successful culture based health promotion. American Journal of Health Promotion, 1(3), 40-47.

American Association on Intellectual and Developmental Disabilities (2009). FAQ on Intellectual Disability. Retrieved April 24, 2009, from http://www.aamr.org/content_104.cfm.

American Psychiatric Association. (1994). Diagnostic and statistical manual of mental disorders ( $4^{\text {th }}$ ed.). Washington, DC: Author. 
Online Autistic Community 105

Ashby, C.E., \& Causton-Theoharis, J.N. (2009). Disqualified in the human race: a close reading of the autobiographies of individuals identified as autistic. International Journal of Inclusive Education, 13, 501-516.

Asperger, H. (1944). “Autistic psychopathy” in childhood. In U. Frith (Ed.), Autism and Aspergers Syndrome. Cambridge: Cambridge.

Autistic Self Advocacy Network, Kent Creative, \& the Dan Marino Foundation. (2009). No Myths. URL (Retrieved April 22, 2009): http://www.youtube.com/watch?v=Y_dPZDcX_ck

Bachrach, K.M. \& Zautra, A.J. (1985). Coping with a community stressor: The threat of a hazardous waste facility. Journal of Health and Social Behaviour, 26, 127-141.

Bagatell, N. (2007). Orchestrating voices: Autism, identity and the power of discourse. Disability and Society, 22(4), 413-426.

Bagatell N. (2010). From cure to community: transforming notions of autism. Ethos, 38, $34-58$.

Baggs, A. (2007). In my own language. URL (accessed May 2008): http://www.youtibe.com/watch?v=JnylM1hI2jc

Ballaban-Gil, K., Rapin, I., Tuchman, R., \& Shinnar, S. (1996). Longitudinal examination of the behavioral, language, and social changes in a population of adolescents and young adults with Autistic disorder. Pediatric Neurology, 15(3), 217-223.

Barak, A. \& Sadovsky, Y. (2008). Internet use and personal empowerment of hearingimpaired adolescents. Computers in Human Behavior, 24, 1802-1815.

Barnard, J., Harvey, V., Potter, D., \& Prior, A. (2001). Ignored or ineligible? The reality 
Online Autistic Community 106 for adults with autism spectrum disorders. The National Autistic Society Report for Autism Awareness Week. London: NAS Publications. Retrieved January 4, 2009, from http://www.autism.org.uk/nas/jsp/polopoly.jsp?d=160\&a=3463.

Baron, R. M., \& Kenny, D. A. (1986). The moderator-mediator variable distinction in social psychological research: Conceptual, strategic and statistical considerations. Journal of Personality and Social Psychology, 51, 1173-1182.

Baron-Cohen, S., Wheelwright, S., Skinner, R., Martin, J., \& Clubley, E. (2001). The Autism-Spectrum Quotient (AQ): Evidence from Asperger Syndrome/ highfunctioning autism, males and females, scientists and mathematicians. Journal of Autism and Developmental Disorders, 31, 5-17.

Barrett, M. (2006). “Like dynamite going off in my ears": Using autobiographical accounts of autism with teaching professionals. Educational Psychology in Practice, 22(2), 95-110.

Bauminger, N. \& Yirmiya (2001). The functioning and well-being of siblings of children with autism: Behaviora-genetic and familial contributions. In J.A. Burack, T. Charman, N. Yirmiya, \& P.R. Zelazo (Eds.) The Development of Autism. Philadelphia, PA: Lawrence Erlbaum Associates, Inc.

Benford, P. \& Standen, P.J. (2009). The Internet: A comfortable communication medium for people with Asperger syndrome (AS) and high functioning autism (HFA)? Journal of Assistive Technologies, 3(2), 44-53.

Berkman, L.F., Glass, T., Seeman, I., \& Brisette, T.E. (2000). From social integration to health: Durkheim in the new millennium. Social Science and Medicine, 51, 843857. 
Biklen, D. (2005). Autism and the myth of the person alone. New York: NYU Press.

Bishop, D.V.M. (1989). Autism, Asperger's syndrome and semantic-pragmatic disorders: Where are the boundaries? British Journal of Disorders of Communication, 24, 107-121.

Blanchard, A.L. (2007). Developing a sense of virtual community measure. CyberPsychology \& Behavior, 10(6), 827- 830.

Blanchard, A.L. \& Markus, M.L. (2002). The experienced "sense" of a virtual community: Characteristics and processes. The Data Base for Advances in Information Systems, 35, 65-79.

Blume, H. (1997a). Autistics, freed from face-to-face encouters, are communicating in cyberspace. Retrieved $28^{\text {th }}$ January 2009 , from http://www.nytimes.com/library/cyber/techcol/063097techcol.html

Blume, H. (1997b). Autism \& the Internet or "It's the wiring, stupid". Retrieved $28^{\text {th }}$ January 2009, from http://web.mit.edu/comm-forum/papers/blume.html

Boundy, K. (2008). “Are you sure, sweetheart, that you want to be well?”: An exploration of the neurodiversity movement. A Journal of Psychology, Politics, \& Radicalism, 7, 1-16.

Bowker, N. \& Tuffin, K. (2002). Disability discourses for online identities. Disability \& Society, 17(3), 327-344.

Boykin, A.W. (1986). The triple quandary and the schooling of Afro-American children. In U. Neisser (Ed.), The school achievement of minority children (pp. 57-92). Hillsdale, NJ: Erlbaum. 
Online Autistic Community 108

Bradley, E.A., Summers, J.A., Wood, H.L., \& Bryson, S.E. (2004). Comparing rates of psychiatric and behavior disorders in adolescents and young adults with severe intellectual disability with and without autism. Journal of Autism \& Developmental Disorders, 34(2), 151-161.

Brisenden, S. (1986). Independent living and the medical model of disability. Disability, Handicap, and Society, 1(2), 173-178.

Broderick, A. \& Ne' eman, A. (2008). Autism as metaphor: Narrative and counter narrative. International Journal of Inclusive Education, 12, 459-476.

Brodsky, A.E. (1996). Resilient single mothers in risky neighborhoods: Negative psychological sense of community. Journal of Community Psychology, 24, 347363.

Brodsky, A., O’Campo, P., \& Aronson, R. (1999). PSOC in community context: Multilevel correlates of a measure of psychological sense of community in low-income, urban neighborhoods. Journal of Community Psychology, 27, 659-679.

Brodsky, A.E. \& Marx, C.M. (2001). Layers of identity: Multiple psychological sense of community within a community setting. Journal of Community Psychology, 29(2), 161-178.

Brown, R.I., \& Brown, I. (2005). The application of quality of life. Journal of Intellectual Disability Research, 49(10), 718-727.

Brownlow, C. (2007). The Construction of the Autistic Individual: Investigations in Online Discussion Groups. University of Brighton. Retrieved January 5, 2009, from http://eprints.brighton.ac.uk/3073/ 
Brownlow, C., \& O’Dell, L. (2002). Ethical issues for qualitative research in on-line communities. Disability \& Society, 17(6), 685-694.

Brugha, T.S., McManus, S., Bankart, J., Scott, F., Purdon, S., Smith, J., \& Meltzer, H. (2011). Epidemiology of autism spectrum disorders in adults in the community in England. Archives of General Psychiatry, 68, 459-465.

Brydon-Miller, M. (1997). Participatory action research: Psychology and social change. Journal of Social Issues 53(4), 657-666.

Buckner, J.C. (1988). The development of an instrument to measure neighborhood cohesion. American Journal of Community Psychology, 16, 771-791.

Burgess, A.F. \& Gutstein, S.E. (2007). Quality of life for people with autism: Raising the standard for evaluating successful outcomes. Child and Adolescent Mental Health, 12(2), 80-86.

Burke, M., Kraut, R., \& Williams, D. (2010). Social use of computer-mediated communication by adults on the autism spectrum. Proceedings of the 2010 ACM Conference on Computer Supported Cooperative Work, ACM: New York City, New York, 425-434.

Burks, M.A., Pardos, J.L., Waddell, L., \& Nakane, M. (2000). The Internet and people with disabilities: Expanding horizons or barrier to information and services. Retrieved April 22, 2009, from http://www.ISOC.org/inet2000/cdproceedings/5c/5c_1.htm

Chamak, B. (2008). Autism and social movements: French parents' associations and international Autistic individuals' organizations. Sociology of Health \& Illness, 30, 76-96. 
Chamak, B., Bonniaua, B., Jaunay, E., \& Cohen, D. (2008). What can we learn about autism from autistic persons? Psychotherapy and Psychosomatics, 77, 271-279.

Chavis, D.M. Hogge, J.H., McMillan, D.W., \& Wandersman A. (1986). Sense of community through Brunswik’s lens: A first look. Journal of Community Psychology, 14, 24-40.

Chavis, D.M., Lee, K.S., \& Acosta, J.D. (2008). The Sense of Community (SCI) Revised: The Reliability and Validity of the SCI-2. Paper presented at the $2^{\text {nd }}$ International Community Psychology Conference, Lisboa, Portugal.

Chipuer, H.M. \& Pretty G.M.H. (1999). A review of the Sense of Community Index: Current uses, factor structure, reliability, and further development. Journal of Community Psychology, 27(6), 643-658.

Clarke, J., \& van Amerom, G. (2007). 'Surplus suffering': Differences between organizational understandings of Asperger's syndrome and those people who claim the 'disorder'. Disability \& Society, 22, 761-776.

Clarke, P.J., Marshall, V.W., Ryff, C.D., \& Wheaton, B. (2001). Measuring psychological well-being in the Canadian Study of Health and Aging. International Psychogeriatrics, 13, 79-90.

Cohen, S.R., Mount, B.M., Tomas, J.J.N., \& Mount, L.F. (1996). Exitential well-being is an important determinant of quality of life: Evidence from the McGill quality of life questionnaire. Cancer, 77(3), 576-586.

Cotton, S.R. (2008). Students' technology use and the impacts on well-being. New Directions for Student Services, 124, 55-70. 
Cramer, E.P. \& Gilson, S.F. (1999). Queers and crips: Parallel identity development processes for persons with nonvisible disabilities and lesbian, gay, and bisexual persons. Journal of Gay, Lesbian, and Bisexual Identity, 4(1), 23-37.

Cromby, J. \& Standon, P. (1999). Cyborgs and stigma: Technology, disability, subjectivy. In A.J. Gordo-Lopez \& I. Parker (Eds.). Cyberpsychology (pp. 95112). New York: Routledge.

Cronbach, L. J. (1951). Coefficient alpha and the internal structure of tests. Psychometrika, 16(3), 297-334.

Dalton, J.H., Elias, M.J., \& Wandersman, A. (2000). Community Psychology: Linking Individuals and Communities. Belmont, CA: Wadsworth Printing.

Davidson, J. (2008). 'More labels than a jam jar': The gendered dynamics of diagnosis for girls and women with autism. In P. Moss \& K. Teghtsoonian (Eds.), Contesting Illness (pp. 239-258). Toronto, ON: University of Toronto Press.

Davidson, W. \& Cotter, P. (1986). Measurement of sense of community within the sphere of city. Journal of Applied Social Psychology, 16, 608-629.

Davidson, W. \& Cotter, P. (1991). The relationship between sense of community and subjective well-being: A first look. Journal of Community Psychology, 18, 246253.

Davidson, J., \& Henderson, V.L. (2010). 'Coming out' on the spectrum: Autism, identity and disclosure. Social \& Cultural Geography, 11, 155-170.

Dowrick, P.W. \& Keys, C.B. (2001). Community psychology and disability studies. Journal of Prevention \& Intervention in the Community, 21(2), 1-14. 
Dye, L., Hendy, S., Hare, D. J., \& Burton, M. (2004). Capacity to consent to participate in research - A recontextualization. British Journal of Learning Disabilities, 32(3), 144-150.

Erikson, E.H. (1956). The problem of ego identity. Journal of the American Psychoanalytic Association, 4, 56-121.

Erickson, W. \& Lee, C. (2008). 2007 Disability Status Report: United States. Ithaca, NY: Cornell University Rehabilitation Research and Training Center on Disability Demograohics and Statistics.

Farley, M.A., McMahon, W.M., Fombonne, E., Jenson, W.R., Miller, J., Gardner, M., Block, H., Pingree, C.B., Ritvo, E.R., Ritvo, R.A., \& Coon, H. (2009). Twentyyear outcomes for individuals with autism and average or near-average cognitive abilities. Autism Research, 2, 1-10.

Farrell, S., Aubry, T., \& Coulombe, D. (2004). Neighborhoods and neighbors: do they contribute to personal well-being? Journal of Community Psychology, 32(1), 925.

Fawcett, S.B., White, G.W., Balcazar, F.E., Suarez-Balcazar, Y., Mathews, R.M., PaineAndrews, A., Seekins, T., \& Smith, J.F. (1994). A contextual-behavioral model of empowerment: Case studies involving people with physical disabilities. American Journal of Community Psychology, 22(4), 1994.

Filipek, P.A., Accardo, P.J., Baranek, G.T., Cook Jr., E.H., Dawson, G., Gordon, B., Gravel, J.S., Johnson, C.P., Kallen, R.J., Levy, S.E., Minshew, N.J., Prizant, B.M., Rapin, I., Rogers, S.J., Stone, W.L., Teplin, S., Tuchman, R.F., \& Volkmar, 
F.R. (1999). The screening and diagnosis of autism spectrum disorders. Journal of Autism and Developmental Disorders, 29(6), 439-484.

Fine, M. \& Asch, A. (1988). Disability beyond stigma: Social interaction, discrimination, and activism. Journal of Social Issues, 44, 3-21.

Folstein, S.E. (1999). Autism, International Review of Psychiatry, 11, 269-277.

Forster, P.M. (2004). Psychological Sense of Community in Groups on the Internet. Behaviour Change 21(2), p. 141-146.

Friere, P. (1972). Pedagogy of the Oppressed. New York: Continuum.

Gallup, Inc. (2009). Computers and the Internet. Retrieved January 3, 2009, from http://www.gallup.com/poll/1591/Computers-Internet.aspx.

Gamson, W.A. (1992). The social psychology of collective action. In A. Morris \& C. Mueller (Eds.), Frontiers of Social Movement Theory. New Haven: Yale University Press.

Gerber, F., Baud, M.A., Giround, M., \& Carminati, G.G. (2008). Quality of life of adults with pervasive developmental disorders and intellectual disabilities. Journal of Autism and Developmental Disabilities, 38, 1654-1665.

Gill, C.J. (1997a). Four types in integration in disability identity development. Journal of Vocational Rehabilitation, 9(1), 39-46.

Gill, C.J. (1997b). Disability Identity Scale. Chicago, Illinois: Chicago center for Disability Research, University of Illinois at Chicago.

Gillberg, C. (2001). Asperger syndrome and high functioning autism: Shared deficits or different disorders? The Journal of Developmental and Learning Disorders, 5, 8194. 
Goodley, D. \& Lawthom, R. (2005). Epistemological journeys in participatory action research: Alliances between community psychology and disability studies. Disability \& Society, 20(2), 135-151.

Gordon, B.O. \& Rosenblum, K.E. (2001). Bringing disability into the sociological frame: A comparison of disability with race, sex, and sexual orientation statuses. Disability \& Society, 16(1), 5-19.

Gray-Little, B. \& Hafdahl, A.R. (2000). Factors influencing racial comparisons of selfesteem: A quantitative review. Psychological Bulletin, 126(1), 26-54.

Guo, B., Bricout, J.C., \& Huang, J. (2005). A common open space or a digital divide? A social model perspective on the online disability community in China. Disability \& Society, 20(1), 49-66.

Haber, M.G., Cohen, J.L., Lucas, T., \& Baltes, B.B. (2007). The relationship between self-reported received and perceived social support: A meta-analytic review. American Journal of Community Psychology, 39, 133-144.

Happé, F., \& Ronald, A. (2008). The 'fractionable autism triad': a review of evidence from behavioural, genetic, cognitive and neural research. Neuropsychology Review, 18, 287-304.

Hart, S., Fonareva, I., Merluzzi, N., \& Mohr, D.C. (2005). Treatment for depression and its relationship to improvement in quality of life and psychological well-being in multiple sclerosis patients. Quality of Life Research, 14, 695-703.

Havercamp, S.M., Scandlin, D., \& Roth, M. (2004). Health disparities among adults with developmental disabilities, adults with other disabilities, and adults not reporting disability in North Carolina. Public Health Reports, 119, 418-426. 
Hemenover, S.H. (2003). The good, the bad, and the healthy: Impacts of emotional disclosure of trauma on resilient self-concept and psychological distress. Personality and Social Psychology Bulletin, 29(10), 1236- 1244.

Hendry, L.B. (1983). Growing Up and Going Out. Adolescents and Leisure. Aberdeen: Aberdeen University Press.

Hoekstra, R.A., Bartels, M., Cath, D.C., \& Boomsma, D.I. (2008). Factor structure, reliability, and criterion validity of the Autism-Spectrum Quotient (AQ): A study in Dutch population and patient groups. Journal of Autism and Developmental Disorders, 38(8), 1555- 1566.

Hurlbutt, K., \& Chalmers, L. (2002). Adults with autism speak out: Perceptions of their life experiences. Focus on Autism and Other Developmental Disabilities, 17, $103-111$.

Israel, B. A., Schultz, A. J., Parker, E. A., Becker, A. B., Allen III, A. J., \& Guzman, J. R. (2003). Critical issues in developing and following community-based participatory research principles. In M. Minkler \& N. Wallerstein (Eds.), Community-Based Participatory Research for Health (pp. 53-76). San Francisco: Jossey-Bass.

Jones, R.S., \& Meldal, T.O. (2001). Social relationships and Asperger's syndrome: A qualitative analysis of first-hang accounts. Journal of Leaning Disabilities 5(1), $35-41$.

Jones, R.S., Zahl, A., \& Huws, J.C. (2001). First-hand accounts of emotional experiences in autism: A qualitative analysis. Disability \& Society, 16(3), 393-401. 
Online Autistic Community 116

Jordan, C.J. (2010). Evolution of autism support and understanding via the world wide web. Intellectual and Developmental Disabilities, 48(3), 220-227.

Kanner, L. (1943). Autistic disturbance of affective contact. Nervous Child, 2, 217-250.

Kaplan, G.A., Shema, S.J., Leite, M.C. (1994). Socioeconomic determinants of psychological well-being: The role of income, income change, and income sources over 29 years. Annals of Epidemiology, 18(7), 531-537.

Keyes, C.L.M., Shmotkin, D., \& Ryff, C.D. (2002). Optimizing well-being: The empirical encounter of two traditions. Journal of Personality and Social Psychology, 82(6), 1007-1022.

Kiang, L., Yip, T., Gonzales-Backen, M., \& Witkow, M. (2006). Ethnic identity and the daily psychological well-being of adolescents from Mexican and Chinese backgrounds. Child Development, 77(5), 1338-1350.

Kim, Y.S., Leventhal, B.L., Koh, Y.J., Fombonne, E., Laska, E., Lim, E.C. \& Grinker, R.R. (2011). Prevalence of autism spectrum disorders in a total population sample. The American Journal of Psychiatry. 168(5),1-9.

Kingston, S., Mitchell, R., Florin, P., \& Stevenson, J. (1999). Sense of community in neighborhoods as a multi-level construct. Journal of Community Psychology, 27, 681-694.

Kirby, S.E., Coleman, P.G., \& Daley, D. (2004). Spirituality and well-being in frail and nonfrail older adults. Journal of Gerontology Psychology Sciences, 59(3), 123129. 
Kraut, R.E., Patterson, M., Lundmark, V., Kiesler, S., Mukhopadhyay, T., \& Scherlis, W. (1998). Internet paradox: A social technology that reduces social involvement and psychological well-being? American Psychologist, 53, 1017-1032.

Lord, J. \& Hutchison, P. (1993). The process of empowerment: Implications for theory and practice. Canadian Journal of Community Mental Health, 12(1), 5-22.

Lord, C., \& Schopler, E. (1985). Brief report: Differences in sex ratios in autism as a function of measured intelligence. Journal of Autism and Developmental Disorders, 15, 185-193.

Marcia, J.E. (1966). Development and validation of ego-identity status. Journal of Personality and Social Psychology, 3(5), 551-558.

McDonald, K.E., Keys, C.B., \& Balcazar, F.E. (2007). Disability, race/ ethnicity and gender: Themes of cultural oppression, acts of individual resistance. American Journal of Community Psychology, 39, 145-161.

McMillan, D.W. (1996). Sense of Community. Journal of Community Psychology, 24(4), $315-325$.

McMillan, D.W. \& Chavis, D.M. (1986). Sense of community: A definition and theory. Journal of Community Psychology, 14(1), 6-23.

Minkler, M. \& Wallerstein, N. (2003). Community Based Participatory Research for Health. San Francisco, CA: Jossey-Bass Publishers.

Morales, L. (2009). Nearly half Americans frequent Internet users. Retrieved January 3, 2009, from http://www.gallup.com/poll/113638/Nearly-Half-AmericansFrequent-Internet-Users.aspx 
Online Autistic Community 118

Müller, E., Schuler, A., \& Yates, G. B. (2008). Social challenges and supports from the perspective of individuals with Asperger syndrome and other autism spectrum disabilities. Autism, 12, 173-190.

Murray, S. (2010). Autism functions/ the function of autism.. Disability Studies Quarterly, 30(1), retrieved on January 6, 2011 from http://www.dsqsds.org/article/view/1063/1222.

Nagi, S.Z. (1969). Disability and Rehabilitation. Columbus, OH: Ohio State University Press.

National Institute of Child Health and Human Development. (2005). Autism overview: What we know. Retrieved April 12, 2009, from http://www.nichd.nih.gov/autism. National Institute of Neurological Disorders and Stroke, NIH (2008). Autism Fact Sheet. Retrieved June 4, 2008, from http://www.ninds.nih.gov/disorders/autism.

Ne'eman, A. (2010). The future (and the past) of autism advocacy, or why the ASA's magazine, The Advocate, wouldn't publish this piece. Disability Studies Quarterly, 30(1), retrieved on January 6, 2011 from http://www.dsqsds.org/article/view/1063/1222.

Newton, A.T., Kramer, A.D.I., McIntosh, D.N. (2009). Autism online: A comparison of Word Usage in Bloggers With and Without Autism Spectrum Disorders. Paper presented at the ACM International Conference on Human Factors in Computing Systems. Boston, MA.

Nicolaidis, C., Raymaker, D., McDonald, K., Dern, S., Ashkenazy, E., Boisclair, C., Robertson, C., Baggs, A. (2011a). Collaboration strategies in nontraditional community-based participatory research partnerships: Lessons from an academic- 
community partnership with autistic self-advocates. Progress in Community Health Partnerships, 5(2), 143-150.

Nicolaidis, C., Raymaker, D., McDonald, K., Dern, S., Ashkenazy, E., Boisclair, W.S., Baggs, A., Delaney, R., Way, R. (2011b). Healthcare disparities experienced by adults on the autistic spectrum. Scientific Poster Presentation. Annual Meeting of the Society for General Internal Medicine. Phoenix, Arizona.

Obst, P., Smith, S.G., \& Zinkiewicz, L. (2002). An exploration of sense of community, part 3: Dimensions and predictors of psychological sense of community in geographical communities. Journal of Community Psychology, 30(1), 119-133.

Obst, P., Zinkiewicz, L., \& Smith, S. (2002a). Sense of community in science fiction fandom, Part 1: Understanding sense of community in an international community of interest. Journal of Community Psychology, 30(1), 87-103.

Obst, P., Zinkiewicz, L., \& Smith, S. (2002b). Sense of community in science fiction fandom, part 2: Comparing neighborhood and interest group sense of community. Journal of Community Psychology, 30(1), 105-117.

Obst, P. \& White, K. (2004). Revisiting the sense of community index: A confirmatory factor analysis. Journal of Community Psychology, 32, 691-705.

Obst, P. \& White, K. (2005). An exploration of the interplay between psychological sense of community, social identification and salience. Journal of Community \& Applied Social Psychology, 15, 127-135.

Oliver, M. (1996). Defining impairment and disability: issues at stake. In C. Barnes and G. Mercer (Ed.), Exploring the Divide (pp. 29-54). Leeds: The Disability Press. 
Online Autistic Community 120

Olney, M.F. \& Kim, A. (2001). Beyond adjustment: Integration of cognitive disability into identity. Disability \& Society, 16(4), 563-583.

O’Neil, S.O. (2008). The meaning of autism: Beyond disorder. Disability \& Society, 23, 787-799.

Orsini, M., \& Smith, M. (2010). Social movements, knowledge and public policy: the case of autism activism in Canada and the US. Critical Policy Studies, 4, 38 - 57.

Orsmond, G.I., Krauss, M.W., \& Seltzer, M.M. (2004). Peer relationships and social and recreational activities among adolescents and adults with autism. Journal of Autism and Developmental Disorders, 34(3), 245-256.

Orsmond, G.I. \& Seltzer, M.M. (2007). Siblings of individuals with autism or Down syndrome: Effects on adult lives. Journal of Intellectual Disability Research, 51(9), 82-696.

Ortega, F. (2009). The cerebral subject and the challenge of neurodiversity. BioSocities, $4,425-445$.

Perkins, D.D., Florin, P., Rich, R.C., Wandersman, A., \& Chavis, D.M. (1990). Participation and the social and physical environment of residential blocks: Crime and community context. American Journal of Community Psychology, 18(1), 83115.

Peterson, N.A., Speer, P.W., \& Hughey, J. (2006). Measuring sense of community: A methodological interpretation of the factor structure debate. Journal of Community Psychology, 34(4), 453-469.

Pledger, C. (2003). Discourse on disability and rehabilitation issue: Opportunity for psychology. American Psychologist, 58, 279-284. 
Pretty, G.M.H., Andrewes, L., \& Collett, C. (1994). Exploring adolescents'sense of community and its relationship to lonliness. Journal of Community Psychology, $22,346-358$.

Pretty, G.M.H., Conroy, C., Dugay, J., Fowler, K., \& Williams, D. (1996). Sense of community and its relevance to adolescents of all ages. Journal of Community Psychology, 24(4), 365-379.

Proescholdbell, R.J., Roosa, M.W., \& Nemeroff, C.J. (2006). Component measures of psychological sense of community among gay men. Journal of Community Psychology, 34(1), 9-24.

Putnam, R. (2000). Bowling Alone: The Collapse and Revival of American Community. New York: Simon \& Schuster.

Renty, J.O. \& Roeyers, H. (2006). Quality of life in high-functioning adults with autism spectrum disorder: The predictive value of disability and support characteristics. Autism, 10(5), 511-524.

Robertson, S.M. (2010). Neurodiversity, quality of life, and Autistic adults: Shifting research and professional focuses onto real-life challenges. Disability Studies Quarterly, 30(1), retrieved on January 6, 2011 from http://www.dsqsds.org/article/view/1063/1222.

Rohall, D.E., Cotton, S.R., \& Morgan, C. (2002). Internet use and the self cencept: Linking specific uses to global self-esteem. Current Research in Social Psychology, 8(1), 1-19. 
Ryan, R.M. \& Deci, E.L. (2001). On happiness and human potentials: A review of research on hedonic and eudaimonic well-being. Annual Review of Psychology, $52,141-166$.

Ryff, C.D. (1989). Happiness is everything, or is it? Explorations on the meaning of psychological well-being. Journal of Personality and Social Psychology, 57, 1069-1081.

Ryff, C.D. (1995). Psychological well-being in adult life. Current Directions in Psychological Science, 4(4), 99-103.

Ryff, C.D., Keyes, C.L.M., \& Hughes, D.L. (2003). Status inequalities, perceived discrimination, and eudaimonic well-being: Do the challenges of minority life hone purpose and growth? Journal of Health and Social Behavior, 44, 275-291.

Sansosti, F.J., \& Powell-Smith, K.A. (2008). Using comuter-resented social stories and video models to increase the social communication skills of children with highfunctioning autism spectrum disorders. Journal of Positive Behavior Interventions, 10(3), 162-178.

Sarason, B.R., Sarason, I.G., \& Pierce, G.R. (1990). Traditional views of social support and their impact on assessment. In B.R. Sarason, I.G. Sarason, \& G.R. Pierce (Eds.), Social Support: An Interactional View (pp.9-25). New York: Wiley.

Sarason, S.B. (1974). The Psychological Sense of Community: Prospects For a Community Psychology. San Francisco: Jossey-Bass.

Schur, L., Shields, T., \& Schriner, K. (2005). Generational cohorts, group membership, and political participation by people with disabilities. Political Research Quarterly, 58(3), 487-496. 
Seymour, W. \& Lupton, D. (2004). Holding the line online: Exploring wired relationships for people with disabilities. Disability \& Society, 19(4), 291-305.

Shelton, J.N., Yip, T., Eccles, J.S., Chatman, C., Fuligni, A.J., \& Wong, C. (2005). Ethnic identity as a buffer in psychological adjustment. In G. Downey, J. Eccles, \& C. Chatman (Eds.), Navigating the future: Social identity, coping and life tasks. New York: The Russell Sage Foundation.

Shipman, D.,L., Sheldrick, R.C., Perrin, E.C. (2011). Quality of life in adolescents with autism spectrum disorders: Reliability and validity of self-reports. Journal of Developmental \& Behavioral Pediatrics, 32(2), 85-89.

Shirky, C. (2003). A group is its own worst enemy [Mailing list post]. Retrieved from http://www.shirky.com/writings/group_enemy.html

Shklovski, I., Kiesler, S., \& Kraut, R. (2006). The Internet and social interaction, a metaanalysis and critique of studies, 1995-2003. In R. Kraut (Ed.), Computers, Phones, and the Internet: Domesticating Information Technology. New York: Oxford University Press.

Siddequee, A. \& Kagan, C. (2006). The Internet, empowerment, and identity: An exploration of participation by refugee women in a community Internet project (CIP) in the United Kingdom (UK). Journal of Community \& Applied Social Psychology, 16, 189-206.

Silver, M. \& Oakes, P. (2001). Evaluation of a new computer intervention to teach people with autism or Asperger syndrome to recognize and predict emotion in others. Autism, 5, 299-316. 
Silverman, C. (2008). Fieldwork on another planet: Social science perspectives on the autism spectrum. BioSocieties, 3, 325-341.

Sinclair, J. (1993). Don't mourn for us. First published in the Autism Network International newsletter, Our Voice, 1. Retrieved January 3, 2009, from http://ani.Autistics.org.dont_mourn.html.

Singh, J. Illes, J., Lazzeroni, L., \& Hallmayer, J. (2009). Trends in US autism research funding. Journal of Autism and Developmental Disorders, 39, 788-795.

Snow, D.L., Grady, K., \& Goyette-Ewing, M. (2000). A perspective on ethical issues on community psychology. In J. Rappaport \& E. Seidman (Eds.) Handbook of Community Psychology. New York: Kluwer Academic/ Plenum Publishers.

Sonn, C.C. (2002). Immigrant adaptation: Exploring the process through sense of community. In A.T. Fisher, C.C. Sonn, \& B.J. Bishop (Eds.), Psychological Sense of Community: Research, Applications and Implications (pp. 205-222). New York, NY: Kluwer Academic/ Plenum Publishers.

Sperry, L. A., \& Mesibov, G. B. (2005). Perceptions of social challenges of adults with autism spectrum disorder. Autism, 9, 362-376.

Sprague, J., \& Hayes, J. (2000). Self-determination and empowerment: A feminist standpoint analysis of talk about disability. American Journal of Community Psychology, 28, 671-695.

Stern, S., \& Brault, M. (2005). Disability Data from the American Community Survey: A Brief Examination of the Effects of a Question Redesign in 2003. Census Bureau Staff Research Report. Washington DC: US Census Bureau, Housing and 
Household Economic Statistics Division. Retrieved April 22, 2009, from http://mail.google.com/mail/?ui=2\&view=bsp\&ver=1 qygpcgurkovy.

Suler, J. (1997). The Psychology of Cyberspace. Retrieved $1^{\text {st }}$ February 2009, from http://www-usr.rider.edu/ suler/psycyber/psycyber.html

Sutherland, G., Couch, M.A., Iacono, T. (2002). Health issues for adults with developmental disability. Research in Developmental Disabilities, 23, 422-445.

Szatmari, P. (2004). A Mind Apart: Understanding Children with Autism and Asperger Syndrome. New York \& London: The Guilford Press.

Tajfel, H. \& Turner, J.C. (1979). An integrative theory of intergroup conflict. In W.G. Austin, S. Worchel (Eds.), The Social Psychology of Intergroup Relations. Montery, CA: Brooks/ Cole Publishing Company.

Tate, D. \& Pledger, C. (2003). An integrative conceptual framework of disability: New directions for research. American Psychologist, 58, 289-295.

Teske, N. (1997). Political activists in America: The identity construction model of political participation. New York: Cambridge University Press.

Turkle, S. (1995). Life On the Screen: Identity in the Age of the Internet. New York: Simon \& Schuster.

Umaña-Taylor, A.J. (2004). Ethnic identity and self-esteem: Examining the role of social context. Journal of Adolescence, 27, 139-146.

US Department of Health \& Human Services (2009). Administration on developmental disabilities: Fact sheet. Retrieved April 22, 2009, from http://www.acf.hhs.gov/opa/fact_sheets/add_printable.html. 
US Department of Health \& Human Services Interagency Autism Coordinating Committee. (2009). The Interagency Autism Coordinating Committee strategic plan for autism spectrim disorder research. Retrieved April 22, 2009, from http://iacc.hhs.gov/reports/2009/iacc-strategic-plan-for-autism-spectrum-disorderresearch-jan26.shtml

Valkenburg, P.M. \& Peter, J. (2007). Preadolescents' and adolescents' online communication and their closeness to friends. Developmental Psychology, 43(2), 267-277.

Whalen, C., Moss, D., Ilan, A.B., Vaupel, M., Fielding, P., MacDonald, K., Cernich, S., \& Symon, J. (2010). Efficacy of TeachTown: Basicals computer-assisted intervention for the Intensive Comprehensive Autism Program in Los Angeles Unified School District. Autism, 14(3), 179-197.

Wandersman, A. \& Florin, P. (2000). Citizen participation and community organizations. In J. Rappaport \& E. Seidman (Eds.). Handbook of Community Psychology. New York: Kluwer Academic/ Plenum Publishers.

Ward, M. J., \& Meyer, R. N. (1999). Self-determination for people with developmental disabilities and autism: two advocates' perspectives. Focus on Autism and Other Developmental Disabilities, 14, 133-139.

Waterman, A.S. (1993). Two conceptions of happiness: Constrasts of personal expressiveness (eudaimonia) and hedonic enjoyment. Journal of Personality and Social Psychology, 64, 678-691. 
Wellman, B. \& Gulia, M. (1999). Net-Surfers Don't Ride Alone: Virtual Communities as Communities. In Wellman, B. (Ed.) Networks in the Global Village: Life in Contemporary Communities (pp. 331- 366). Boulder, CO: Westview Press.

Whitney, C. (2006). Intersections in identity: Identity development among queer women with disabilities. Sexuality and Disability, 24(1), 39- 52.

Wing, L. (1997). The autism spectrum. The Lancet, 350, 1761-1766.

Wing, L., Gould, J., Gillberg, C. (2011). Autism spectrum disorders in the DSM-V: better or worse than the DSM-IV? Research in Developmental Disabilities, 32, 768-773.

Wing, L., \& Potter, D. (2002). The epidemiology of autistic spectrum disorders: Is the prevalence rising? Mental Retardation and Developmental Disabilities Research Reviews, 8, 151-161.

Woodbury-Smith, M.R., Robinson, J., Wheelwright, S., \& Baron-Cohen, S. (2005). Screening adults for Asperger Syndrome using the AQ: A preliminary study of its diagnostic validity in clinical practice. Journal of Autism and Developmental Disorders, 35(3), 331-335.

Yergeau, M. (2010). Circle wars: Reshaping the typical autism essay. Disability Studies Quarterly, 30(1), retrieved on January 6, 2011 from http://www.dsqsds.org/article/view/1063/1222.

Yoo, H.C. \& Lee, R.M. (2005). Ethnic identity and approach-type coping as moderators of the racial discrimination/ well-being relation in Asian Americans. Journal of Counseling Psychology, 52(4), 497-506. 
Appendix A. Principles of CBPR

Online Autistic Community

\section{The following Principles of Community Based Participatory Research are derived}

\section{from:}

Isreal, Barbara A. "Community-Based Participatory Research: Principles, Rationale and Policy Recommendations." Successful Models of Community-Based Participatory Research, pp. 16-22, March 2000, Washington, DC.

- $\quad$ CBPR acknowledges community as a unit of identity. The community is not just a population that shares some characteristic--it is a mutual network of individuals with common symbols, history, and a sense of emotional safety and identification.

- $\quad C B P R$ builds on strengths and resources in the community. Researchers acknowledge and make use of community resources, including supporting community development if needed.

- CBPR facilitates a collaborative, equitable partnership in all phases of research. All partners--researchers and community members--are informed, included, and involved in all aspects of the research process.

- CBPR facilitates co-learning and capacity building among all partners. Researchers and community members learn from each other throughout the research process.

- CBPR integrates and achieves a balance between knowledge generation and intervention for the mutual benefit of all partners. Research findings and plans for affecting change based on those findings are both valued and considered intrinsically connected. Everyone benefits from the work.

- $\quad$ CBPR involves systems development using a cyclical and iterative process. The development of a CBPR partnership requires constant evaluation and improvement to both the science and to how the partnership functions.

- $\quad C B P R$ focuses on community relevance and on ecological perspectives that attend to the multiple determinants of health and wellbeing. Relevance is defined by the community. Ecological perspectives see whole systems and whole people rather than isolated events, single causes, or individuals without context. Health is broadly defined to include the physical, emotional, economic, and social health of individuals and communities.

- $\quad$ CBPR disseminates results to all partners and involves them in the wider dissemination of results. Research findings are communicated in channels beneficial to all partners; for example, findings may be published in a scholarly journal, released to the lay press, and used as policy points by community advocates.

- CBPR involves a long-term process and commitment to sustainability. CBPR is slow and hard work; however, after the initial effort, a healthy, committed partnership can continue indefinitely as a "learning organization" making pay-off over time well worth the initial investment. 


\section{Appendix B. Gateway Project recruitment announcement}

APPROVED: Aug. 12, 2009

\section{Participate in the AASPIRE Gateway Project}

\section{You could win a $\$ 25$ gift certificate to Amazon.com!}

What is the AASPIRE Gateway Project? The AASPIRE Gateway Project is a series of online research studies on topics such as health care, online sense of community, and problem solving.

Who Can Participate? Anyone who is at least 18 years old and has access to the Internet.

How Do I Participate? The first step is to complete the online AASPIRE Gateway Survey at www. aaspire.org/gateway. The survey takes about 20 minutes and asks about personal information such as age and gender, and personal preferences regarding interests, habits, social interactions.

After finishing the survey, you can enter a drawing for a 1 in 25 chance of winning a \$25 Amazon.com gift certificate. The AASPIRE team will email you whenever new AASPIRE studies are available.

This online research project is conducted by the Academic Autistic Spectrum Partnership in Research and Education (AASPIRE, http:llaaspire.org) in collaboration with Oregon Health \& Science University. the University of WisconsinMadison, Portland State University. and the Autistic Self-Advocacy Network. AASPIRE conducts research that may benefit the lives of people on the autistic spectrum.

OHSU IRB \# 3762; UW IRB\# SE-2008-0749 Christina Nicolaidis, MD, MPH, Oregon Health \& Science University Morton Ann Gemsbacher, PhD, University of Wisconsin-Madison Katherine McDonald, PhD, Portland State University Dora Raymaker, Autistic Self-Advocacy Network
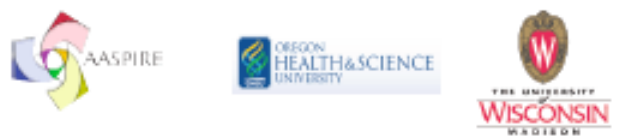

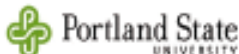

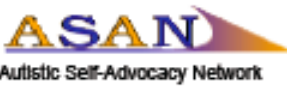




\section{Appendix C. Gateway Project participant information sheet}

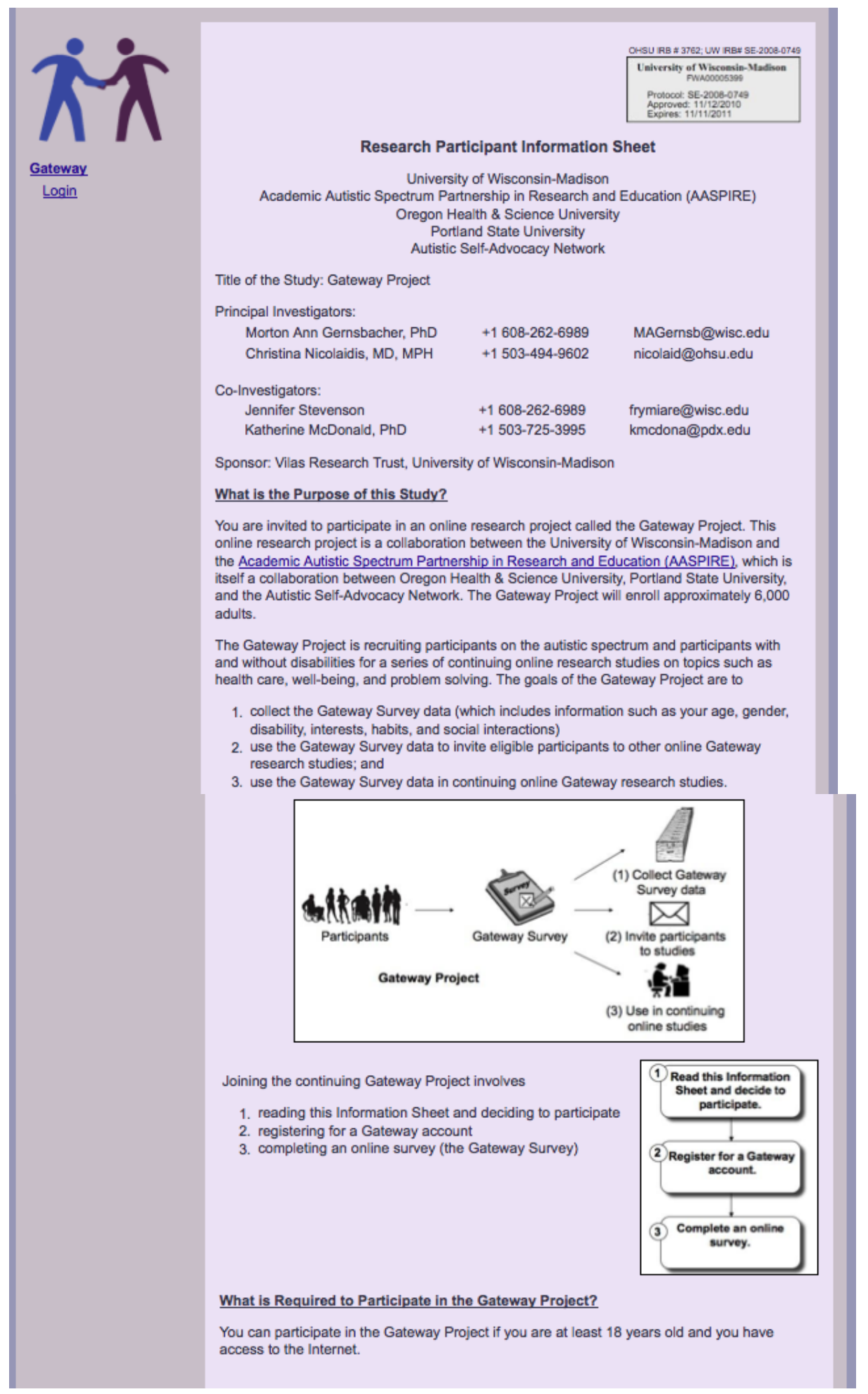


1. After you complete the Gateway Survey, you will be registered for the Gateway Project.

2. You will receive email notifications whenever the Gateway has a new research study that you might be able to participate in. If you want to learn more about the new research study, you will log in with your email address and password. Every time you receive one of these notifications, you will have the option to 'unsubscribe' (withdraw from participating in this ongoing project) so that you do not receive future notifications.

3. You may also receive email notifications if the Gateway investigators learn of a new study that they feel might be of benefit to you.

\section{How Will My Privacy be Protected?}

- The Gateway investigators will not record your Internet Protocol (IP) address.

- The Gateway investigators will use Secure Sockets Layer (SSL) encryption to make sure no one can see the information you are sending through the Internet while it is being sent.

- Any information you provide during your participation in the Gateway Project will always be stored on a password-protected computer. Only the Gateway research team will have access to this information. The Gateway research team includes the Principal Investigators and Co-Investigators listed on this Information Sheet, their research staff, and their graduate and undergraduate students. You can receive a full list of the Gateway research team by emailing info@thegatewayproject.org.

- At any time, you can ask the Gateway investigators to delete the information you provided during your participation in the Gateway Project by contacting info@thegatewayproject.org.

- For every study in the Gateway Project, a code number will be used to link the information you provide in that study to any information that can identify you, such as your email address. Only the Gateway investigators, as listed on this Information Sheet, will be able to link the code numbers to any information that can identify you, such as your email address.

- The Gateway investigators will not use any information that can identify you in publications, presentations, or reports. The Gateway investigators will only publish general information about groups of participants and will never publish individual information about specific participants.

- The Gateway investigators will keep the information you provide during your participation in the Gateway Project indefinitely or until they are asked to destroy it.

What are the Possible Risks of Participating in the Gateway Project?

- There is a small risk of loss of privacy, as described above.

- There is a small risk that you might get frustrated if you have computer or Internet problems.

- There is a small risk that you might get tired or find some of the items in that study difficult to answer. 
What are the Possible Benefits of Participating in the Gateway Project?

- You will not benefit directly from participating in the Gateway Project.

- Your participation might benefit persons on the autistic spectrum or persons with disabilities in the future.

- You may feel satisfied from contributing to research.

Will it Cost Anything to Participate in the Gateway Project?

You do not have to pay anything to participate in the Gateway Project.

Will I Be Compensated for My Participation in the Gateway Project?

For some of the studies in the Gateway Project, you might be compensated directly for participating in that study. If you will be compensated directly for participating in a study, you will be told about the direct compensation prior to your starting the study.

For other studies, you can choose to be entered into a drawing for a gift certificate to Amazon.com. Depending on the length of the study, the amount of the gift certificate and the odds of winning the certificate will vary. However, if you withdraw from the study before completing the study, you will not be eligible to enter the drawing for a gift certificate.

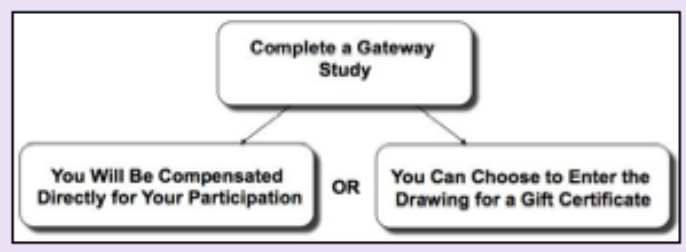

For the first study, the Gateway Survey, you can choose to be entered into a drawing for a \$25 gift certificate to Amazon.com. A random winner will be chosen after each group of 25 participants has completed the Gateway Survey, so your chances of winning this drawing will be 1 in 25 .

If you are an undergraduate student at the University of Wisconsin-Madison, you may choose to receive 1 extra credit point in your introductory psychology class for participating in some of the studies in the Gateway Project, including the Gateway Survey. If you choose to receive extra credit, you may not enter into the drawing for a gift certificate.

\section{What Are My Rights as a Research Participant in the Gateway Project?}

Your participation in the Gateway Project is completely voluntary. You are not required to participate in the Gateway Project. If you do decide to participate in the Gateway Project, and you later change your mind, you may quit at any time. 


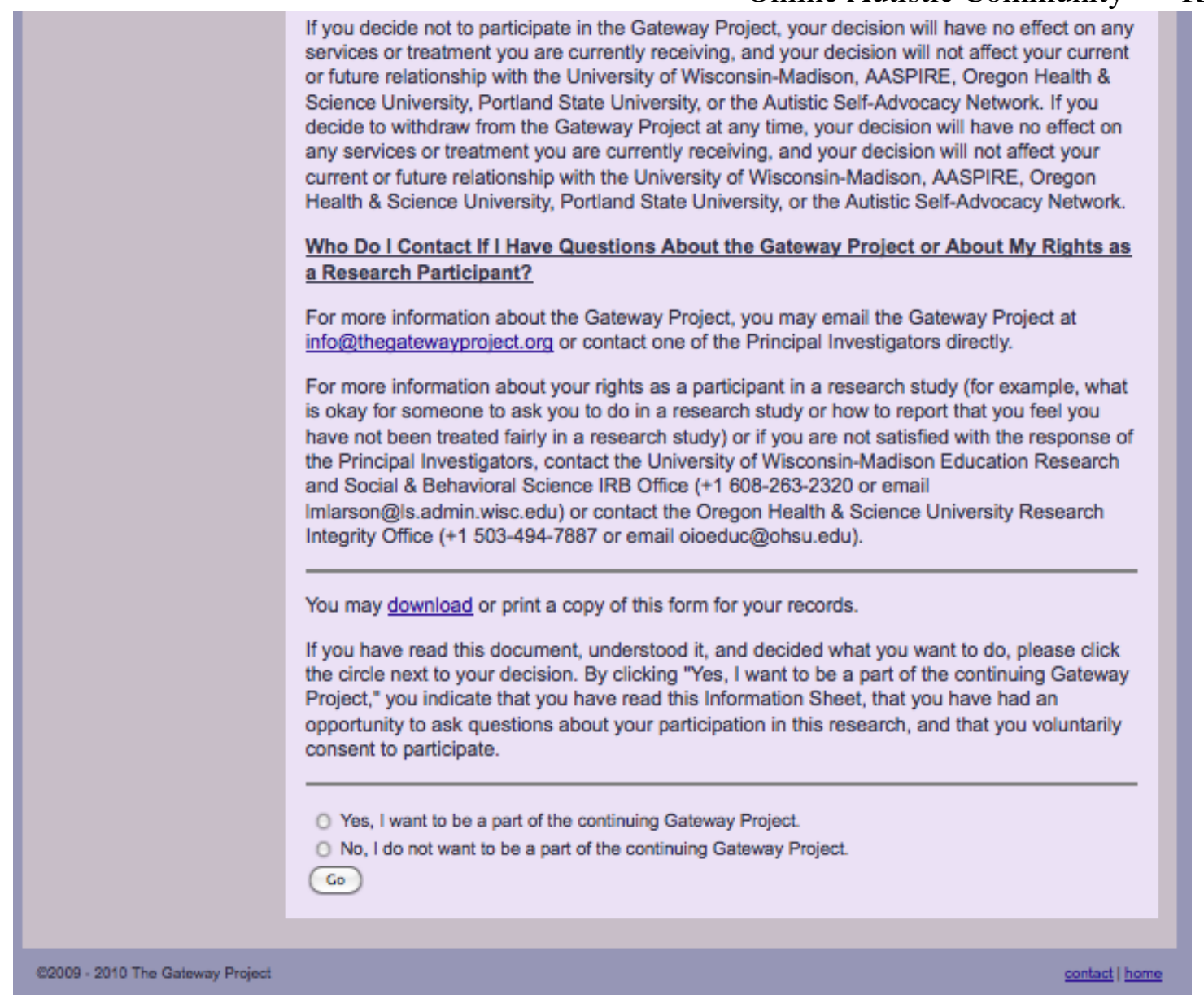




\section{Appendix D. Gateway Survey}

Appendix D was removed November 2014 per a request from Ursinus College and the University of Wisconsin-Madison. 


\section{Appendix E. AASPIRE Internet Use, Community, and Well-Being Study general}

\section{recruitment flyer}

\section{Will You Help with a Research Project? You could win a gift certificate to Amazon.com}

The Academic Autistic Spectrum Partnership in Research and Education (AASPIRE) and the Gernsbacher Lab have created the Gateway Project. The project serves as a gateway for research that is committed to inclusion, respect, accessibility, and community relevance.

Gateway studies address topics such as healthcare experiences and problem-solving. A new Gateway study focuses on Internet use and well-being, including feelings about connecting with other people via the Internet and social support. AASPIRE expects to use the information learned from the AASPIRE Internet Use, Community and Well-Being study to understand how involvement in online communities may benefit individuals.

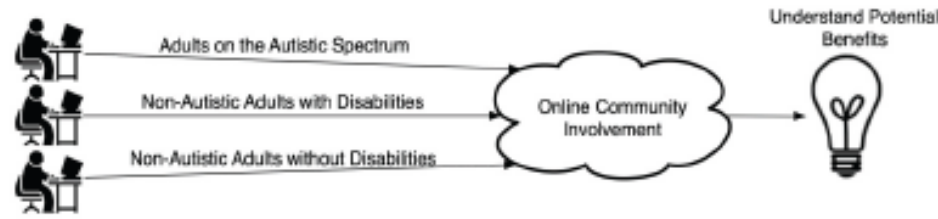

To participate in the AASPIRE Internet Use, Community and Well-Being Study and any of the Gateway Project studies:

1. Register online for a Gateway account starting at http//www.thegatewayproject.org

2. Take the online Gateway Survey. The survey takes about 20-40 minutes to complete.

3. Wait for email messages about further studies. You may be eligible for some studies and not for others. You will only receive email messages for studies for which you are eligible.

4. If you are eligible for the Internet Use, Community and Well-Being Study and decide to participate, it will take about $\mathbf{4 0}$ minutes to complete.

5. After finishing each survey, you can enter a drawing for an Amazon.com gift certificate.

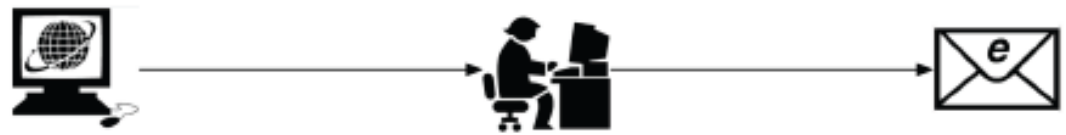

Register with the Gateway

Take the Gateway Survey

Receive a notification if you are

lound to be eligible for the

AASPIRE Well-Being Study

Completing the survey entitles you to a 1 in 15 chance to win a \$25 Amazon.com gift certificate.

If you would like to learn more about the AASPIRE Internet Use, Community, \& Well-Being Study or or the Gateway Project

Th. Go to the AASPIRE Well-Being Study page at http://aaspire.org/wellbeing

Send an email to Dora Raymaker at dora@aaspire.org

TMake a telephone call to Dr. Christina Nicolaidis at 1-503-494-9602

OHSU IRB \# 5588

Principal Investigators: $\quad$ Christina Nicolaidis, MD, MPH, Oregon Health \& Science University Katherine McDonald, PhD, Portland State University Dora Raymaker, MS, Autistic Self-Advocacy Network

Please pass this information along to your friends!

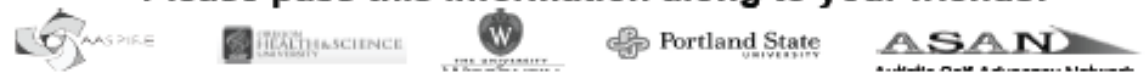




\section{Appendix F. AASPIRE Internet Use, Community, and Well-Being Study participant}

\section{information sheet}

Please read the Information Sheet below describing the AASPIRE Internet Use, Community and Well-Being study. You may also download a PDF of the information sheet for your records.

\section{AASPIRE Internet Use, Community and Well-Being INFORMATION SHEET}

IRBH: 5568

Protocol Approval Date: 4/19/2010

\section{OREGON HEALTH \& SCIENCE UNIVERSITY} Participant Information Sheet

Title of the Study: AASPIRE Internet Use, Community and Well-Being

Principal Investigators

Christina Nicolaidis, MD, MPH (Oregon

Health \& Science University)

+1 503-494-9602_nicolaid@ohsu.edu

Katherine McDonald, PhD (Portland State

University)

+1 503-725-3995 kmcdona@pdx.edu

Dora Raymaker, MS (Autistic Self

Advocacy Network)

Co-Investigators

$\begin{array}{lll}\text { Colleen Kidney (Portland State University) } & +1503-725-3962 & \text { ckidney@pdx.edu } \\ \text { Aubrey Perry (Portland State University) } & +1503-725-3962 & \text { awperry@pdx.edu }\end{array}$

Community Partners:

Elesia Ashkenazy, Cody Boisclair, and Sebastian Dern

Sponsor: Portland State University Faculty Enhancement Grant

What is the purpose of this Information Sheet?

The purpose of this Information Sheet is to give you details about a research study called the AASPIRE Internet Use, Community and Well-Being Study. You are invited to participate in this study as part of the Gateway Project.

When you originally agreed to participate in the Gateway Project, you read the Gateway Project Information Sheet. The information provided below only discusses details that specifically relate to the AASPIRE Internet Use, Community and Well-Being Study.

What is the purpose of this study?

The purpose of this online survey is to compare the experiences with Internet use, online communities, well-being, and socia support of three groups of adults: autistic adults, adults with other disabilities, and adults without disabilities. The study will enroll 600 participants. 


\section{Online Autistic Community}

\section{What can I expect as a participant?}

Most of the survey questions are in multiple choice formats, with some of the questions giving you the option to write in an answer. They survey questions cover various topics related to Internet use and well-being such as Internet use, identity, sense of community, well-being, and social support. This online survey takes between 20 and 40 minutes to complete.

\section{Will it cost anything to participate?}

It does not cost anything to participate. After completing the online survey, you will be entered into a drawing with a 1 in 15 chance of winning a $\$ 25$ e-certificate to Amazon.com.

How can I review information about participating in the Gateway Project?

Other important information related to your participation in this study was previously described in the Gateway Project Information Sheet and has not changed. If you would like to review that information, you can re-read the entire Gateway Project Information Sheet or you can re-read the sections called

- How will my privacy be protected?

- What are the Possible Risks of Participating in the Gateway Project?

- What are the Possible Benefits of Participating in the Gateway Project?

- What Are My Rights as a Research Participant in the Gateway Project?

For more information about this study contact Katherine McDonald at +1 503-725-3995 or kmcdona@pdx.edu or Dora Raymaker at dora@aaspireproject.org.

For more information about your rights as a participant in a research study at OHSU, contact the OHSU Research Integrity Office at +1877-733-8313 (toll free) or oioeduc@ohsu.edu.

You may download a copy of the information sheets for your records. To do so, use the links below.

- AASPIRE Internet Use, Community and Well-Being Study Information Sheet

- Gateway Project Information Sheet

If you have read this document, understood it, and decided what you want to do, please click the circle next to your decision. By clicking "Yes, I want to participate," you indicate that you have read this Information Sheet, that you have had an opportunity to ask questions about your participation in this research, and that you voluntarily consent to participate.

OYes, I want to participate.

No, I do not want to participate.

(C) 


\section{Appendix G. AASPIRE Internet Use, Community, and Well-Being Survey}

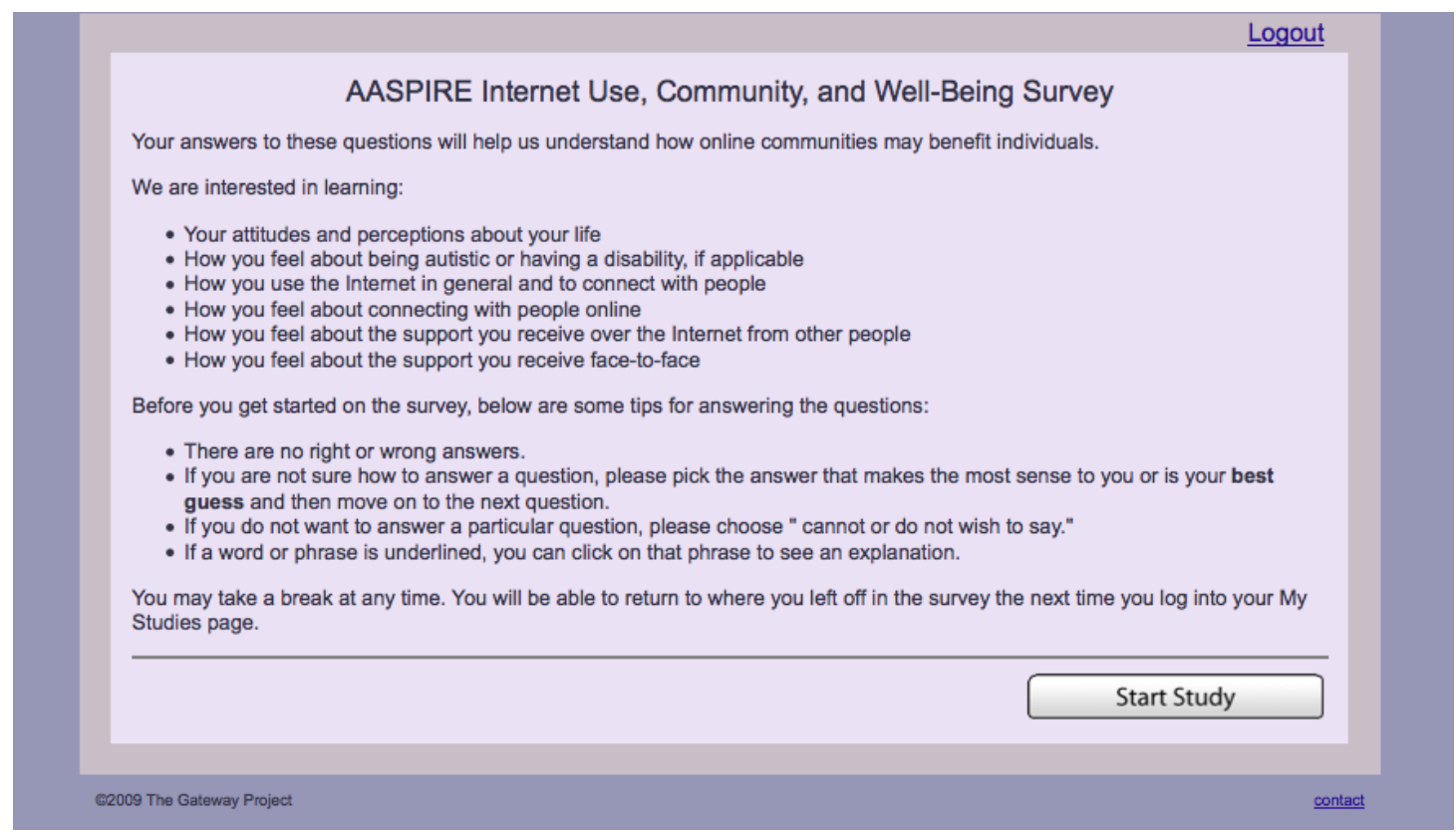


SECTION 1: UPDATE YOUR INFORMATION. The next 3 items ask you to update the information you provided when you completed the Gateway Survey, such as the type of Internet connection and computer you are currently using to complete this study.
The Internet
O DSL
() cable modem
O satellite
public WiFi
- T1 or other fiber optic connection
cell phone network
other
cannot or do not wish to say

The computer or device I am currently using to access the Internet is

(-) my own computer

a shared computer where I live

a public computer (e.g., library, school)

a computer where I work

$O$ a mobile phone or PDA

$O$ other

cannot or do not wish to say

The space in which I am currently using the Internet is

o a private space with no other people around me (for example, in a room alone)

( $)$ a semi-private space with only a couple of other people around me (for example, in a shared office)

o public space with several people around me (for example, in a coffee shop)

o cannot or do not wish to say 
SECTION 2: ATTITUDES AND PERCEPTIONS. This next section asks about how you feel about yourself and your life. Please indicate how much you agree or disagree with each of the 27 statements.

I am not afraid to voice my opinions, even when they are in opposition to the opinions of most people.

Strongly Moderately

Disagree Disagre

Slightly Disagree Slightly Agree Moderately Agree Strongly Agree

$\odot$

O

O

o

o Cannot or do not wish to say

In general, I feel I am in charge of the situation in which I live.

Strongly Moderately

Disagree Disagree

a

Disagre

Slightly Disagree Slightly Agree Moderately Agree Strongly Agree

Cannot or do not wish to say

When I look at the story of my life, I am pleased with how things have turned out.
Strongly Moderately
Disagree Disagre
Slightly Disagree Slightly Agree Moderately Agree Strongly Agree
O
○ 0
C
O
○

O Cannot or do not wish to say

My decisions are not usually influenced by what everyone else is doing.

$\begin{array}{lcc}\text { Strongly } & \text { Moderately } & \text { Slightly Disagree Slightly Agree Moderately Agree Strongly Agree } \\ \text { Disagree } & \text { Disagree }\end{array}$

0 e 0 - 0

- Cannot or do not wish to say

The demands of everyday life often get me down.

Strongly Moderately

Disagree Disagree

Slightly Disagree Slightly Agree Moderately Agree Strongly Agree

not wish to say

O Cannot or do not wish to say

In general, I feel confident and positive about myself.

$\begin{array}{ccc}\text { Strongly } & \text { Moderately } \\ \text { Disagree } & \text { Disagree } & \text { Slightly Disagree Slightly Agree Moderately Agree Strongly Agree }\end{array}$

$\odot$

○ 0

O

0

Cannot or do not wish to say

I tend to worry about what other people think of me.
Strongly Moderately
Disagree Disagree
$\odot$
Slightly Disagree Slightly Agree Moderately Agree Strongly Agree
o
c
o
O
○

Cannot or do not wish to say

I do not fit very well with the people and the community around me.

Strongly Moderately

Disagree Disagree

Slightly Disagree Slightly Agree Moderately Agree Strongly Agree

( $)$

o

0

○

Cannot or do not wish to say

I feel like many of the people I know have gotten more out of life than I have.

$\begin{array}{ccc}\text { Strongly } & \text { Moderately } \\ \text { Disagree } & \text { Disagree } & \text { Slightly Disagree Slightly Agree Moderately Agree Strongly Agree }\end{array}$

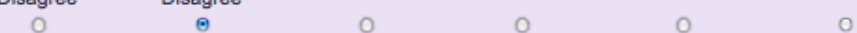

o Cannot or do not wish to say

You have completed $2 \%$ of the AASPIRE Internet Use, Community, and Well-Being Survey(A).

You may take a break at any time.

Go back to Previous PAGE

You can Go Back to Previous PAGE,

but responses on this page won't be saved. 


\begin{tabular}{|c|c|c|c|c|c|}
\hline Help & & & & & Logout \\
\hline \multicolumn{6}{|c|}{ SECTION 2: ATTITUDES AND PERCEPTIONS } \\
\hline \multicolumn{6}{|c|}{ Being happy with myself is more important to me than having others approve of me. } \\
\hline $\begin{array}{c}\text { Strongly } \\
\text { Disagree }\end{array}$ & $\begin{array}{c}\text { Moderately } \\
\text { Disagree }\end{array}$ & Slightly Disagree & Slightly Agree & Moderately Agree & Strongly Agree \\
\hline 0 & $\odot$ & 0 & o & 0 & o \\
\hline
\end{tabular}

I am quite good at managing the many responsibilities of my daily life.

$\begin{array}{cccccc}\text { Strongly } & \text { Moderately } & \text { Slightly Disagree } & \text { Slightly Agree } & \text { Moderately Agree } & \text { Strongly Agree } \\ \text { Disagree } & \text { Disagree } & 0 & 0 & 0 & 0\end{array}$

Cannot or do not wish to say

I like most aspects of my personality. Strongly Moderately Disagree Disagree O 0

Slightly Disagree Slightly Agree Moderately Agree Strongly Agree $0 \quad 0 \quad 0 \quad 0$

Cannot or do not wish to say

I tend to be influenced by people with strong opinions.
Strongly
Moderately
Disagree
Slightly Disagree Slightly Agree Moderately Agree Strongly Agree
Disagree
$\odot$
○
○
○
O

Cannot or do not wish to say

I often feel overwhelmed by my responsibilities.

$\begin{array}{lccc}\text { Strongly } & \text { Moderately } & \text { Slightly Disagree Slightly Agree Moderately Agree Strongly Agree } \\ \text { Disagree } & \text { Disagree }\end{array}$

Disagree Disagree

$\odot$

O

0

0

○

Cannot or do not wish to say

I made some mistakes in the past, but I feel that all in all everything has worked out for the best.

$\begin{array}{lc}\text { Strongly } & \text { Moderately } \\ \text { Disagree } & \text { Disagree }\end{array}$

Cannot or do not wish to say

o 0

O $O$

0

$\odot$ ly Agree

○ 
Online Autistic Community

I have confidence in my opinions, even if they are contrary to the general consensus.

$\begin{array}{ccc}\text { Strongly } & \text { Moderately } & \text { Slightly Disagree Slightly Agree Moderately Agree Strongly Agree } \\ \text { Disagree } & \text { Disagree }\end{array}$

0000000

Cannot or do not wish to say

I generally do a good job of taking care of my personal finances and affairs.

Strongly Moderately

Disagree Disagree

Slightly Disagree Slightly Agree Moderately Agree Strongly Agree

(1)

$\odot$

o 0

0

0 O

- Cannot or do not wish to say

In many ways, I feel disappointed about my achievements in life.

$\begin{array}{ccc}\text { Strongly } & \text { Moderately Slightly Disagree Slightly Agree Moderately Agree Strongly Agree } \\ \text { Disagree } & \text { Disagree }\end{array}$

$\begin{array}{llllll}0 & 0 & 0 & 0 & 0\end{array}$

Cannot or do not wish to say

Copyright @ 1989, 2008 Ryff. All rights reserved. Reproduced under license.

You have completed $9 \%$ of the AASPIRE Internet Use, Community, and

Well-Being Survey(A).

You may take a break at any time.

Go back to Previous PAGE

You can Go Back to Previous PAGE,

but responses on this page won't be saved.

E2009 The Gateway Project

contact

\section{Help}

(1)

$\underline{\text { Logout }}$

Go to Next PAGE

\section{SECTION 2: ATTITUDES AND PERCEPTIONS}

Being happy with myself is more important to me than having others approve of me.

$\begin{array}{lccl}\text { Strongly } & \text { Moderately } \\ \text { Disagree } & \text { Disagree } & \text { Slightly Disagree Slightly Agree Moderately Agree Strongly Agree }\end{array}$

0

0

0

0

○

O Cannot or do not wish to say

I am quite good at managing the many responsibilities of my daily life.

$\begin{array}{lcc}\text { Strongly } & \text { Moderately Slightly Disagree Slightly Agree Moderately Agree Strongly Agree } \\ \text { Disagree } & \text { Disagree }\end{array}$
c
$\odot \quad 0$
o
o
c

- Cannot or do not wish to say

I like most aspects of my personality.

$\begin{array}{lccl}\text { Strongly } & \text { Moderately } \\ \text { Disagree } & \text { Disagree } & \text { Slightly Disagree Slightly Agree Moderately Agree Strongly Agree }\end{array}$

0

0

(e)

Cannot or do not wish to say

I tend to be influenced by people with strong opinions.

$\begin{array}{lcc}\text { Strongly } & \text { Moderately } \\ \text { Disagree } & \text { Disagree } & \text { Slightly Disagree Slightly Agree Moderately Agree Strongly Agree }\end{array}$

$\begin{array}{ccccc}0 & \text { Disagree } & 0 & 0 & 0\end{array}$

Cannot or do not wish to say

I often feel overwhelmed by my responsibilities.

$\begin{array}{lccl}\text { Strongly } & \text { Moderately } & \text { Slightly Disagree Slightly Agree Moderately Agree Strongly Agree } \\ \text { Disagree } & \text { Disagree }\end{array}$

$\begin{array}{llllll}0 & \odot & 0 & 0 & 0 & 0\end{array}$

O Cannot or do not wish to say

I made some mistakes in the past, but I feel that all in all everything has worked out for the best.

Strongly Moderately

Disagree Disagree

0 o

Slightly Disagree Slightly Agree Moderately Agree Strongly Agree

o Cannot or do not wish to say 
Online Autistic Community

I have confidence in my opinions, even if they are contrary to the general consensus.

Strongly Moderately

Disagree Disagree

Slightly Disagree Slightly Agree Moderately Agree Strongly Agree

O

$\odot$

0

o

O

0

o Cannot or do not wish to say

I generally do a good job of taking care of my personal finances and affairs

Strongly Moderately

Disagree Disagree

Slightly Disagree Slightly Agree Moderately Agree Strongly Agree

o

○

○

o

- Cannot or do not wish to say

In many ways, I feel disappointed about my achievements in life.

Strongly Moderately

Disagree Disagree

Slightly Disagree Slightly Agree Moderately Agree Strongly Agree

o

o

O

O Cannot or do not wish to say

Copyright (-) 1989, 2008 Ryff. All rights reserved. Reproduced under license.

You have completed $9 \%$ of the AASPIRE Internet Use, Community, and Well-Being Survey(A).

You may take a break at any time.

Go back to Previous PAGE

You can Go Back to Previous PAGE,

but responses on this page won't be saved.

Go to Next PAGE 
Online Autistic Community

\begin{tabular}{|c|c|c|c|c|c|}
\hline Help & & & & & $\underline{\text { Logout }}$ \\
\hline \multicolumn{6}{|c|}{ SECTION 2: ATTITUDES AND PERCEPTIONS } \\
\hline \multicolumn{6}{|c|}{ It's difficult for me to voice my own opinions on controversial matters. } \\
\hline $\begin{array}{l}\text { Strongly } \\
\text { Disagree }\end{array}$ & $\begin{array}{c}\text { Moderately } \\
\text { Disagree }\end{array}$ & Slightly Disagree & Slightly Agree & Moderately Agree & Strongly Agree \\
\hline 0 & $\odot$ & 0 & 0 & 0 & 0 \\
\hline \multicolumn{6}{|c|}{ Cannot or do not wish to say } \\
\hline \multicolumn{6}{|c|}{ I am good at juggling my time so that I can fit everything in that needs to get done. } \\
\hline $\begin{array}{l}\text { Strongly } \\
\text { Disagree }\end{array}$ & $\begin{array}{l}\text { Moderately } \\
\text { Disagree }\end{array}$ & Slightly Disagree & Slightly Agree & Moderately Agree & Strongly Agree \\
\hline Cannot or do not wis & $\odot$ & 0 & 0 & 0 & 0 \\
\hline
\end{tabular}

My attitude about myself is probably not as positive as most people feel about themselves.
Strongly Moderately
Disagree Disagree
Slightly Disagree Slightly Agree Moderately Agree Strongly Agree
$\odot \quad 0 \quad 0$
○

Cannot or do not wish to say

I often change my mind about decisions if my friends or family disagree.

$\begin{array}{ccc}\text { Strongly } & \text { Moderately } & \text { Slightly Disagree Slightly Agree Moderately Agree Strongly Agree } \\ \text { Disagree } & \text { Disagree }\end{array}$

Cannot or do not wish to say

$\odot$

0

o

I have difficulty arranging my life in a way that is satisfying to me.

Strongly Moderately

Disagree Disagree

Slightly Disagree Slightly Agree Moderately Agree Strongly Agree

$\odot$

○

O

O

O

Cannot or do not wish to say

The past had its ups and downs, but in general, I wouldn't want to change it.

$\begin{array}{lcc}\text { Strongly } & \text { Moderately } & \text { Slightly Disagree Slightly Agree Moderately Agree Strongly Agree } \\ \text { Disagree } & \text { Disagree }\end{array}$

000

- Cannot or do not wish to say 
Online Autistic Community

I judge myself by what I think is important, not by the values of what others think is important.

Strongly Moderately

Disagree Disagree

Slightly Disagree Slightly Agree Moderately Agree Strongly Agree

(

O

○

O Cannot or do not wish to say

I have been able to build a home and a lifestyle for myself that is much to my liking.

Strongly Moderately

Disagree Disagree

Slightly Disagree Slightly Agree Moderately Agree Strongly Agree

$\odot$

o 0

o 0

O

Cannot or do not wish to say

When I compare myself to friends and acquaintances, it makes me feel good about who I am.
Strongly Moderately
Disagree
Slightly Disagree Slightly Agree Moderately Agree Strongly Agree
Disagree

0
0
O 0
○
9

Cannot or do not wish to say

Copyright (ㄷ) 1989, 2008 Ryff. All rights reserved. Reproduced under license.

Copyright (a) 1989, 2008 Ryff. All rights reserved. Reproduced under license.
You have completed $15 \%$ of the AASPIRE Internet Use, Community, and
Well-Being Survey(A).
You may take a break at any time.

Go back to Previous PAGE

Go to Next PAGE

You can Go Back to Previous PAGE,

but responses on this page won't be saved.

SECTION 3: AUTISTIC IDENTITY. This next section will ask about attitudes that either you or other people may have toward people on the autistic spectrum. Please indicate how much you agree or disagree with each of the 18 statements.

I believe that because I am a person on the autistic spectrum, I have many strengths

Strongly Disagree $0 \circ \bigcirc \odot 0 \circ$ Strongly Agree

O Cannot or do not wish to say

I often regret that I am a person on the autistic spectrum.

Strongly Disagree $\bigcirc \circ \circ \odot 0_{0} \circ$ Strongly Agree

o Cannot or do not wish to say

Overall, people on the autistic spectrum are considered valuable by others.

Strongly Disagree $0 \circ \bigcirc \odot 0 \circ$ Strongly Agree

O Cannot or do not wish to say

Overall, being a person on the autistic spectrum has very little to do with how I feel about myself.

Strongly Disagree $0 \quad 0 \quad 0 \quad 0 \quad 0 \quad 0 \quad$ Strongly Agree

(-) Cannot or do not wish to say

I feel that people on the autistic spectrum have made major accomplishments and advancements.

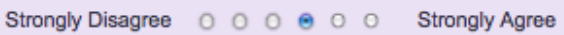

Cannot or do not wish to say

I am happy to be a person on the autistic spectrum.

Strongly Disagree $0 \circ \bigcirc \odot 0 \quad 0 \quad$ Strongly Agree

o Cannot or do not wish to say 
In general, being a person on the autistic spectrum is an important part of my self-image.

Strongly Disagree $0 \circ 00 \odot 0$ Strongly Agree

o Cannot or do not wish to say

I have a strong sense of belonging to the autistic community.

Strongly Disagree $0 \circ 00 \odot 0$ Strongly Agree

O Cannot or do not wish to say

I almost never tell people I am a person on the autistic spectrum.

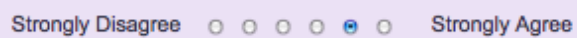

Cannot or do not wish to say

Copyright (ㄷ) 1997 Chicago Center for Disability Research (Dr. Carol Gill). All rights reserved. Reproduced under license.

You have completed $28 \%$ of the AASPIRE Internet Use, Community, and Well-Being Survey(A).

You may take a break at any time.

Go back to Previous PAGE

Go to Next PAGE

You can Go Back to Previous PAGE,

but responses on this page won't be saved.

C2009 The Gateway Project

SECTION 4: INTERNET USAGE. This next section includes items that ask you about computer use, Internet access, and use of online communities. Online communities are groups of people who communicate with each other regularly over the Internet and share some common interests, goals, activities, and/or identity.

I prefer to communicate with other autistic people

0 over the Internet.

(e face-to-face.

$O$ other

O I have no preference.

O Cannot or do not wish to say.

I prefer to communicate with non-autistic people

o over the Internet.

(e) face-to-face.

$O$ other

O I have no preference.

o Cannot or do not wish to say.

In the past six months, I used the Internet to socialize, interact, exchange information, coordinate events, or participate in any activity that involved interacting with other people over the Internet

o never.

less than once a month.

(2) at least once a month but less than once a week

$O$ at least once a week but less than once a day.

O less than one hour daily.

o 1-3 hours daily.

3-6 hours daily.

O more than 6 hours daily.

o Cannot or do not wish to say.

You have completed $34 \%$ of the AASPIRE Internet Use, Community, and Well-Being Survey(A).

You may take a break at any time. 


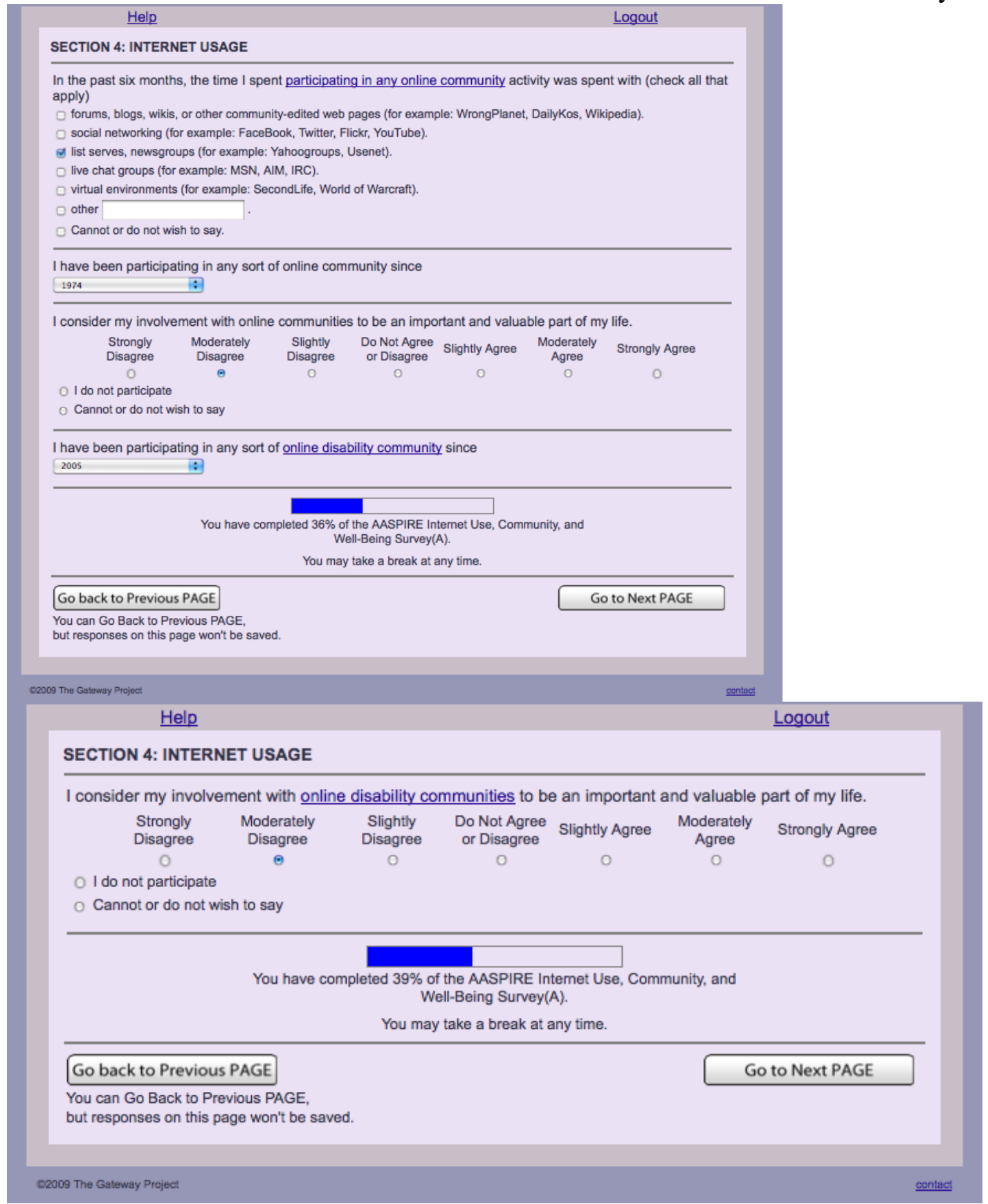




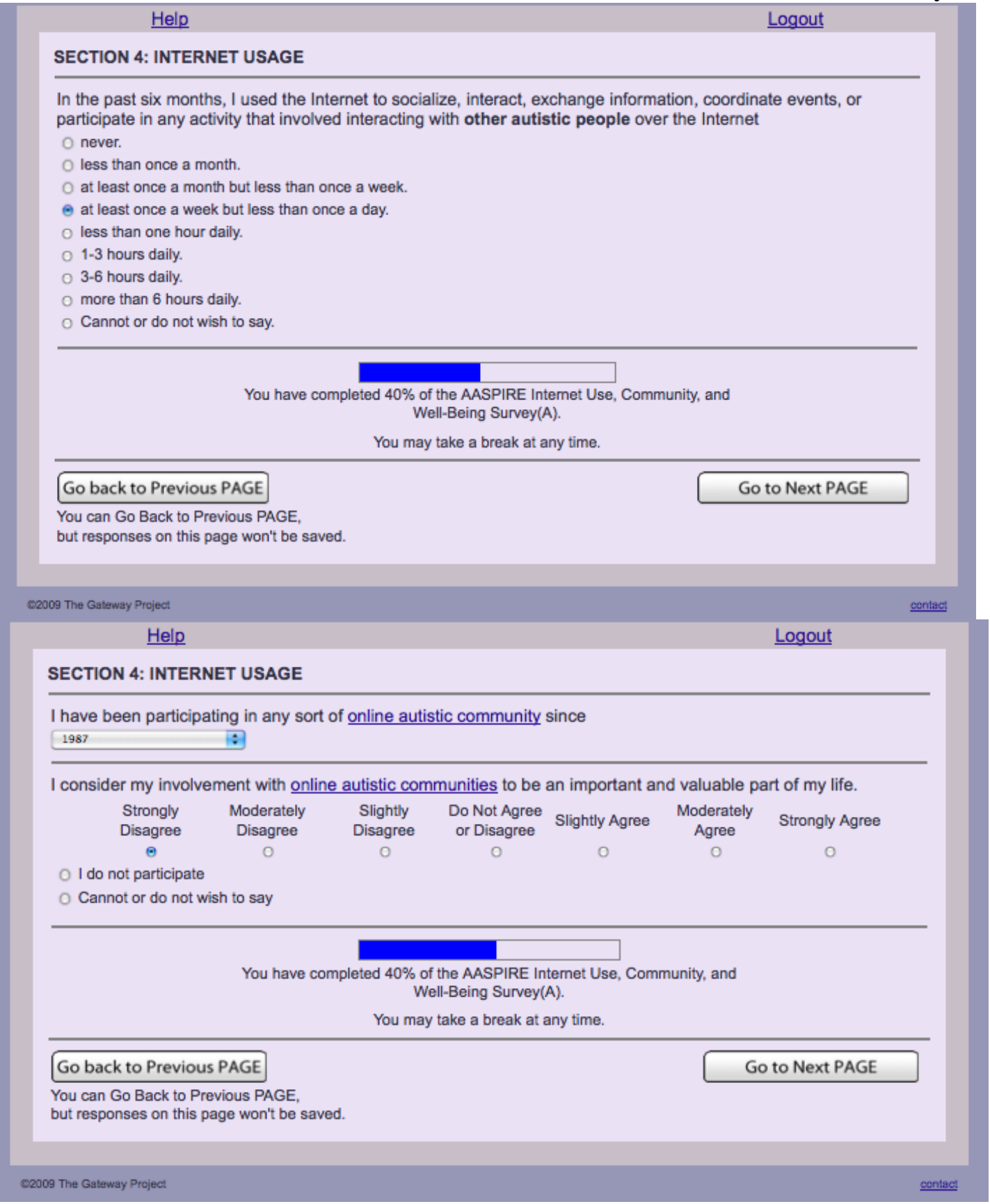


SECTION 5: SENSE OF COMMUNITY INDEX. This next section includes 25 items about the online autistic community. The online autistic community may be composed primarily of people on the autism spectrum (such as WrongPlanet, the LiveJournal Aspergers community, or the AutisticSpectrumTreehouse yahoo group, alt.support.autism news group), or may have a common purpose that is specifically related to autistic advocacy (such as the Autistic Self Advocacy Network yahoo group, the AutismHub blog group, or the PosAutive YouTube community). Think about the community as the aspects of online autistic community in which you feel most involved.

How important is it to you to feel a sense of community with other community members?

Prefer not to be a part
of this community Not at all important Somewhat important Important Very important
0 ○

Cannot or do not wish to say

Copyright () 2008 Chavis, Lee, and Acosta. All rights reserved. Reproduced under license.

You have completed $42 \%$ of the AASPIRE Internet Use, Community, and Well-Being Survey(A).

You may take a break at any time.

Go back to Previous PAGE

Go to Next PAGE

You can Go Back to Previous PAGE,

but responses on this page won't be saved.

\section{SECTION 5: SENSE OF COMMUNITY INDEX}

How well does each of the following statements represent how you feel about this community? Indicate the extent to which you agree with each of the statements.

I get important needs of mine met because I am part of this community.
Do not agree at all
Somewhat agree
Mostly agree
Completely agree
(ै)

o 0
o

Cannot or do not wish to say

Community members and I value the same things.
Do not agree at all
Somewhat agree
Mostly agree
0
Completely agree

O Cannot or do not wish to say

This community has been successful in getting the needs of its members met.
Do not agree at all
Somewhat agree
Mostly agree
Completely agree
e
o

Cannot or do not wish to say

Being a member of this community makes me feel good.

$\begin{array}{cccc}\text { Do not agree at all } & \text { Somewhat agree } & \text { Mostly agree } & \text { Completely agree }\end{array}$

o Cannot or do not wish to say

When I have a problem, I can talk about it with members of this community.

$\begin{array}{cccc}\text { Do not agree at all } & \text { Somewhat agree } & \text { Mostly agree } & \text { Completely agree } \\ \odot & 0 & 0 & 0\end{array}$

Cannot or do not wish to say

People in this community have similar needs, priorities, and goals.
Do not agree at all
Somewhat agree
Mostly agree
Completely agree
O
○

$\odot$

O Cannot or do not wish to say 
I can trust people in this community.

Do not agree at all

$$
\text { e }
$$

Cannot or do not wish to say
Somewhat agree

0
Mostly agree

0
Completely agree

I can recognize most of the members in this community.
Do not agree at all
Somewhat agree
Mostly agree
O
Completely agree

Cannot or do not wish to say

Most community members know me.

Do not agree at all

e

Somewhat agree

0

Mostly agree

0

Completely agree

o

O Cannot or do not wish to say

This community has symbols and expressions of membership such as clothes, signs, art, architecture, logos, landmarks, and flags that people can recognize.
Do not agree at all
Somewhat agree
Mostly agree
o
Completely agree
$\odot$
o
o

Cannot or do not wish to say

I put a lot of time and effort into being part of this community.

$\begin{array}{cccc}\text { Do not agree at all } & \text { Somewhat agree } & \text { Mostly agree } & \text { Completely agree } \\ \odot & 0 & 0 & 0\end{array}$

Cannot or do not wish to say

Being a member of this community is a part of my identity.

Do not agree at all Somewhat agree Mostly agree Completely agree

$\odot$

○

O

o

Cannot or do not wish to say

Copyright $@ 2008$ Chavis, Lee, and Acosta. All rights reserved. Reproduced under license.

You have completed $43 \%$ of the AASPIRE Internet Use, Community, and Well-Being Survey(A).

You may take a break at any time. 


\begin{tabular}{|c|c|c|c|}
\hline Help & & & Logout \\
\hline \multicolumn{4}{|c|}{ SECTION 5: SENSE OF COMMUNITY INDEX } \\
\hline \multicolumn{4}{|c|}{ Fitting into this community is important to me. } \\
\hline Do not agree at all & Somewhat agree & Mostly agree & Completely agree \\
\hline$\odot$ & 0 & 0 & 0 \\
\hline \multicolumn{4}{|l|}{ Cannot or do not wish to say } \\
\hline \multicolumn{4}{|c|}{ This community can influence other communities. } \\
\hline Do not agree at all & Somewhat agree & Mostly agree & Completely agree \\
\hline$\odot$ & 0 & o & 0 \\
\hline \multicolumn{4}{|l|}{ Cannot or do not wish to say } \\
\hline \multicolumn{4}{|c|}{ I care about what other community members think of me. } \\
\hline Do not agree at all & Somewhat agree & Mostly agree & Completely agree \\
\hline$\Theta$ & 0 & o & 0 \\
\hline \multicolumn{4}{|l|}{ Cannot or do not wish to say } \\
\hline \multicolumn{4}{|c|}{ I have influence over what this community is like. } \\
\hline Do not agree at all & Somewhat agree & Mostly agree & Completely agree \\
\hline$\odot$ & 0 & 0 & 0 \\
\hline \multicolumn{4}{|l|}{ Cannot or do not wish to say } \\
\hline \multicolumn{4}{|c|}{ If there is a problem in this community, members can get it solved. } \\
\hline Do not agree at all & Somewhat agree & Mostly agree & Completely agree \\
\hline$\odot$ & 0 & 0 & 0 \\
\hline \multicolumn{4}{|l|}{ Cannot or do not wish to say } \\
\hline \multicolumn{4}{|l|}{ This community has good leaders. } \\
\hline Do not agree at all & Somewhat agree & Mostly agree & Completely agree \\
\hline$\odot$ & 0 & 0 & 0 \\
\hline \multicolumn{4}{|l|}{ O Cannot or do not wish to say } \\
\hline \multicolumn{4}{|c|}{ It is very important to me to be a part of this community. } \\
\hline Do not agree at all & Somewhat agree & Mostly agree & Completely agree \\
\hline$\odot$ & 0 & 0 & 0 \\
\hline Cannot or do not wish to say & & & \\
\hline
\end{tabular}


Online Autistic Community

I can trust people in this community.

Do not agree at all

Somewhat agree

Mostly agree

0

Completely agree

Cannot or do not wish to say

c

I can recognize most of the members in this community.
Do not agree at all
Somewhat agree
Mostly agree
Completely agree
$\odot$
o
o

Cannot or do not wish to say

Most community members know me.

Do not agree at all

Somewhat agree

O

Mostly agree

0

Completely agree

$$
\odot
$$

O Cannot or do not wish to say

This community has symbols and expressions of membership such as clothes, signs, art, architecture, logos, landmarks, and flags that people can recognize.
Do not agree at all
Somewhat agree
Mostly agree
0
Completely agree
$\odot$
o

O Cannot or do not wish to say

I put a lot of time and effort into being part of this community.

$\begin{array}{cccc}\text { Do not agree at all } & \text { Somewhat agree } & \text { Mostly agree } & \text { Completely agree } \\ \odot & 0 & 0 & 0\end{array}$

- Cannot or do not wish to say

Being a member of this community is a part of my identity. Do not agree at all Somewhat agree Mostly agree

Completely agree $\Theta$

O

0

o

Cannot or do not wish to say

Copyright $@ 2008$ Chavis, Lee, and Acosta. All rights reserved. Reproduced under license.

You have completed $43 \%$ of the AASPIRE Internet Use, Community, and Well-Being Survey(A).

You may take a break at any time. 


\begin{tabular}{|c|c|c|c|}
\hline Help & & & Logout \\
\hline \multicolumn{4}{|c|}{ SECTION 5: SENSE OF COMMUNITY INDEX } \\
\hline \multicolumn{4}{|c|}{ Fitting into this community is important to me. } \\
\hline Do not agree at all & Somewhat agree & Mostly agree & Completely agree \\
\hline$\odot$ & 0 & 0 & 0 \\
\hline \multicolumn{4}{|l|}{ Cannot or do not wish to say } \\
\hline \multicolumn{4}{|c|}{ This community can influence other communities. } \\
\hline Do not agree at all & Somewhat agree & Mostly agree & Completely agree \\
\hline$\odot$ & 0 & o & 0 \\
\hline \multicolumn{4}{|l|}{ Cannot or do not wish to say } \\
\hline \multicolumn{4}{|c|}{ I care about what other community members think of me. } \\
\hline Do not agree at all & Somewhat agree & Mostly agree & Completely agree \\
\hline$\Theta$ & 0 & o & 0 \\
\hline \multicolumn{4}{|l|}{ Cannot or do not wish to say } \\
\hline \multicolumn{4}{|c|}{ I have influence over what this community is like. } \\
\hline Do not agree at all & Somewhat agree & Mostly agree & Completely agree \\
\hline$\odot$ & 0 & 0 & 0 \\
\hline \multicolumn{4}{|l|}{ Cannot or do not wish to say } \\
\hline \multicolumn{4}{|c|}{ If there is a problem in this community, members can get it solved. } \\
\hline Do not agree at all & Somewhat agree & Mostly agree & Completely agree \\
\hline$\odot$ & 0 & 0 & 0 \\
\hline \multicolumn{4}{|l|}{ Cannot or do not wish to say } \\
\hline \multicolumn{4}{|l|}{ This community has good leaders. } \\
\hline Do not agree at all & Somewhat agree & Mostly agree & Completely agree \\
\hline$\odot$ & 0 & 0 & 0 \\
\hline \multicolumn{4}{|l|}{ O Cannot or do not wish to say } \\
\hline \multicolumn{4}{|c|}{ It is very important to me to be a part of this community. } \\
\hline Do not agree at all & Somewhat agree & Mostly agree & Completely agree \\
\hline$\odot$ & 0 & 0 & 0 \\
\hline Cannot or do not wish to say & & & \\
\hline
\end{tabular}


Online Autistic Community

I am with other community members a lot and enjoy being with them.

$\begin{array}{cccc}\text { Do not agree at all } & \text { Somewhat agree } & \text { Mostly agree } & \text { Completely agree }\end{array}$

- Cannot or do not wish to say

I expect to be a part of this community for a long time.

Do not agree at all Somewhat agree

$\odot$

O

Mostly agree

o

Completely agree

Cannot or do not wish to say

Members of this community have shared important events together, such as holidays, celebrations, or disasters.

$$
\text { Do not agree at all Somewhat agree Mostly agree Completely agree }
$$

(e)

O

0

c

o Cannot or do not wish to say

I feel hopeful about the future of this community.

$\begin{array}{cccc}\text { Do not agree at all } & \text { Somewhat agree } & \text { Mostly agree } & \text { Completely agree }\end{array}$

Cannot or do not wish to say

Members of this community care about each other.

Do not agree at all Somewhat agree Mostly agree Completely agree

$\odot$

o

Cannot or do not wish to say

Copyright @ 2008 Chavis, Lee, and Acosta. All rights reserved. Reproduced under license.

You have completed $51 \%$ of the AASPIRE Internet Use, Community, and Well-Being Survey(A).

You may take a break at any time.

\section{Go back to Previous PAGE}

You can Go Back to Previous PAGE,

but responses on this page won't be saved. 
SECTION 6: SOCIAL SUPPORT OVER THE INTERNET. In answering the following 24 questions, think about your current relationships in the online community with which you spend the most time. Please indicate to what extent each statement describes your current relationships with other people in the online community with which you spend the most time. So, for example, if you feel a statement is very true of your current relationships, you would respond with a strongly agree. If you feel a statement clearly does not describe your relationships, you would respond with a strongly disagree. There are no right or wrong answers. Instead, we are interested in hearing about your experiences and opinions.

In my online relationships, there are people I know will help me if I really need it.

\begin{tabular}{cccc} 
Strongly Disagree & Disagree & Agree & Strongly Agree \\
- & 0 & 0 & 0 \\
\hline
\end{tabular}

In my online relationships, I do not have close relationships with other people.

Strongly Disagree Disagree Agree Strongly Agree

(थ) 0 O

o Cannot or do not wish to say

In my online relationships, there is no one I can turn to in times of stress.

$\begin{array}{cccc}\text { Strongly Disagree } & \text { Disagree } & \text { Agree } & \text { Strongly Agree } \\ \odot & 0 & 0 & 0\end{array}$

O Cannot or do not wish to say

In my online relationships, there are people who call on me to help them.

$\begin{array}{cccc}\text { Strongly Disagree } & \text { Disagree } & \text { Agree } & \text { Strongly Agree } \\ \odot & 0 & 0 & 0\end{array}$

- Cannot or do not wish to say

In my online relationships, there are people who like the same social activities I do.

$\begin{array}{cccc}\text { Strongly Disagree } & \text { Disagree } & \text { Agree } & \text { Strongly Agree } \\ & 0 & 0 & 0\end{array}$

Cannot or do not wish to say

In my online relationships, other people do not think I am good at what I do.

$\begin{array}{cccc}\text { Strongly Disagree } & \text { Disagree } & \text { Agree } & \text { Strongly Agree } \\ \odot & 0 & 0 & 0\end{array}$

Cannot or do not wish to say 
Online Autistic Community

In my online relationships, I feel responsible for supporting someone else.

$\begin{array}{cccc}\text { Strongly Disagree } & \text { Disagree } & \text { Agree } & \text { Strongly Agree } \\ \odot & 0 & 0 & 0\end{array}$

Cannot or do not wish to say

In my online relationships, I am with a group of people who think the same way I do about things.

$\begin{array}{cccc}\text { Strongly Disagree } & \text { Disagree } & \text { Agree } & \text { Strongly Agree } \\ \odot & 0 & 0 & 0\end{array}$

Cannot or do not wish to say

In my online relationships, I do not think that other people respect what I do.
Strongly Disagree
Disagree
Agree
Strongly Agree
e
0
O
O

O Cannot or do not wish to say

In my online relationships, if something went wrong with my life, no one would help me.

$\begin{array}{cccc}\text { Strongly Disagree } & \text { Disagree } & \text { Agree } & \text { Strongly Agree } \\ \odot & 0 & 0 & 0\end{array}$

Cannot or do not wish to say

In my online relationships, I have close relationships that make me feel good.

$\begin{array}{cccc}\text { Strongly Disagree } & \text { Disagree } & \text { Agree } & \text { Strongly Agree } \\ \odot & 0 & 0 & 0\end{array}$

O Cannot or do not wish to say

In my online relationships, I have someone to talk to about decisions in my life.

$\begin{array}{cccc}\text { Strongly Disagree } & \text { Disagree } & \text { Agree } & \text { Strongly Agree } \\ \odot & 0 & 0 & 0\end{array}$

Cannot or do not wish to say

Copyright (ㅇ) 1984 Cutrona and Russell. All rights reserved. Reproduced under license.

You have completed $60 \%$ of the AASPIRE Internet Use, Community, and Well-Being Survey(A).

You may take a break at any time. 
Online Autistic Community

\begin{tabular}{|c|c|c|c|}
\hline \multicolumn{4}{|c|}{ SECTION 6: SOCIAL SUPPORT OVER THE INTERNET } \\
\hline \multicolumn{4}{|c|}{ In my online relationships, there are people who value my skills and abilities. } \\
\hline Strongly Disagree & Disagree & Agree & Strongly Agree \\
\hline$\odot$ & 0 & 0 & 0 \\
\hline
\end{tabular}

In my online relationships, there is no one who has the same interests and concerns as me.

Strongly Disagree Disagree Agree Strongly Agree

Cannot or do not wish to say Logout

In my online relationships, there is no one who needs me to take care of them.

$\begin{array}{cccc}\text { Strongly Disagree } & \text { Disagree } & \text { Agree } & \text { Strongly Agree } \\ \text { Cannot or do not wish to say } & 0 & 0 & 0\end{array}$

In my online relationships, I have a trustworthy person to turn to if I have problems.

In my online relationships, I have a trustworthy person to turn to if I have problems.
Strongly Disagree

In my online relationships, I feel a strong emotional tie with at least one other person.

Strongly Disagree
Disagree

Cannot or do not wish to say

In my online relationships, there is no one I can count on for help if I really need it.

$\begin{array}{cccc}\text { Strongly Disagree } & \text { Disagree } & \text { Agree } & \text { Strongly Agree } \\ & 0 & 0 & 0\end{array}$

O Cannot or do not wish to say

In my online relationships, there is no one I feel comfortable talking about problems with.
Strongly Disagree
Disagree
Agree
Strongly Agree
o
0
0

Cannot or do not wish to say 
Online Autistic Community

In my online relationships, there are people who admire my talents and abilities.

$\begin{array}{cccc}\text { Strongly Disagree } & \text { Disagree } & \text { Agree } & \text { Strongly Agree } \\ 0 \text { Cannot or do not wish to say } & 0 & 0 & 0\end{array}$

In my online relationships, I do not have a feeling of closeness with anyone.

$\begin{array}{cccc}\text { Strongly Disagree } & \text { Disagree } & \text { Agree } & \text { Strongly Agree } \\ \odot & 0 & 0 & 0\end{array}$

Cannot or do not wish to say

In my online relationships, there is no one who likes to do the things I do.

Strongly Disagree Disagree Agree Strongly Agree

$\begin{array}{lccc}(- & 0 & 0 & 0\end{array}$

O Cannot or do not wish to say

In my online relationships, there are people I can count on in an emergency.

Strongly Disagree Disagree Agree Strongly Agree

$\odot$

o 0

O 0

Cannot or do not wish to say

In my online relationships, no one needs me to take care of them.

Strongly Disagree Disagree Agree Strongly Agree

$\odot$

O

O

O

Cannot or do not wish to say

Copyright (E) 1984 Cutrona and Russell. All rights reserved. Reproduced under license.

You have completed $68 \%$ of the AASPIRE Internet Use, Community, and Well-Being Survey(A).

You may take a break at any time.

Go back to Previous PAGE

You can Go Back to Previous PAGE,

but responses on this page won't be saved.

Go to Next PAGE 
SECTION 7: SOCIAL SUPPORT- FACE-TO-FACE. In answering the following 24 questions, think about your current face-to-face relationships in your life. Please indicate to what extent each statement describes your current relationships with other people in your life. So, for example, if you feel a statement is very true of your current relationships, you would respond with a strongly agree. If you feel a statement clearly does not describe your relationships, you would respond with a strongly disagree. There are no right or wrong answers. Instead, we are interested in hearing about your experiences and opinions.

In my face-to-face relationships, there are people I know will help me if I really need it.

$\begin{array}{cccc}\text { Strongly Disagree } & \text { Disagree } & \text { Agree } & \text { Strongly Agree } \\ \odot & 0 & 0 & 0\end{array}$

Cannot or do not wish to say

In my face-to-face relationships, I do not have close relationships with other people.

$\begin{array}{cccc}\text { Strongly Disagree } & \text { Disagree } & \text { Agree } & \text { Strongly Agree } \\ \odot & 0 & 0 & 0\end{array}$

Cannot or do not wish to say

In my face-to-face relationships, there is no one I can turn to in times of stress.

$\begin{array}{cccc}\text { Strongly Disagree } & \text { Disagree } & \text { Agree } & \text { Strongly Agree } \\ \odot & 0 & 0 & 0\end{array}$

Cannot or do not wish to say

In my face-to-face relationships, there are people who call on me to help them.

$\begin{array}{cccc}\text { Strongly Disagree } & \text { Disagree } & \text { Agree } & \text { Strongly Agree } \\ - & 0 & 0 & 0\end{array}$

Cannot or do not wish to say

In my face-to-face relationships, there are people who like the same social activities I do.
Strongly Disagree
Disagree
Agree
Strongly Agree
$\odot$
o
O
O

O Cannot or do not wish to say

In my face-to-face relationships, other people do not think I am good at what I do.

Strongly Disagree Disagree $\quad$ Agree Strongly Agree
(ै)
O
O
O

Cannot or do not wish to say 
Online Autistic Community

In my face-to-face relationships, I feel responsible for supporting someone else.

$\begin{array}{cccc}\text { Strongly Disagree } & \text { Disagree } & \text { Agree } & \text { Strongly Agree } \\ & 0 & 0 & 0\end{array}$

Cannot or do not wish to say

In my face-to-face relationships, I am with a group of people who think the same way I do about things.

$\begin{array}{cccc}\text { Strongly Disagree } & \text { Disagree } & \text { Agree } & \text { Strongly Agree } \\ & 0 & 0 & 0\end{array}$

Cannot or do not wish to say

In my face-to-face relationships, I do not think that other people respect what I do.

$\begin{array}{cccc}\text { Strongly Disagree } & \text { Disagree } & \text { Agree } & \text { Strongly Agree } \\ \text { C Cannot or do not wish to say } & 0 & 0 & 0\end{array}$

In my face-to-face relationships, if something went wrong with my life, no one would help me.
Strongly Disagree
Disagree
Agree
Strongly Agree

(e)

O

O

O

O Cannot or do not wish to say

In my face-to-face relationships, I have close relationships that make me feel good.

$\begin{array}{cccc}\text { Strongly Disagree } & \text { Disagree } & \text { Agree } & \text { Strongly Agree } \\ \ominus & 0 & 0 & 0\end{array}$

Cannot or do not wish to say

In my face-to-face relationships, I have someone to talk to about decisions in my life.
Strongly Disagree
Disagree
Agree
O
Strongly Agree

O Cannot or do not wish to say

Copyright (ㄴ) 1984 Cutrona and Russell. All rights reserved. Reproduced under license.

You have completed $77 \%$ of the AASPIRE Internet Use, Community, and Well-Being Survey(A).

You may take a break at any time. 


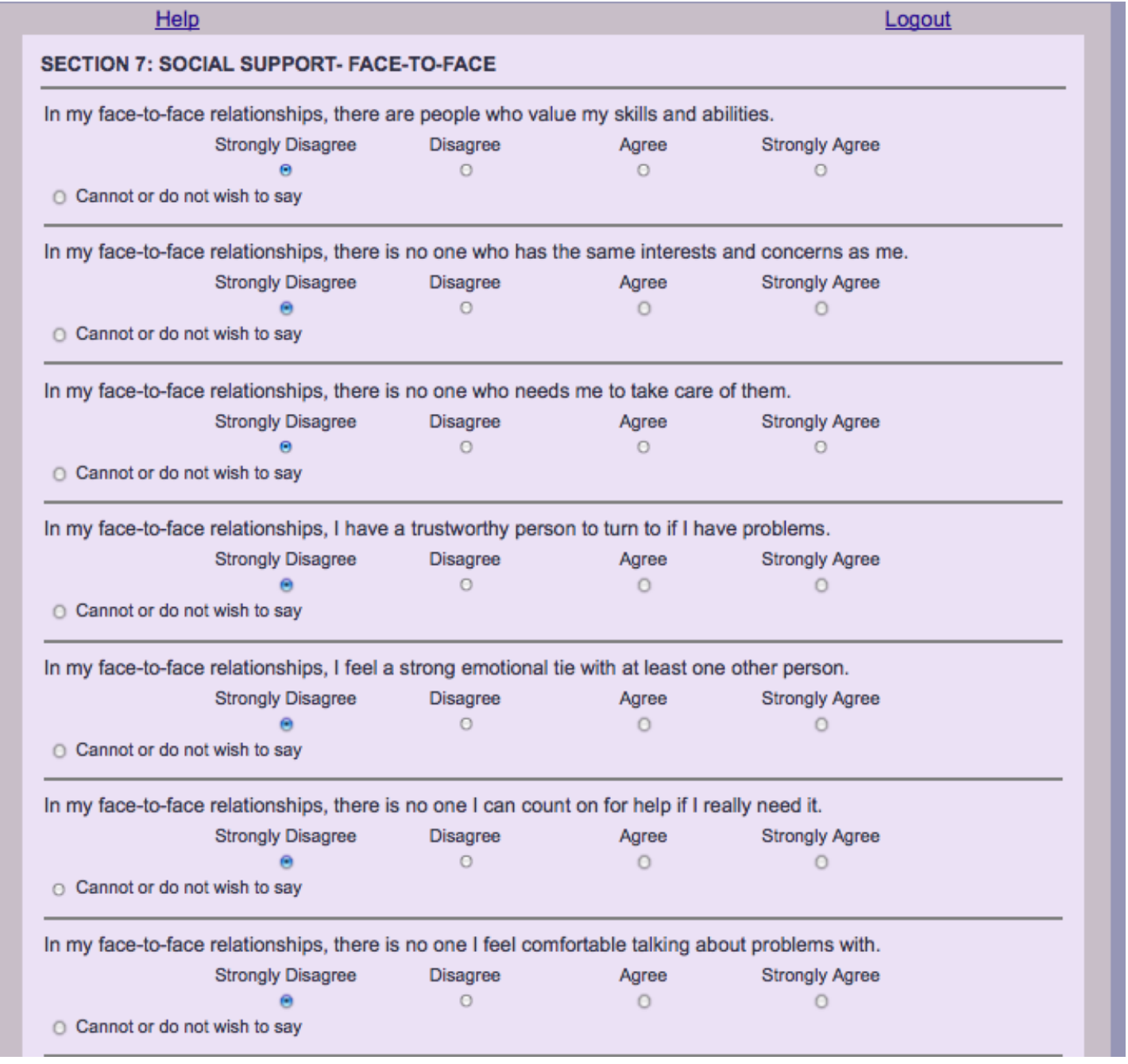


Online Autistic Community

In my face-to-face relationships, there are people who admire my talents and abilities.

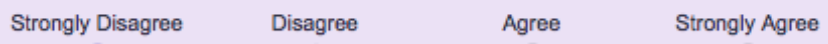

(e) 0 D 0

O Cannot or do not wish to say

In my face-to-face relationships, I do not have a feeling of closeness with anyone.

$$
\begin{array}{cccc}
\text { Strongly Disagree } & \text { Disagree } & \text { Agree } & \text { Strongly Agree } \\
\odot & 0 & 0 & 0
\end{array}
$$

Cannot or do not wish to say

In my face-to-face relationships, there is no one who likes to do the things I do.
Strongly Disagree
Disagree
Agree
Strongly Agree
O
O
O

()

Cannot or do not wish to say

In my face-to-face relationships, there are people I can count on in an emergency.
Strongly Disagree
Disagree
Agree
Strongly Agree
$\odot$
O
O
O

Cannot or do not wish to say

In my face-to-face relationships, no one needs me to take care of them.

$\begin{array}{cccc}\text { Strongly Disagree } & \text { Disagree } & \text { Agree } & \text { Strongly Agree }\end{array}$

Cannot or do not wish to say

Copyright 봉 1984 Cutrona and Russell. All rights reserved. Reproduced under license.

You have completed $85 \%$ of the AASPIRE Internet Use, Community, and Well-Being Survey(A).

You may take a break at any time.

\section{Go back to Previous PAGE}

Go to Next PAGE

You can Go Back to Previous PAGE,

but responses on this page won't be saved. 
Online Autistic Community Logout

SECTION 8: WRAP-UP. The last 9 items ask you to update your information such as age and gender, and how accurately you completed this survey and whether you want to be entered into a drawing for a $\$ 25$ Amazon.com gift certificate.

The month and year of my birth are January : 1946 :

The country in which I currently live is

United States

My gender is

O male

e female

o transgendered (male to female)

O transgendered (female to male)

O androgynous, gender neutral, or none

o do not wish to say

The racial category I identify with is (check all that apply)

$\checkmark$ American Indian or Alaska Native

Asian

Native Hawaiian or Other Pacific Islander

D) Black or African American

White

$\checkmark$ Multi-racial

do not wish to say

I am of Latino or Hispanic origin.

yes

$\odot$ no

do not wish to say 
Is there anything else you would like to share with us?

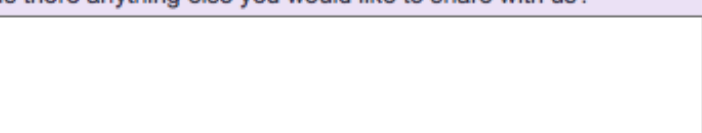
I found out about this survey from
$O$ a disability-related organization, website, or blog
(थ an autism-related organization, website, or blog
$O$ an undergraduate psychology class
$O$ a family member, co-worker, or friend
$O$ an email announcement
$O$ an online posting
o Other
Cannot or do not wish to say

I completed this survey to the best of my ability.

$\begin{array}{cccc}\text { Do Not Agree } & \text { Slightly Agree } & \text { Mostly Agree } & \text { Strongly Agree } \\ \text { C Cannot or do not wish to say } & \circ & 0 & 0\end{array}$

I would like to be entered into the drawing for a \$25 Amazon.com electronic gift certificate. (Winners will be contacted via the e-mail address provided during the registration process.)

(e) Yes

O No

You have completed $94 \%$ of the AASPIRE Internet Use, Community, and Well-Being Survey(A).

You may take a break at any time.

\section{Go back to Previous PAGE}

You can Go Back to Previous PAGE, but responses on this page won't be saved.

\section{Finish STUDY}

You will not be able to return to the survey after pressing Finish

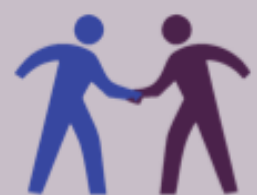

My Home My Settings FAQ $\underline{\text { Logout }}$
Your responses have been submitted. Thank you for participating in the AASPIRE Internet Use, Community, and Well-Being Study.

We will post information about the results of this study on our web site at http://aaspire.org when we are finished with the study.

Please be aware that it often takes a long time (over a year) for a study to be completed. If you're on our mailing list http://lists.aaspireproject.org/mailman

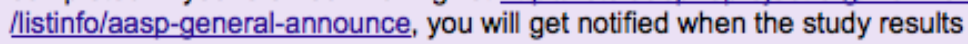
are posted. 
$\underline{\text { Hotlinks }}$

Online communities are groups of people who communicate with each other regularly over the Internet and share some common interests, goals, activities, and/or identity.

The online Autistic community may be composed primarily of people on the autism spectrum (such as WrongPlanet, the LiveJournal Aspergers community, or the AutisticSpectrumTreehouse Yahoo group, alt.support.autism news group), or may have a common purpose that is specifically related to Autistic advocacy (such as the Autistic Self Advocacy Network yahoo group, the AutismHub blog group, or the PosAutive YouTube community).

The online disability community may be composed primarily of people with disabilites or may have a common purpose that is specifically related to disability advocacy.

Participating in any online community refers to using the Internet to socialize, interact, exchange information, coordinate events, or participate in any activity that involved interacting with $<$ strong $>$ other people $</$ strong $>$ over the internet.

The people and the community around me generally refers to the people you live by or are around on a regular basis and the community in which you live.

Build a home in this context means creating a home environment:

I have been able to (build a home) create a home environment and a lifestyle for myself that is much to my liking.

Juggling in this context means organizing or balancing:

I am good at (juggling) organizing or balancing my time so that I can fit everything in that needs to get done.

Arranging my life in this context means organizing my life:

I have difficulty (arranging) organizing my life in a way that is satisfying to me.

I feel good about people on the Autistic spectrum, or I feel that people on the Autistic spectrum are worthwhile.

Being with other community members describes spending time communicating with others online.

Feel responsible for in this context means obligated to:

I feel (responsible for) obligated to supporting someone else.

Close relationships in this context means intimate relationships:

I have (close relationships) intimate relationships that make me feel good. 
Social activities in this context means leisure activities:

There are people who like the same (social acitivities) leisure activities I do.

When I compare myself to friends and acquaintances, it makes me feel good about who I am, or I don't feel bad about myself when compared to others.

Consensus in this context means agreement:

I have confidence in my opinions, even if they are contrary to the general (consensus) agreement.

Finances and affairs in this context means personal responsibilities:

I generally do a good job of taking care of my personal (finances and affairs) personal responsibilities.

In charge of the situation in which I live in this context means I am in control of all or most of the decisions in regards to my living situation:

I feel (in charge of the situation in which I live), in control of all or most of the decisions in regards to my living situation.

Needs of mine in this context means emotional, financial, physicial, etc. needs:

I get important (needs of mine) emotional, financial, physical, etc. needs met because I am part of this community.

Recognize in this context means recognize by name, photo, avatar, etc.:

I can (recognize) recognize by name, photo, avatar, etc. most of the members in this community. 